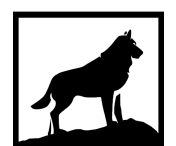

Michigan Technological

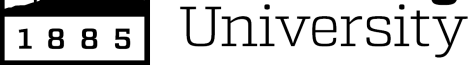

Michigan Technological University Digital Commons @ Michigan Tech

2018

\title{
IMPACT OF INRUSH CURRENTS AND GEOMAGNETICALLY INDUCED CURRENTS ON TRANSFORMER BEHAVIOR
}

Nishchal Sharma

Michigan Technological University, nsharma1@mtu.edu

Copyright 2018 Nishchal Sharma

\section{Recommended Citation}

Sharma, Nishchal, "IMPACT OF INRUSH CURRENTS AND GEOMAGNETICALLY INDUCED CURRENTS ON TRANSFORMER BEHAVIOR", Open Access Master's Report, Michigan Technological University, 2018.

https://doi.org/10.37099/mtu.dc.etdr/683

Follow this and additional works at: https://digitalcommons.mtu.edu/etdr

Part of the Power and Energy Commons 


\title{
IMPACT OF INRUSH CURRENTS AND GEOMAGNETICALLY INDUCED CURRENTS ON TRANSFORMER BEHAVIOR
}

\author{
By
}

Nishchal Sharma

\section{A REPORT}

Submitted in partial fulfillment of the requirements for the degree of MASTER OF SCIENCE

In Electrical Engineering

\section{MICHIGAN TECHNOLOGICAL UNIVERSITY 2018}

(C) 2018 Nishchal Sharma 

This Report has been approved in partial fulfillment of the requirements for the Degree of MASTER OF SCIENCE in Electrical Engineering.

Department of Electrical and Computer Engineering

Report Advisor: $\quad$ Dr. Bruce Mork

Committee Member: Dr. Jeffrey Burl

Committee Member: John Lukowski

Department Chair: $\quad$ Dr. Daniel R. Fuhrmann 



\section{Dedication}

\section{To my Parents, Family, Teachers and Friends.}





\section{TABLE OF CONTENTS}

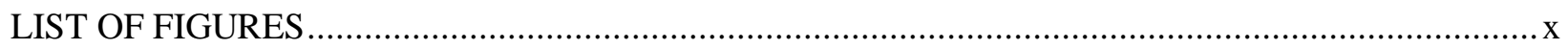

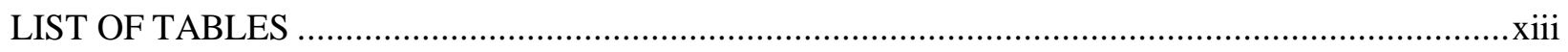

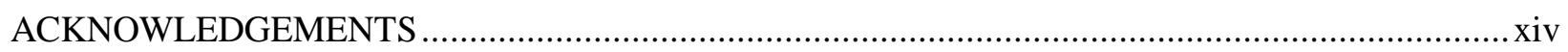

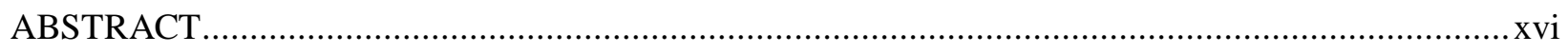

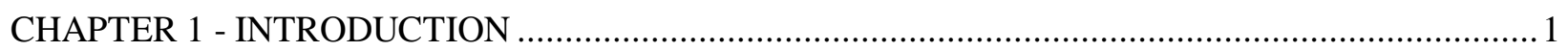

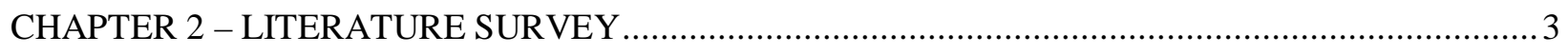

2.1 MAGNETIZING INRUSH CURRENTS ……………...............................................

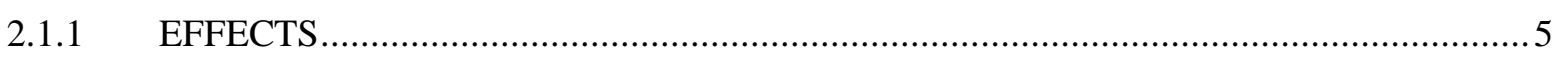

2.1.2 ENERGIZATION ………………………….............................................

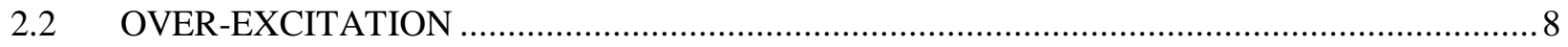

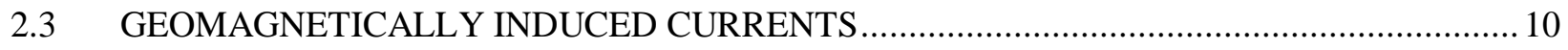

2.3.1 HOW ARE THEY INDUCED...............................................................................

2.3.2 EFFECTS OF GIC ON POWER TRANSFORMERS ...................................................11

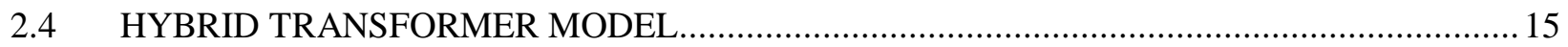

CHAPTER 3 - DEVELOPMENT, IMPLEMENTATION AND RESULTS ...........................................18

3.1 TRANSFORMER INRUSH CURRENTS MODEL ………………………….......................18

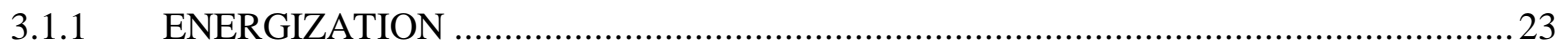

3.1.2 SENSITIVITY TO MAGNETIZATION SLOPE AT SATURATION (La).....................29

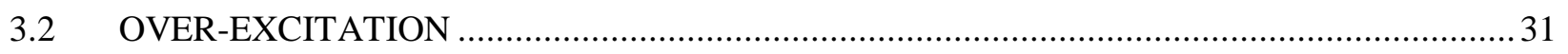

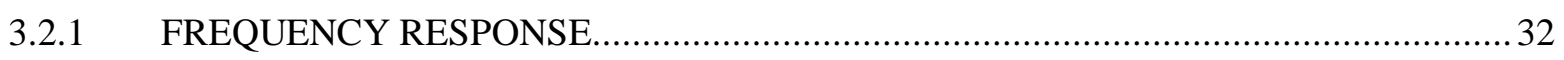

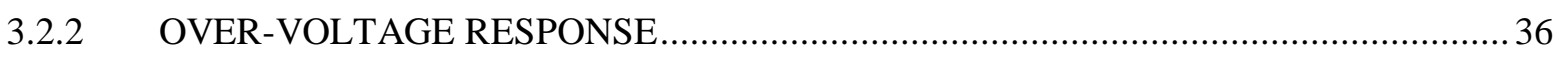

3.3 GEOMAGNETICALLY INDUCED CURRENTS MODEL ……............................................4

3.3.1 GIC WITH 3-LEGGED CORE.................................................................................. 43

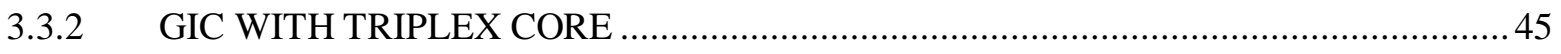

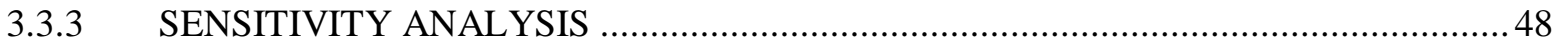

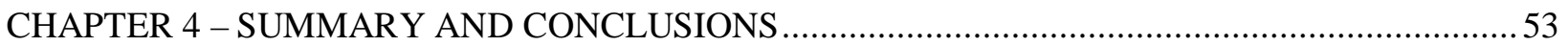

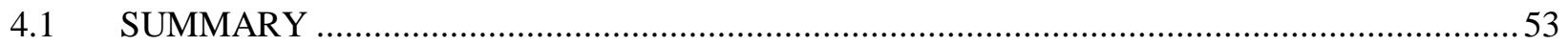

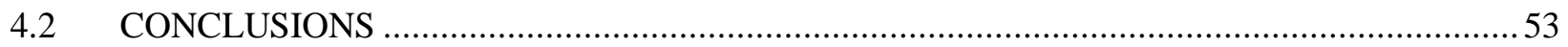

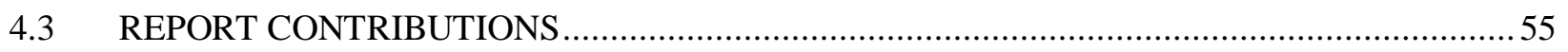

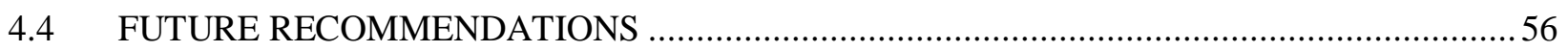




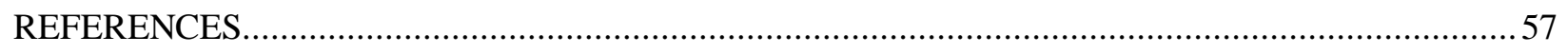

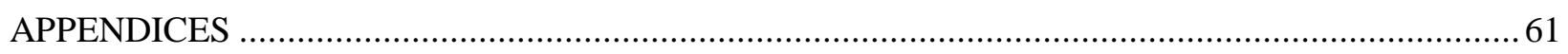

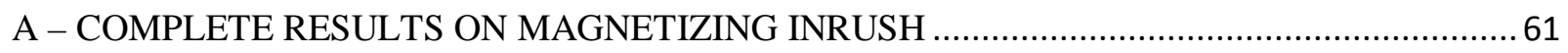

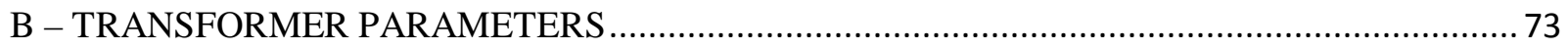

C - REPORT ON ISOLATION OF INRUSH FOR DIFFERENTIAL RELAYS .............................. 75 



\section{LIST OF FIGURES}

Figure 2.1: Equivalent circuit for a single-phase transformer....................................4

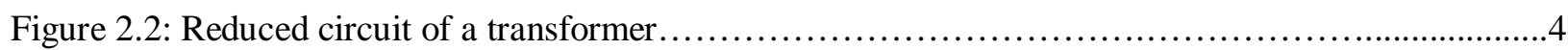

Figure 2.3: Ring-down/Residual Flux ......................................................6

Figure 2.4: Single Phase transformer model depicting flux contributors............................8

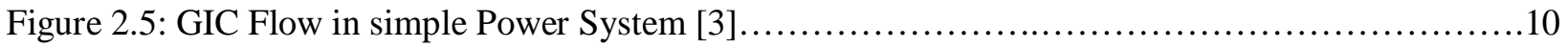

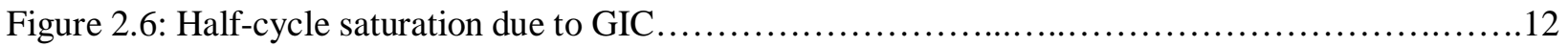

Figure 2.7: Flux Density shift due to DC [2], Copyright (C) 2011, IEEE...............................12

Figure 2.8: Part Cycle Saturation due to DC [2], Copyright (C) 2011, IEEE.............................13

Figure 2.9: GIC vs var absorption in transformer [7], Copyright (C 2011, IEEE........................13

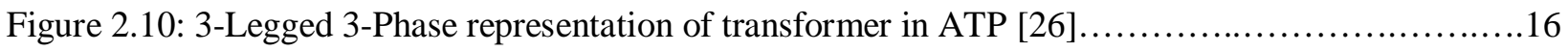

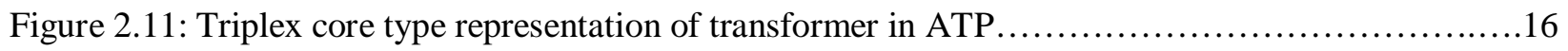

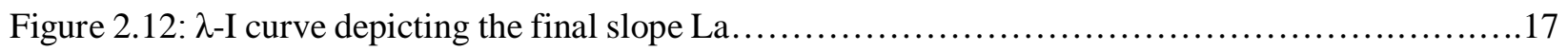

Figure 3.1: Flux linkage initialization Syntax............................................. 19

Figure 3.2: GUI representation of initialized flux-linkage across a type-93 inductance...................20

Figure 3.3: Syntax for initialized flux-linkage visualization...................................20

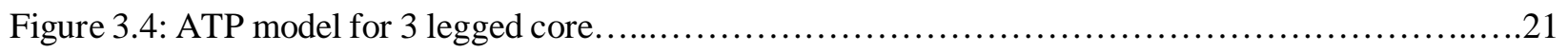

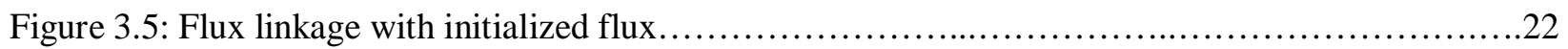

Figure 3.6: Inrush current comparison for 30-50\% initialized flux linkage in triplex core for all phases from

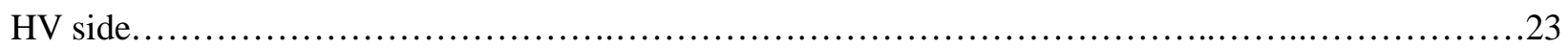

Figure 3.7: Inrush current comparison for 30-50\% initialized flux linkage in triplex core for all phases from HV side.

Figure 3.8: Inrush current comparison for 30-50\% initialized flux linkage in 3-legged core for all phases

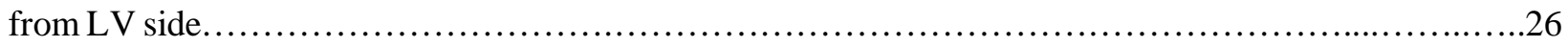

Figure 3.9: Inrush current comparison for 30-50\% initialized flux linkage in Triplex core for all phases from

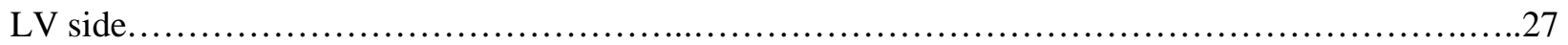

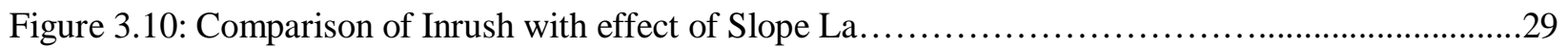




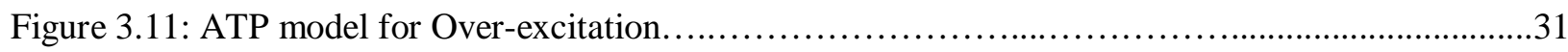

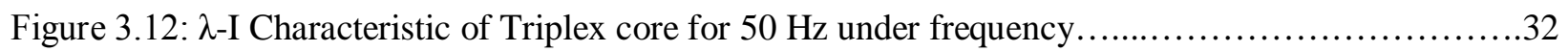

Figure 3.13: 1st and 5th Harmonics as seen by relays in the excitation current for Triplex core for $50 \mathrm{~Hz}$

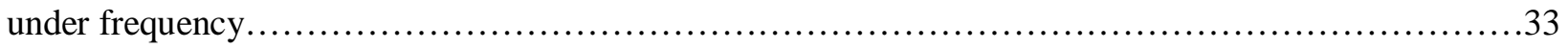

Figure 3.14: $\lambda$-I Characteristic of 3-legged core for $50 \mathrm{~Hz}$ under frequency..................................34

Figure 3.15: 1st and 5th Harmonics as seen by relays in the excitation current for 3-legged core for $50 \mathrm{~Hz}$

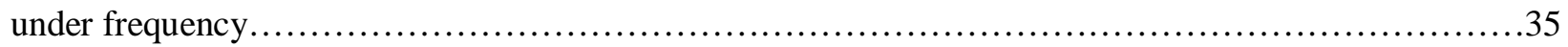

Figure 3.16: $\lambda$-I Characteristic of Triplex core for $120 \%$ of nominal excitation voltage......................36

Figure 3.17: 1st and 5th Harmonics as seen by relays in the excitation current for Triplex core for $120 \%$

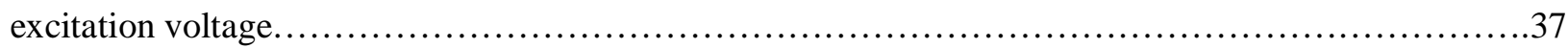

Figure 3.18: $\lambda$-I Characteristic of 3-legged core for $120 \%$ of nominal excitation........................38

Figure 3.19: 1st and 5th Harmonics as seen by relays in the excitation current for 3-legged core for 120\%

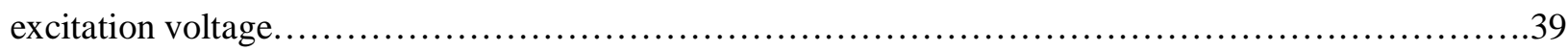

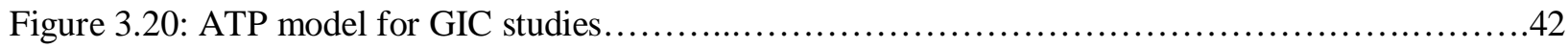

Figure 3.21: Magnetizing Currents in the core of 3-legged xfmr showing half-cycle saturation in core

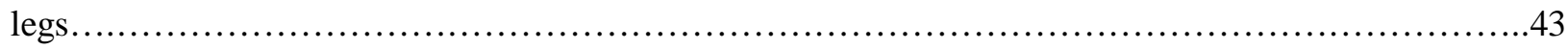

Figure 3.22: $\lambda$-I characteristics for core parts of 3-Legged Transformer..............................44

Figure 3.23: Magnetizing Currents in the core of Triplex xfmr showing half-cycle saturation in core

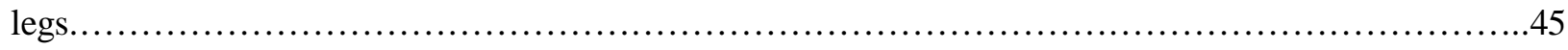

Figure 3.24: $\lambda$-I characteristics for core parts of 3-Legged Transformer...........................46

Figure 3.25: Sensitivity analysis for different GIC amplitudes for 3-legged core.........................48

Figure 3.26: Sensitivity analysis for different GIC frequencies for 3-legged core.....................49

Figure 3.27: Sensitivity analysis for different GIC for Triplex core...........................................50

Figure 3.28: Sensitivity analysis for different GIC for Triplex core.....................................51

Figure A.1: Inrush Currents in Phase-A, Phase-B and Phase-C with 42\% residual flux linkage for 3-legged

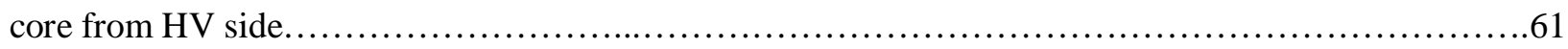

Figure A.2: Inrush Currents for Phase A, Phase B and Phase C at 30\% residual flux linkage 3-legged core

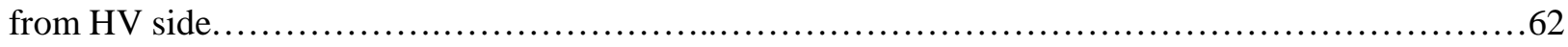

Figure A.3: Inrush Currents for Phase A, Phase B and Phase C at 50\% residual flux linkage 3-legged core from HV side. .63 
Figure A.4: Inrush Currents for Phase A, Phase B and Phase C at 42\% residual flux linkage for Triplex core from HV side. .64

Figure A.5: Inrush Currents for Phase A, Phase B and Phase C at 30\% residual flux linkage for Triplex core from HV side. .65

Figure A.6: Inrush Currents for Phase A, Phase B and Phase C at 50\% residual flux linkage for Triplex core from HV side... .66

Figure A.7: Inrush Currents for Phase A, Phase B and Phase C at 40\% residual flux linkage for 3-legged core from LV side.

Figure A.8: Inrush Currents for Phase A, Phase B and Phase C at 30\% residual flux linkage for 3-legged core from LV side. ..68

Figure A.9: Inrush Currents for Phase A, Phase B and Phase C at 50\% residual flux linkage for 3-legged core from LV side.

Figure A.10: Inrush Currents for Phase A, Phase B and Phase C at 30\% residual flux linkage for Triplex Core from LV side. .70

Figure A.11: Inrush Currents for Phase A, Phase B and Phase C at 30\% residual flux linkage for Triplex Core from LV side. .71

Figure A.12: Inrush Currents for Phase A, Phase B and Phase C at 50\% residual flux linkage for Triplex Core from LV side. .72

Figure B.1: Parameters for Hybrid XFMR model used in inrush and Over-excitation modelling. .73

Figure B.2: Parameters for Hybrid XFMR model used in inrush and Over-excitation modelling. .74 


\section{LIST OF TABLES}

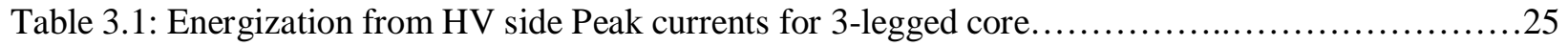

Table 3.2: Energization from LV side Peak currents for 3-legged and Triplex core....................28

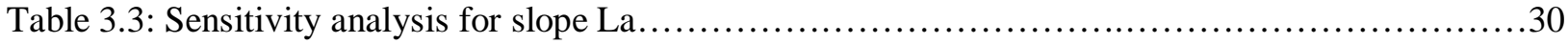

Table 3.4: Magnetization Current Comparison for under-frequency response.........................35

Table 3.5: 1st and 5th Harmonics as seen by relays in the excitation current for $50 \mathrm{~Hz}$ under-frequency......35

Table 3.6: Magnetization Current Comparison for over-voltage response............................39

Table 3.7: 1st and 5th Harmonics as seen by relays in the excitation current for $120 \%$ excitation voltage....39

Table 3.8: GIC response comparison between 3-legged core and triplex core.........................46

Table 3.9: Sensitivity analysis of 3-legged Transformer Core with respect to GIC level...................49

Table 3.10: Sensitivity analysis for different frequencies of GIC for 3-legged core.......................49

Table 3.11: Sensitivity analysis of Triplex Transformer Core with respect to GIC level..................50

Table 3.12: Sensitivity analysis for different frequencies of GIC for Triplex Core......................51 


\section{ACKNOWLEDGEMENTS}

I would like to thank Dr. Bruce Mork, for his continued support not just with this project but throughout my degree. He has been a perfect mentor who has always guided me through all the difficulties I have faced in my academic career at Michigan Tech.

I would also like to thank my committee members Dr. Jeffrey Burl and John Lukowski as well as Hemanth and Liza for their continued guidance on this project and clearing my doubts.

I would like to thank Michigan Tech community for making Michigan Tech such an amazing place to learn and persevere. As an International student, the Michigan Tech community has welcomed me with open arms and gave me the perfect environment to succeed in academic career and has prepared me well for my professional career ahead.

Most importantly I would thank my parents for their unshakeable trust in my decisions, my friends who have always had my back and made this place a home away from home for me. This would not have been possible without their constant support. 



\begin{abstract}
Transformers are the tie-points of electrical power systems. Their protection from power system faults and other innate issues is of prime importance. A few of the issues that are studied in this report are magnetic inrush currents, geomagnetically induced currents in power transformers and Over-excitation.
\end{abstract}

This project develops a novel way of initializing and visualizing the flux linkage in the transformer core for studies on energization inrush currents. In addition, a quasi-DC source for GIC has been developed in order to study the GIC effects on power transformers and a sensitivity analysis has been carried out to understand effects of GIC amplitudes and frequencies on the transformer core. Lastly, a study has been carried out in order to understand Overexcitation effects on transformers. The cases have been simulated in ATP (Alternative Transients Program) using the hybrid transformer model available in the program.

The simulation results suggest the models developed are capable of providing an in depth analysis of GIC, inrush currents and over-excitation. Future recommendations include studies on relationship of var absorption and GIC amplitude as well as developing a model for studying controlled switching with residual flux linkage monitoring for minimizing inrush currents. 



\section{CHAPTER 1 - INTRODUCTION}

The motivation for this project came from the fact that transformer operation is necessary for a stable power system. Studying scenarios that could affect this stable operation can prevent adverse circumstances in the future. The studies in this report provides a platform for analyzing the effects of the magnetizing inrush, geomagnetically induced currents behaviors and Overexcitation.

Magnetic inrush is a common problem in power systems which occurs when a transformer is energized or re-energized. When energized, a transformer can draw a transient current up to 1015 times its rated current. The worst inrush occurs when the transformer is energized at the zero crossing of the excitation voltage because it leaves the system with 2 times peak flux linked to handle which results in very high current due to saturation of core. These inrush currents are very rich in harmonics and may cause a lot of problems for power system components. Inrush problems can be handled by controlled-separate switching of circuit breaker poles, by ensuring that each phase is energized at the voltage peak. But this issue becomes difficult to estimate when remnant/residual flux linkage is involved, which would be the case when the transformer is being re-energized. It is difficult to estimate the residual flux linkage in the core and the residual flux linkage can influence the inrush currents heavily. In this report, a study has been conducted to better understand magnetic inrush problem better.

Geomagnetically induced currents are another problem faced by power transformers. Geomagnetically induced currents (GIC) are induced when the electrically charged solar flares interact with Earth's magnetic field. This interaction results in an earth surface potential (ESP). Neutral grounded transformers tend to induce currents due to this ESP, which is a quasi-DC 
signal of frequency ranging from $0.0001-0.1 \mathrm{~Hz}$. This quasi DC has very adverse effects on transformers such as half-cycle saturation, high var absorption, winding hotspots and harmonics. In this report a model for GIC has been established in order to study the effects of GIC on transformers.

Over-excitation occurs when the excitation voltage to the transformer is more than the nominal value. Over-excitation results in transformer core saturation and hence can potentially create nuisance operation of relays. Over-excitation can also occur due to reduced frequency of the excitation source, this can also result in core saturation. In modern day systems, over-excitation is detected using over-fluxing protection which is essentially volts per hertz or V/f. In a healthy system this ratio remains a constant value, any change in excitation voltage or frequency would result in a change of this value. The protective relays are set with a pre-defined value for this ratio. When the calculated value of E/f goes over the pre-defined value, over-fluxing is detected and if necessary the energization source could be disconnected but this only occurs if the overfluxing persists for a long time. Under most cases V/f is used to block the relay operation as over-excitation is generally a temporary situation. In this report a model of the effects of overexcitation (frequency response and over-voltage response) is developed using the hybrid transformer model in ATP. 


\section{CHAPTER 2 - LITERATURE SURVEY}

This chapter provides a literature survey and foundational concepts on magnetizing inrush currents, geomagnetically induced current, over-excitation and hybrid transformer modelling using ATP.

\subsection{MAGNETIZING INRUSH CURRENTS}

Magnetizing inrush is one of the most common problem associated with power transformers, this problem is usually observed while energizing a new transformer and even with charging a transformer while there is another in-service transformer in the same system (sympathetic inrush). The inrush currents can potentially result in false relay operations especially in differential relays. To overcome this problem $2^{\text {nd }}$ harmonic restraint or blocking is used. The inrush currents are rich in $2^{\text {nd }}$ harmonics which can be detected and the operation could be restrained or blocked but at the same time sensitivity of these relays is not compromised and they should be able to detect a regular fault condition. To achieve this, the restraint is used only after a particular magnitude of $2^{\text {nd }}$ harmonics is detected and not otherwise. These inrush currents can be limited by controlled switching of circuit breaker poles. This controlled switching is to make sure the circuit breaker is closed when the excitation voltage is at its peak. If done correctly this kind of operation can restrict the inrush currents to safe limits.

For,

$$
\begin{gathered}
e(t)=\mathrm{E} \sin (\omega t+\phi) \\
\lambda(t)=\int_{0}^{t} e(t) d t+\lambda(0)=\frac{E}{\omega}(\operatorname{Cos}(\phi)-\operatorname{Cos}(\omega t+\phi))+\lambda(0)
\end{gathered}
$$

Where $\mathrm{E}=$ maximum excitation voltage, $\omega=$ frequency in radians, $\lambda=$ flux linkage, $\phi=$ phase angle of excitation voltage at energization. 
The equivalent circuit for a transformer is given in Figure 2.1. The reduced circuit for the transformer is shown in Figure 2.2. The dominating factors in the circuit are the magnetizing inductance $\left(\mathrm{L}_{\mathrm{m}}\right)$ and winding resistance $\mathrm{R}_{1}$ while core resistance $\left(\mathrm{R}_{\mathrm{c}}\right.$ ) and winding inductance $\left(\mathrm{L}_{1}\right)$ are small in comparison to $\mathrm{L}_{m}$ and $\mathrm{R}_{1}$. The winding inductance is very small in comparison to core inductance and can be ignored. $\mathrm{R}_{1}$ acts as a damping resistance and is responsible for decaying of the inrush current [13].
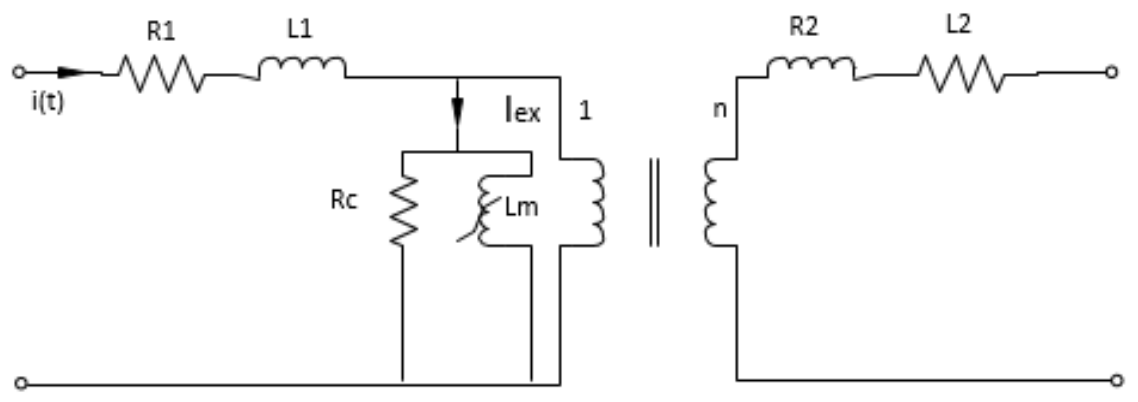

Figure 2.1: Equivalent circuit for a single-phase transformer

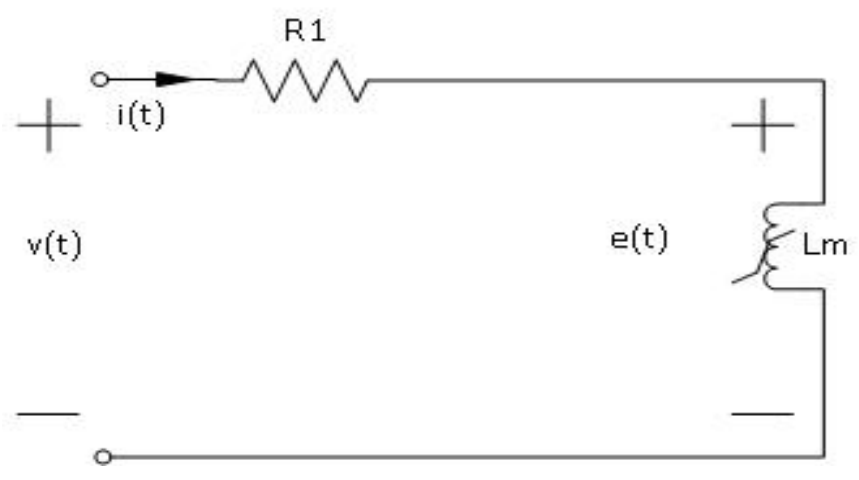

Figure 2.2: Reduced circuit of a transformer

A lot of factors actually affect the inrush currents, such as network topology, transformer construction, winding coupling, residual fluxes, and circuit breakers (CB’s) current-chopping characteristic. 


\subsubsection{EFFECTS}

As already established from Equation (2), there are multiple factors contributing to inrush currents. The effects of these currents are quite varied on different equipment and fault sensing devices such as relays. A few of these effects are listed below:

1. Degrades the security of transformer differential protection. These inrush currents may lead to mis-operation of differential relays if proper precautions are not taken for restraint during inrush [10].

2. They also pose a threat to the other equipment which are already in operation. Mis-operations have occurred in protection of the transformer, generator and even the transmission line already in operation when a transformer was being energized. When a transformer is energized in a system where there is another transformer in operation a sympathetic inrush is induced in the already operating transformer resulting in saturation of the core for this transformer as well, which in turn results in increased magnetizing current [10].

\subsubsection{ENERGIZATION}

Energization of the transformer is the primary reason for magnetizing inrush currents. As seen from Equation (2) a lot depends on the term $\frac{V}{\omega} \operatorname{Cos}(\phi)$ where $\phi$ is the point (Phase angle) of the voltage wave where energization occurs. For $\phi=90$ and $v(t)=V \sin (\omega t+\phi)$, the flux linkage would be maximum and hence the maximum inrush is observed. Similarly, for $\phi=0$, the flux linkage is minimum and hence there is no inrush currents. A point to be noted here is that often 
transformers are energized in a no-load condition which only aggravates the inrush issue and hence limiting the inrush current is particularly important.

In order to achieve this nearly zero inrush, controlled switching is used, wherein a controller monitors the voltage and closes the breaker when the AC voltage reaches its peak value. For 3phase transformers independent pole switching is used to negotiate the inrush.

Energization with residual flux, can result in high inrush currents, sometimes even worse. The problem with energization with residual flux is that it is the most common form of inrush and prediction of residual flux is quite difficult which is what brings the uncertainty to the switching operation. The $\lambda(0)$ in Equation (2) is the residual flux linkage involved in the operation. Figure 2.3 shows the ring-down flux or residual flux in a transformer with triplex core, which was deenergized at $\mathrm{t}=0$, ring down then determines residual flux and then energized at $\mathrm{t}=0.2 \mathrm{~s}$. The residual flux depends on the phase angle of de-energization of the transformer [14]. For a 3legged core the $\lambda(0)$ for phases would be same for core legs, while the yokes will have residual flux equal to the core legs they are parallel attached with.

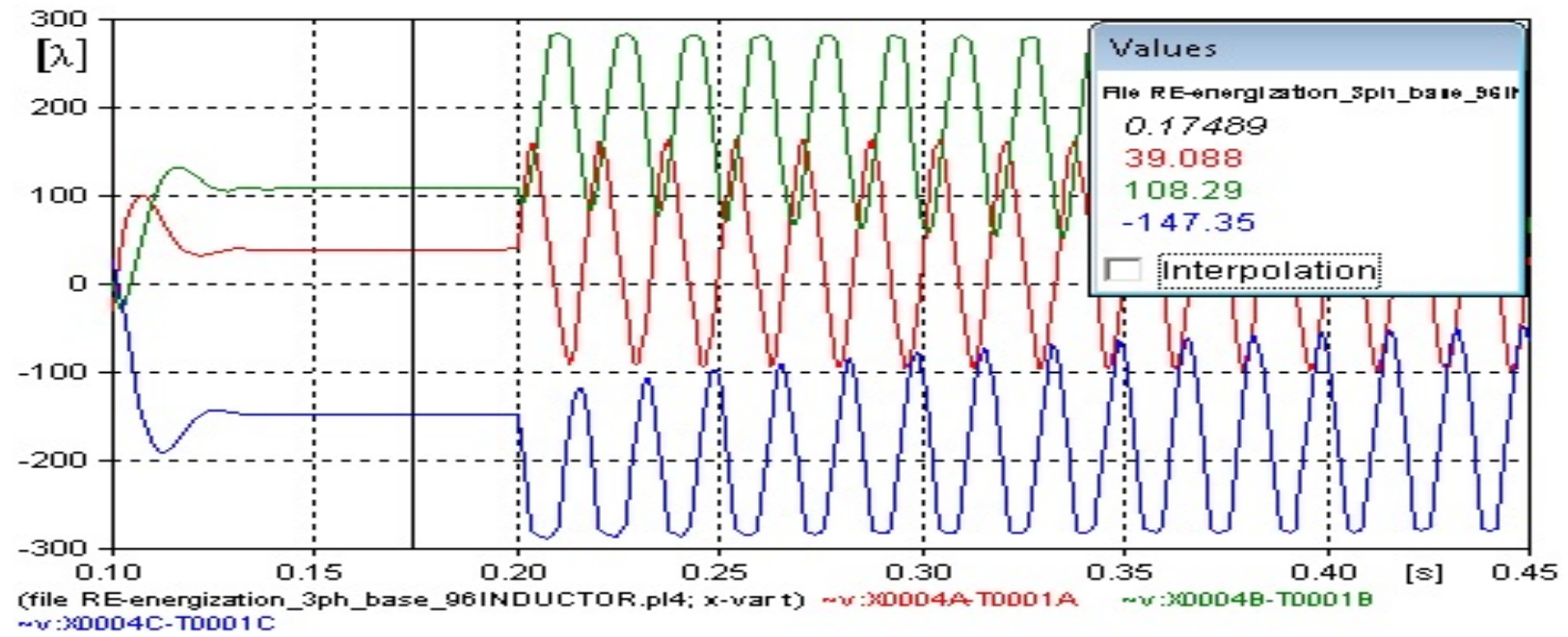

Figure 2.3: Ring-down/Residual Flux 
Controlled switching can be used in the case of energization with residual flux as well but requires another parameter for monitoring in addition to the voltage, which is the residual flux of the transformer. During de-energization residual fluxes may be calculated and when the residual flux and prospective flux matches for a phase, the pole is closed. After the first phase is closed the residual fluxes are brought down to zero by core flux equalization and once that has been achieved the other poles are closed [11]. Different ways of initializing flux in the transformer core have been discussed in [18]. 


\subsection{OVER-EXCITATION}

According to reference [16], the induced electro-motive force (EMF) in a transformer is given

by,

$$
\mathrm{E}=4.44 * \mathrm{f} * \mathrm{~N} * \phi
$$

Equation-3 can be re-written as,

$$
\begin{aligned}
& \frac{E}{f} \alpha \phi \\
& \phi=B * A
\end{aligned}
$$

Where $\mathrm{f}=$ frequency, $\mathrm{N}=$ no. of turns, $\phi=$ flux,

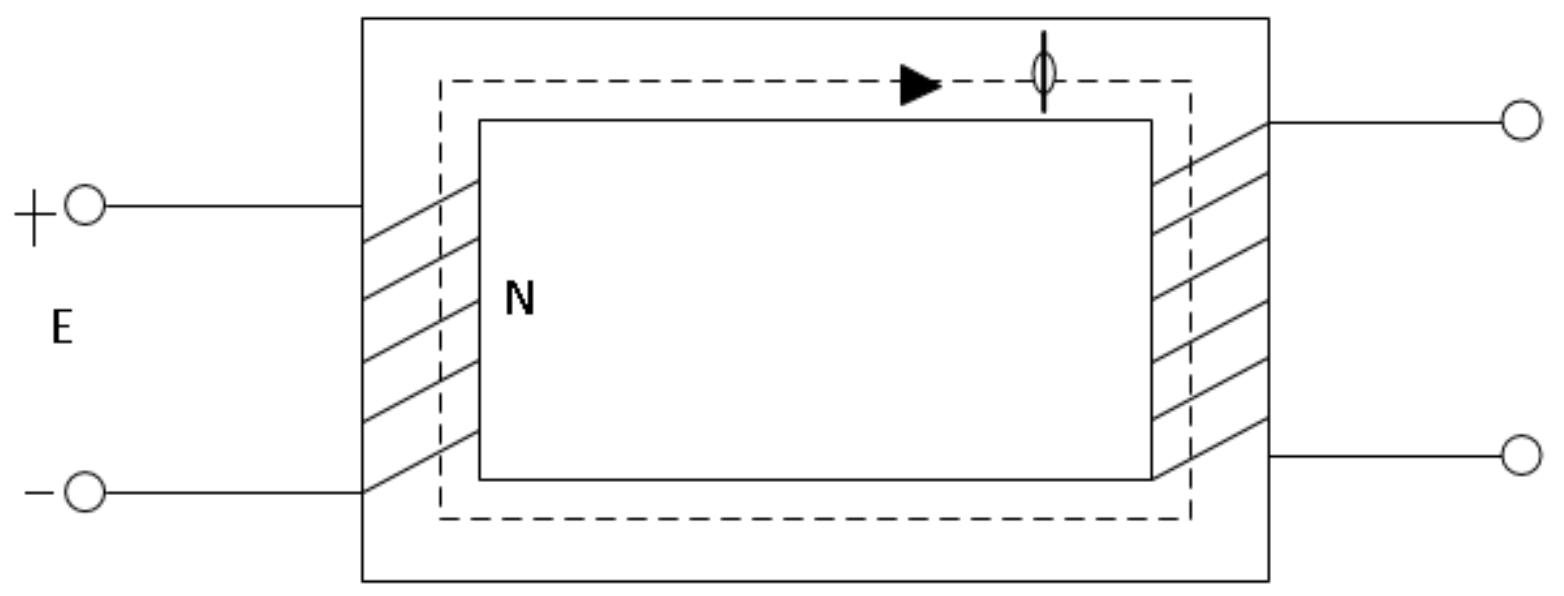

Figure 2.4: Single Phase transformer model depicting flux contributors 
From Equation (4), it can be concluded that E/f is directly proportional to the flux. Over fluxing can thereby occur if the excitation voltage is increased or the frequency of the source is decreased. In either condition, the core of the transformer ends up in saturation, if the condition persists. This condition is often called "over-excitation" and is generally observed when the load increases and the generator frequency is reduced. When this generator is feeding the excitation to a connected transformer, the transformers are affected. But because these conditions are not of long duration, the protection devices need not trip. When over-excitation occurs, the transformer starts to operate in the nonlinear zone of the magnetization curve, resulting in a lot of odd harmonics at the CT secondary, which can operate the differential relays at the transformer [19]. The $3^{\text {rd }}$ harmonic cannot be used to block the relay operation because they are generally filtered by the relays or the delta connections on the CT, moreover it is very difficult to discriminate between zero sequence faults and Over-excitation using the $3^{\text {rd }}$ harmonic. Hence for detection of over-excitation the $5^{\text {th }}$ harmonic is used [20]. But for conditions in which over-fluxing persists, it is necessary to disconnect from the source. Detailed explanation of the concept and guidelines for protection of transformers and generators from over-excitation are explained in [17] and [20]. [18] Also discusses strategies to tackle this issue for relays. 


\subsection{GEOMAGNETICALLY INDUCED CURRENTS}

Geomagnetically induced currents are induced in the ground connected neutrals of power transformers when a geomagnetic disturbance takes place due to the magnetically charged solar flares interaction with earth’s magnetic field. These disturbances induce a quasi-dc (a signal of very small frequency, mostly $0.0001-0.1 \mathrm{~Hz}$ ) voltage which results in a geomagnetically induced current in the transformer neutral which then flows through the transformer windings to the network. This quasi-dc current results in half-cycle saturation of the transformer core leading to hotspot heating, increased reactive power absorption and also harmonics [3], [8]. The GIC can be between $10 \mathrm{~A}$ to $100 \mathrm{~A}$ in amplitude, while the induced voltage could be between 1-10 V/km [2],[3].

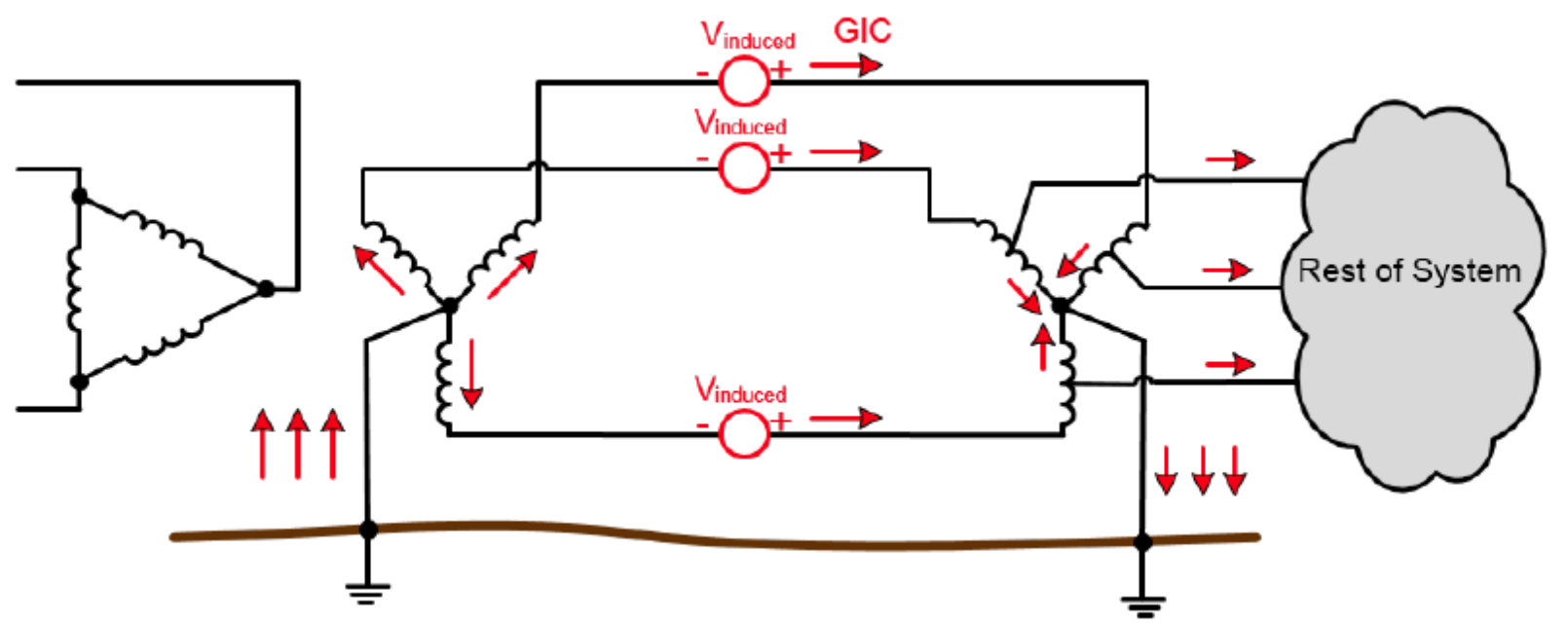

Figure 2.5: GIC Flow in simple Power System [3] 


\subsubsection{HOW ARE THEY INDUCED}

Geomagnetically induced currents are formed by the interaction of magnetically charged solar flares from sun and earth's magnetic field. This interaction results in geomagnetic fluctuation which is termed as a geomagnetic storm. These geomagnetic fluctuations induce an earth surface potential and this in turn induces a current component with a frequency of $0.0001-0.1 \mathrm{~Hz}$, which is also referred to as a quasi-DC component in grounded power transformers. This current carries from the ground to the whole network [1], [3], [8].

\subsubsection{EFFECTS OF GIC ON POWER TRANSFORMERS}

Effects of GIC can be understood from the understanding of the effects of DC on a power transformer. When a DC bias is applied to a transformer core, a unidirectional flux is developed in the core, the magnitude of which is dependent on the magnitude of the DC, number of windings and the reluctance of the path of this DC flux. This DC flux adds to one half-cycle of AC flux and subtracts from other half-cycle of AC flux. For a high enough DC flux half-cycle saturation is observed in the core [2]. Because of this half-cycle saturation and narrow current pulse, the system's var requirements increase resulting in increase in requirement of currents from var compensators and capacitor banks, which in turn can trip the relays protecting these banks and hence affect the stability of the power system [2], ,6]. The GIC and var consumption follows a linear relationship irrespective of the size or core structure of the transformer, which means for an increase in the GIC a linear increase in var consumption will be seen [7]. Figure 2.9 from [7] explains this relationship. For details on experimental results for GIC vs vars, please refer to [7]. 


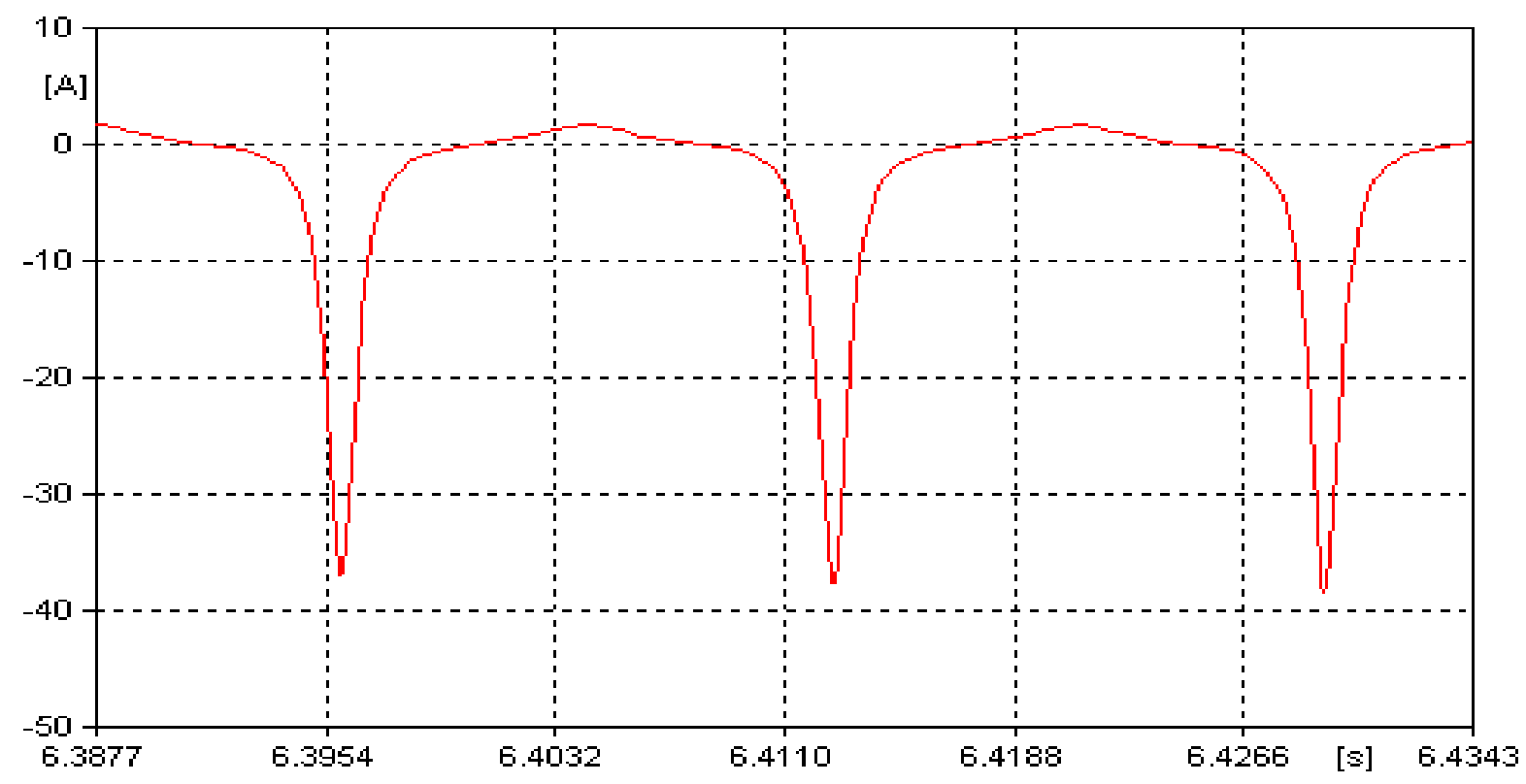

Figure 2.6: Half-cycle saturation due to GIC

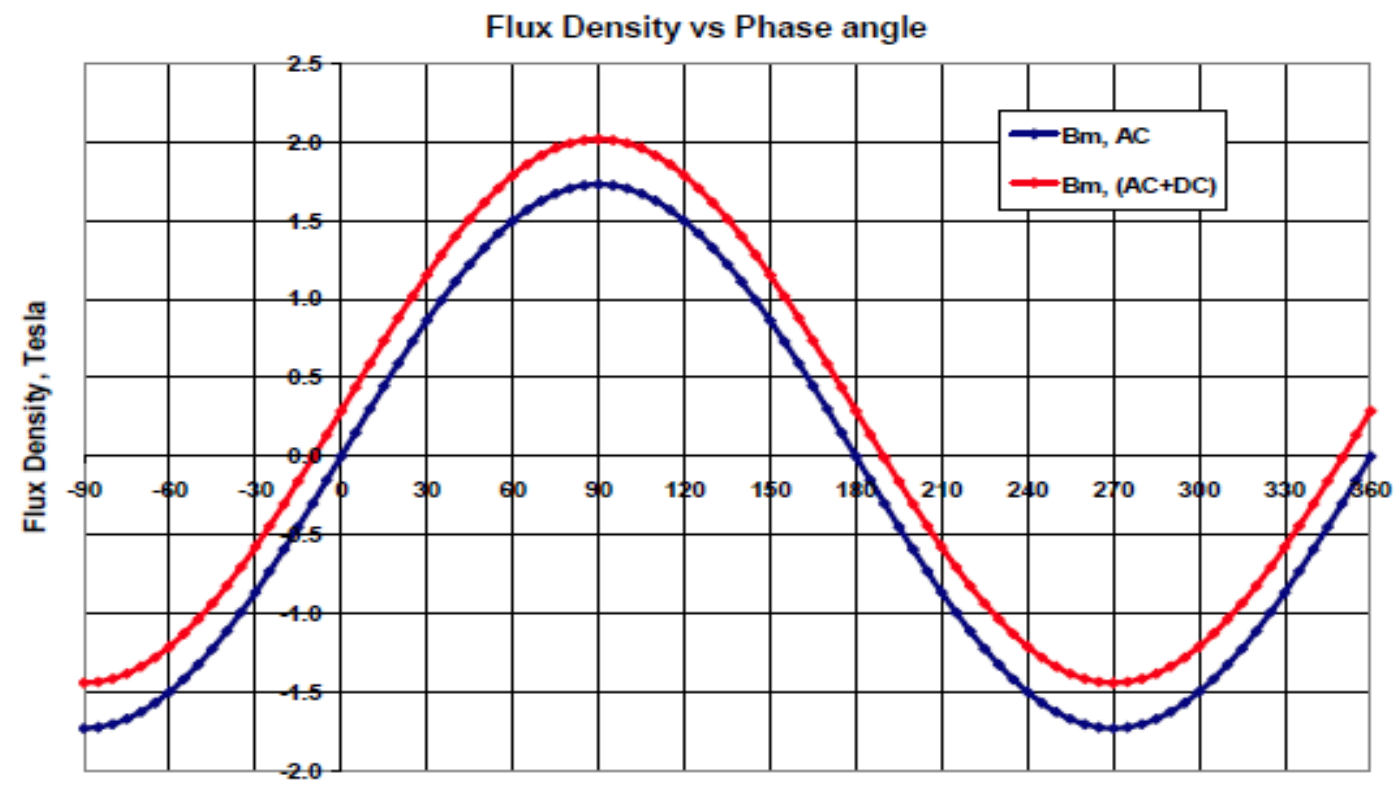

Phase Angle, Degrees

Figure 2.7: Flux density shift due to DC [2], Copyright (C) 2011, IEEE 


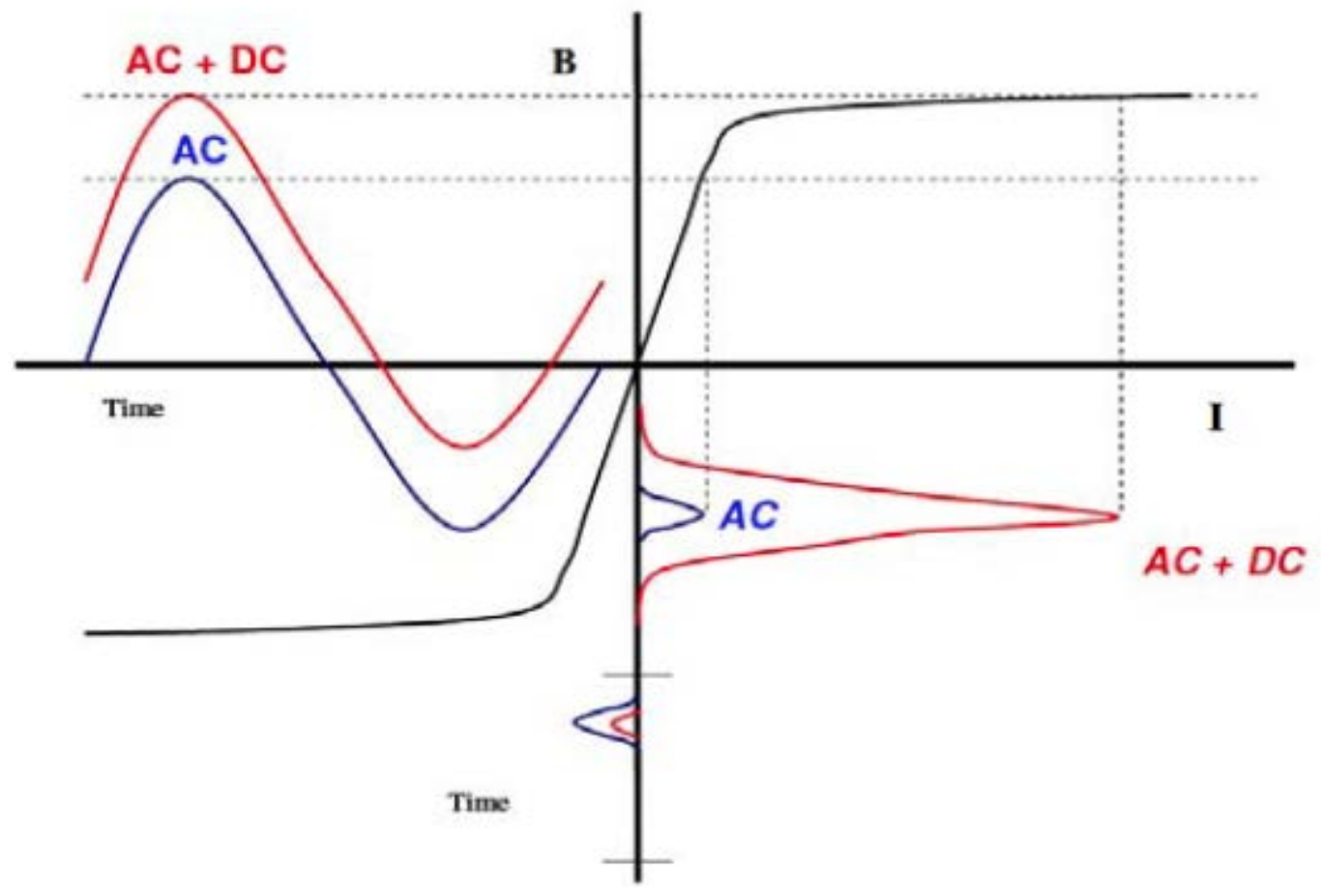

Figure 2.8: Half-cycle saturation due to DC [2], Copyright (C) 2011, IEEE

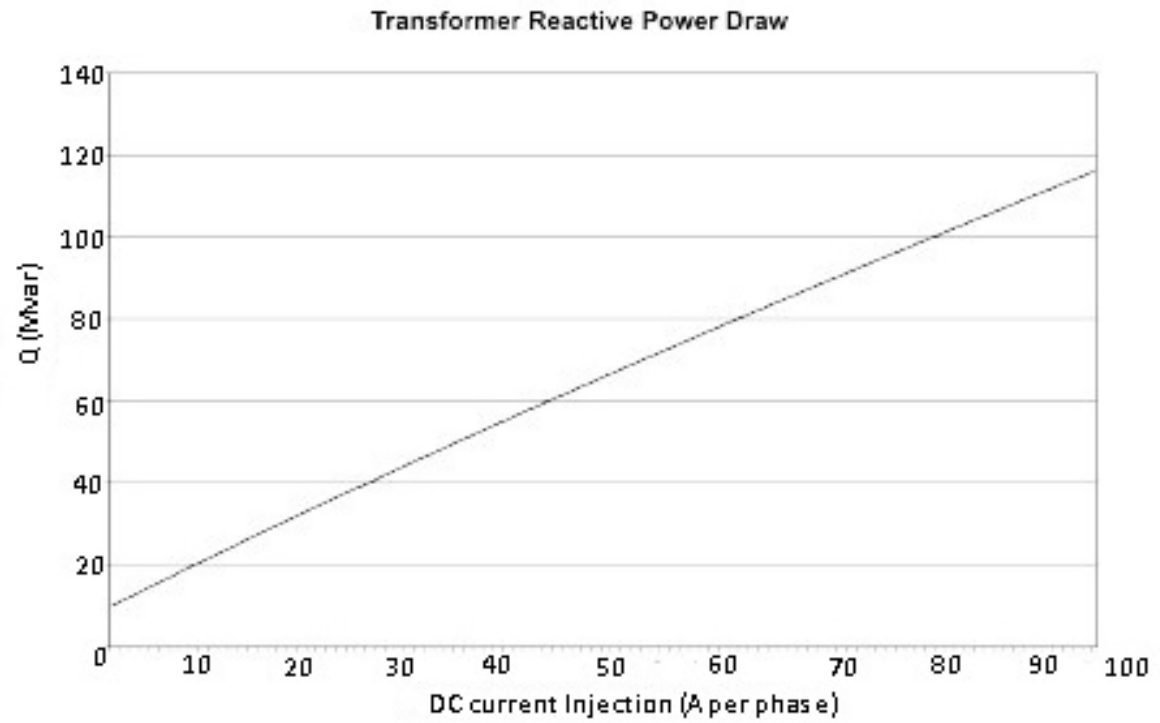

Figure 2.9: GIC vs var absorption in transformer [7], Copyright (C 2011, IEEE 
The effect of the DC signal depends on the core construction, core type and the geometry. The effect is more prevalent when the core reluctance is low and diminishes when the reluctance is high. The magnetization current and DC current comparison for single phase and 3-legged 3phase is provided in [2]. In GIC there is a significant amount of harmonics generated which also depends on the core type and design. These harmonics are evenly distributed among lower and higher orders in the case of single phase transformers. In the case of a 3-phase transformer, the lower order harmonics are generally higher in comparison to the higher order harmonics. For 3phase 3-legged transformers, the $2^{\text {nd }}$ order harmonics amplitude is quite high and is easily monitored by the differential relays in operation. For other constructions and single phase transformers the amplitude of $2^{\text {nd }}$ order harmonics is not as high and can result in improper operation of relays [2].

Hot spots in the windings and the core is another problem associated with GIC. High magnetizing current rich in harmonics results in higher eddy current and circulating current losses in the windings. This can lead to a rise in the windings temperature. Reference [2] compares the winding temperature rise for different GICs in a 1-phase transformer. When the core flux density reaches the saturation flux density levels, there will be a spillage of flux to other structural parts of the transformers such as the tank, tie plates, yoke clamps, etc. The comparison of the tie plate's temperature for different GIC levels is shown in [2]. Reference [2] also claims after comparison that the hot spot is not a major problem with GIC because the duration of a peak GIC is typically 1-2 min and overall GIC could typically last half hour, which will not increase temperature to any dangerous levels [2]. 


\subsection{HYBRID TRANSFORMER MODEL}

The hybrid transformer model of ATP is one of the most sought after models for transient simulation. This model can handle frequencies from near DC upto 3-5 kHz. The hybrid model (XFMR) includes the leakage effects in the core and coil. Different transformer cores have been included, and the effects of distributed capacitance have been considered. In addition to these, a topographically correct nonlinear duality-transform-based core model has been implemented and it also utilizes frequency-dependent winding resistances to produce the correct results. More on this model is given in [21]. The model has been found to be topologically correct and quite effective for transient simulations. The model development and parameter estimation of the transformer has been discussed in [21].

The hybrid model has been tested based on parameters estimation, factory test reports, design data and core ratings in [21]. Reference [22] discusses how the hybrid model parameters can be obtained with direct laboratory measurements and how these tests are to be conducted. The results from short-circuit tests, open-circuit tests and zero-sequence tests were used to calculate the positive-sequence and zero-sequence impedances. Reference [22] also shows how data waveforms can be used to calculate similar parameters. The results from these tests used in the hybrid model and compared with the factory tests reports have been published in [22]. The model benchmarking for steady-state tests such as open-circuit, harmonics and for inrush tests have been done and the results have also been published in [22]. More details on the XFMR model and parameter estimation can be found in [23], [24] and [25].

The hybrid model provides option for the type of nonlinear inductance used for the B-H curve. The available model includes 3 different types of nonlinear inductors: pseudo-nonlinear (98), true nonlinear (93) and hysteretic (96). Types-93 and type-98 are non-hysteretic magnetizing 
inductors while type-96 is a simplified hysteretic inductor. Type-96 is modeled with loops that are empirically based and do not exactly replicate the magnetic material behavior. Type-98 is modeled by linearized value at each time step. Type-93 is solved iteratively at each time step. Reference [21] describes the in-depth differences between the three types of nonlinear inductors and the math behind calculations of magnetization curves for each nonlinear inductor in ATP.

The 3-legged 3-phase transformer core representation is provided in the Figure 2.10, a third delta tertiary winding is also present in all cases studied. Triplex core representation is shown in Figure 2.11.

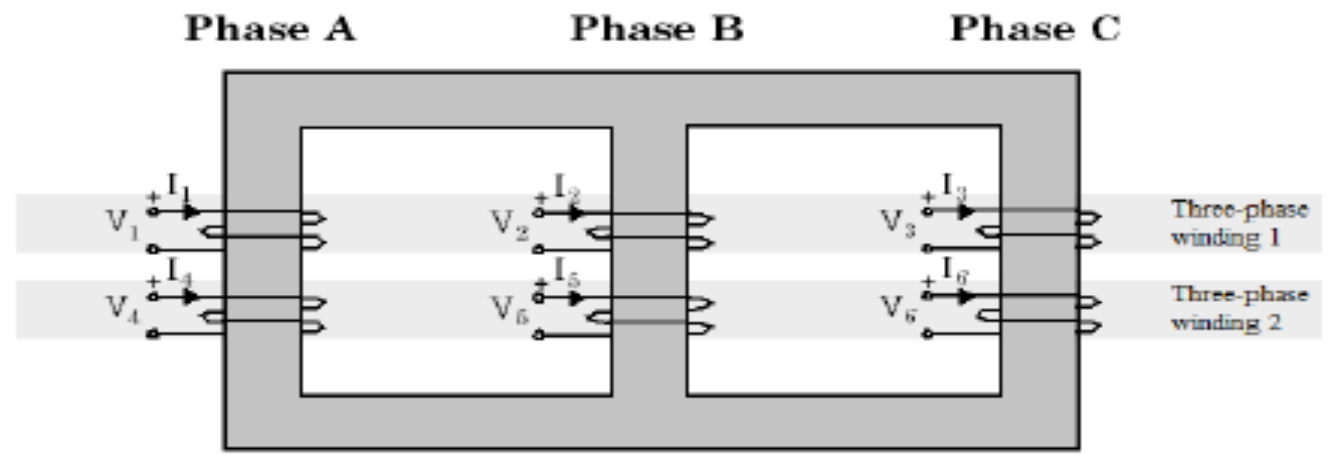

Figure 2.10: 3-Legged core type 3-Phase representation of transformer in ATP [26]
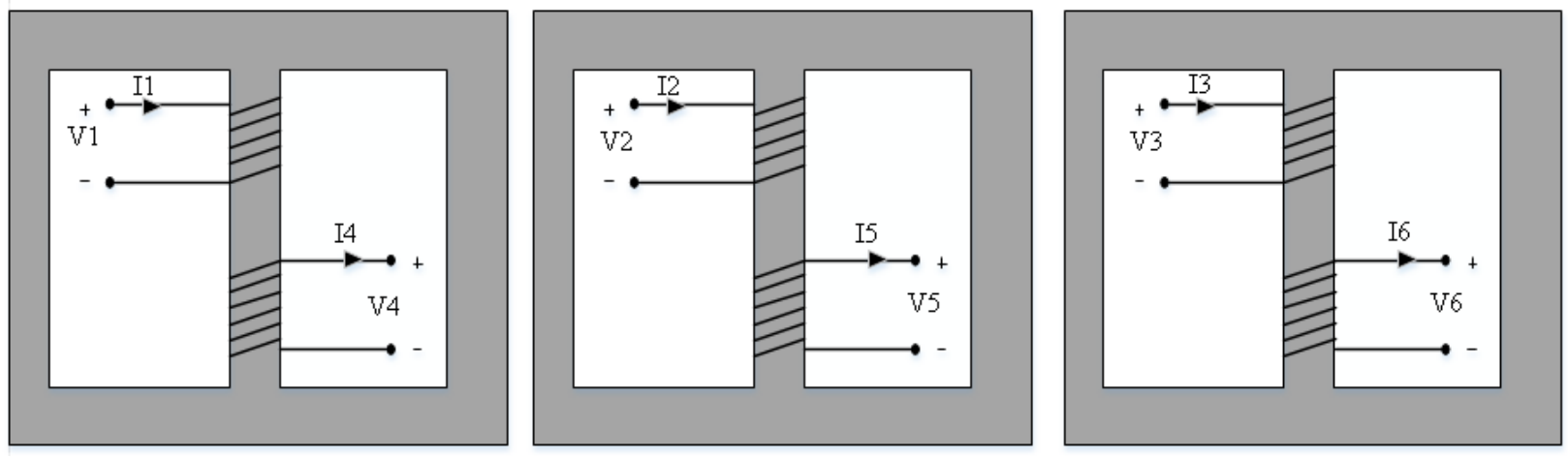

Figure 2.11: Triplex core type representation of transformer in ATP 
Air core inductance or final slope of the core inductance $\mathrm{L}_{\mathrm{a}}$ is another essential parameter which can affect the peak magnetizing current and especially inrush. Even a small change in this value can greatly affect the inrush current peaks.

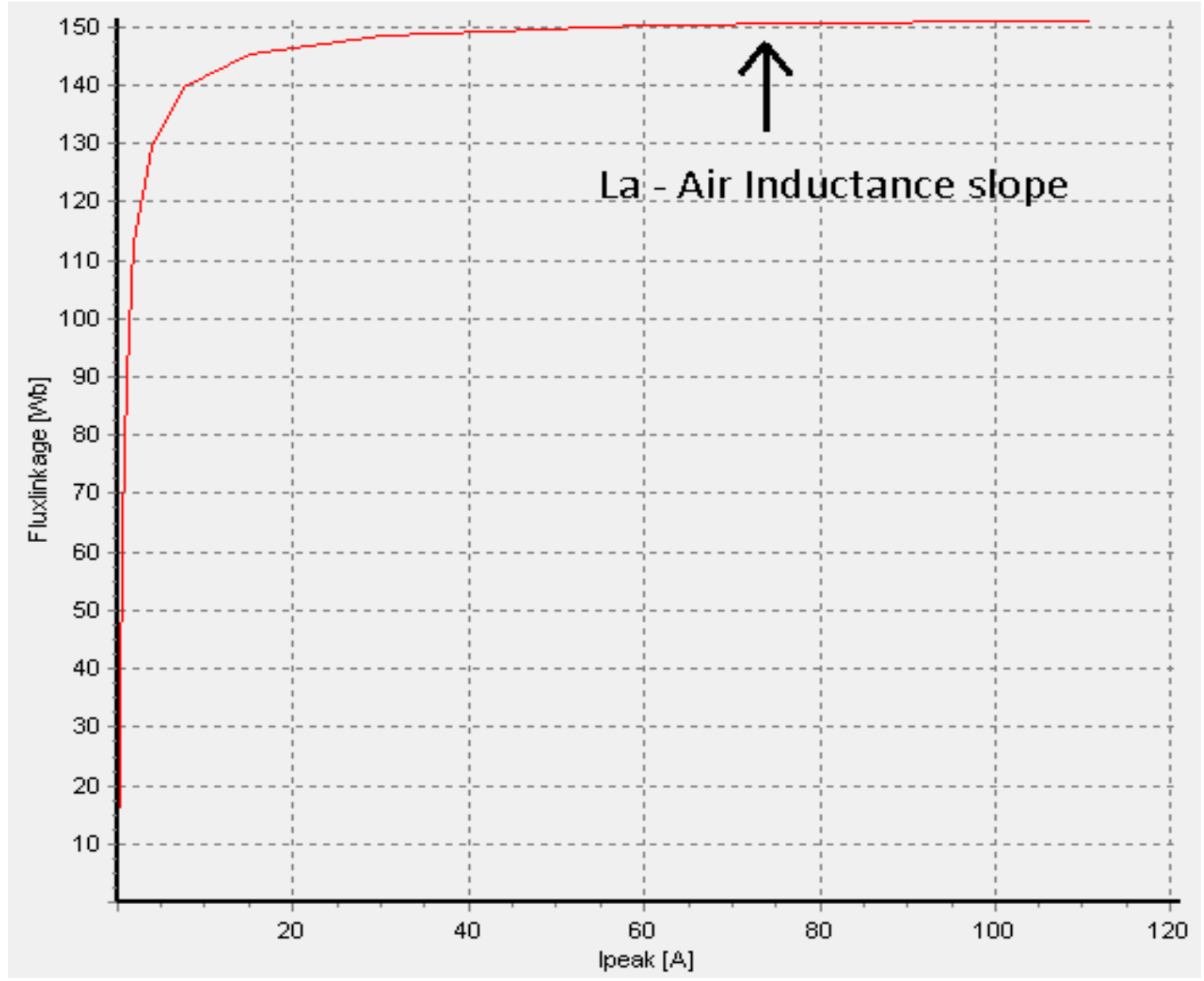

Figure 2.12: $\lambda$-I curve depicting the final slope $L_{a}$ 


\section{CHAPTER 3 - DEVELOPMENT, IMPLEMENTATION AND RESULTS}

\subsection{TRANSFORMER INRUSH CURRENTS MODEL}

Models for transformer inrush currents are developed in this section for an autotransformer bank made up of a) three individual transformers and b) 3-phase 3-legged autotransformer. For inrush modelling, residual flux linkage values have been assumed in the transformer. Initialization of flux linkage is done using the .atp file generated for each model. The procedure is as follows:

1. In the .atp file find out the nonlinear core characteristics.

2. Under the characteristics would be the two nodes which form the nonlinear core inductance with the type of nonlinearity chosen in the hybrid model i.e. type-96, type-93 or type-98.

3. The flux linkage can then be initialized using the node names under the initialization row below the source description.

4. The first field has the nodes, second field has values for the initialized current and third column has the values for the initialized flux linkage.

5. Please keep in mind the initialized values of currents should be between columns 25-29 and initialized flux linkage between columns 39-44.

6. Below figure shows the initialization syntax.

7. The initialized flux linkages are calculated by using the steady-state flux linkage of each phase. The flux linkages are then calculated using the steady-state values in accordance the percentages of residual flux linkages. 
8. $\quad$ For a 3-legged core the total flux linkage should sum to zero for core legs and the yokes follow the flux linkage of the core leg it is magnetically parallel with.

9. For the Triplex core, the flux linkage initialization is done individually.

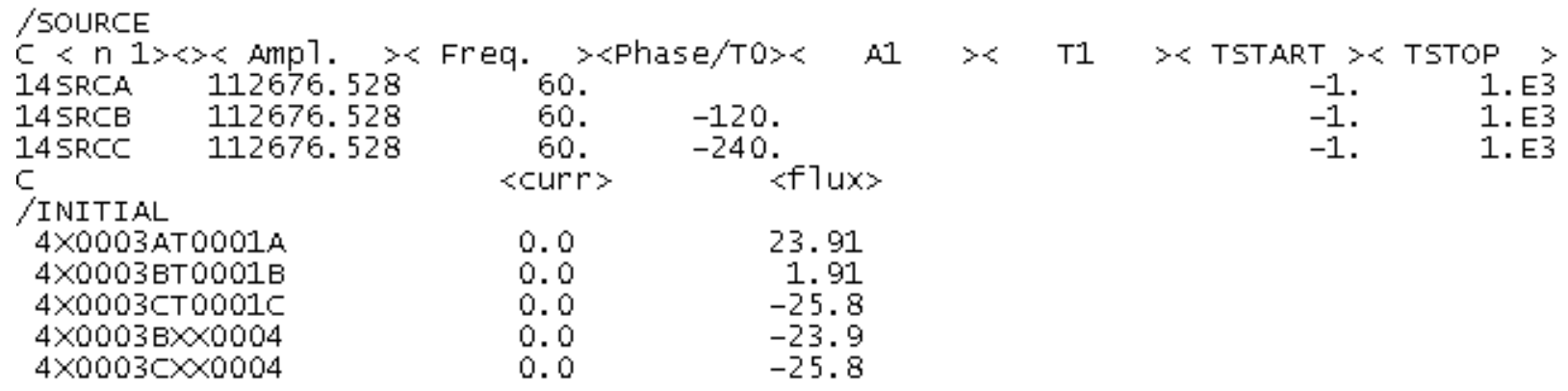

Figure 3.1: Flux linkage initialization syntax

Another important thing to implement after initializing the flux linkage is visualizing this flux linkage on a plot. Currently this feature is not available from the ATP GUI. So the following procedure needs to be followed in order to visualize the initialized flux linkage with the plot program.

a. A TACS probe was required to visualize this flux linkage.

b. The nodes for the nonlinear inductance that was initialized earlier were chosen and a new node was generated.

c. The generated node name must not match with an existing node name.

d. The new node is then initialized with the flux linkage initialization value. The syntax is mentioned in Figure 3.2, which shows the syntax for visualization of a 3-legged core transformer flux linkage (3 core legs and 2 yokes).

e. The initialized value of the flux linkage should be set between columns 16-21. 


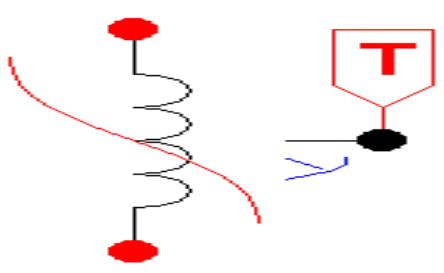

Figure 3.2: GUI representation of initialized flux linkage across a type-93 inductance

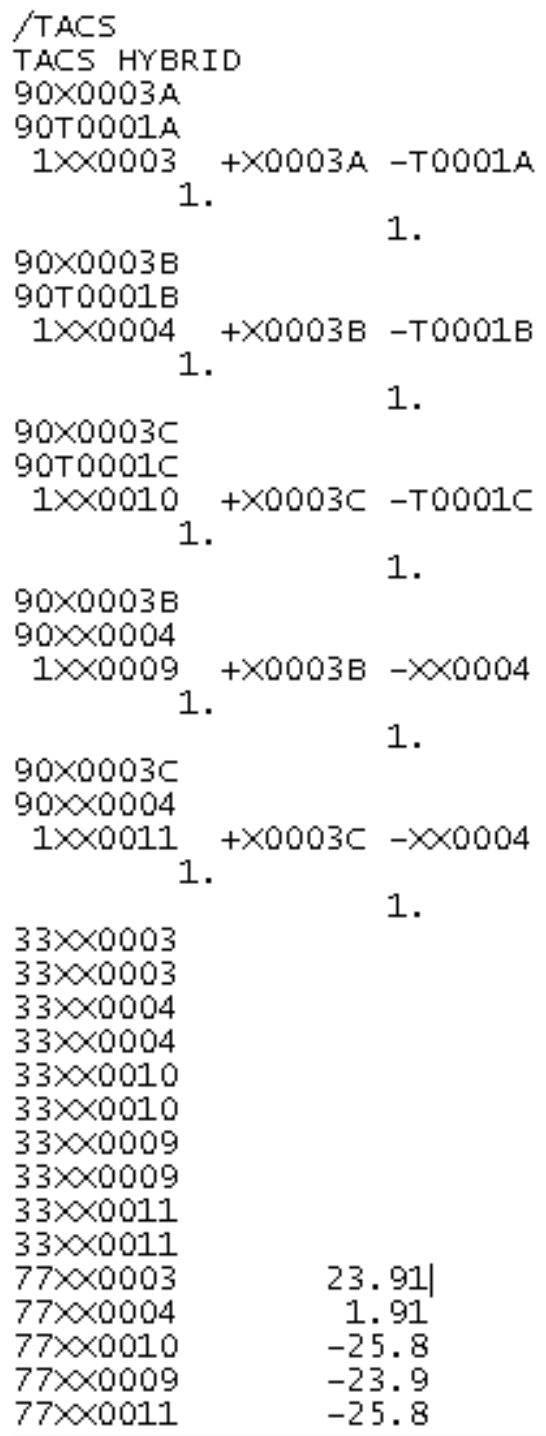

$$
\begin{array}{r}
23.91 \\
1.91 \\
-25.8 \\
-23.9 \\
-25.8
\end{array}
$$

1.

1.

1.

$$
1 .
$$

Figure 3.3: Syntax for initialized flux linkage visualization 
The circuit model for the energization is shown below.

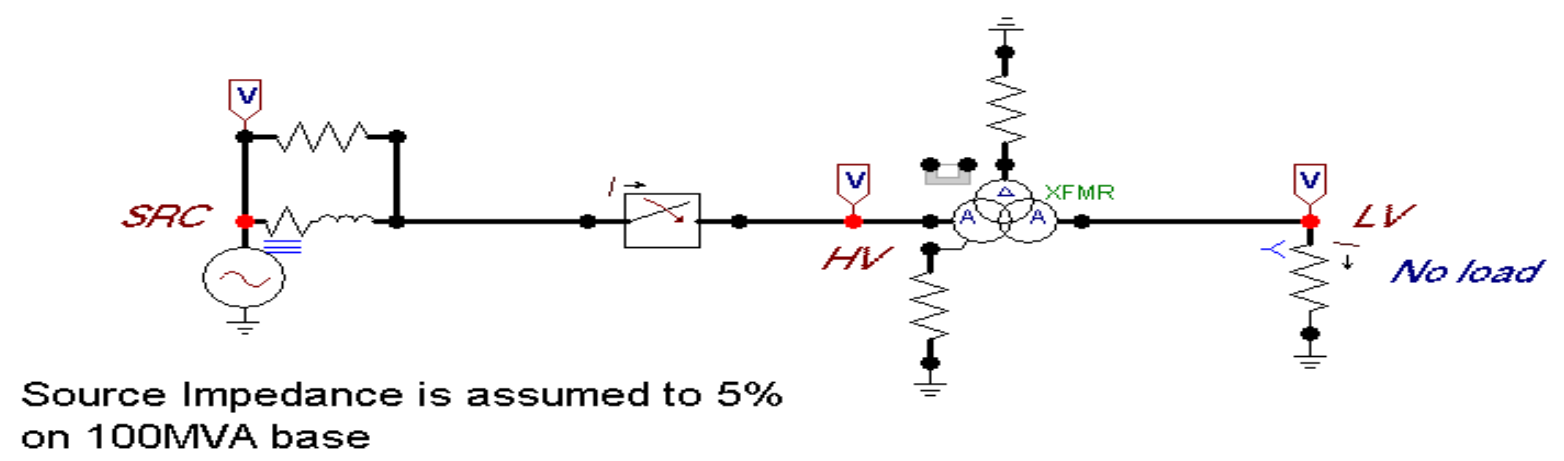

Figure 3.4: ATP model for 3- legged core

Following are a few assumptions made while modeling for inrush current:

1. Source reactance was considered to be $5 \%$ on the 100 MVA base in both cases (from HV and LV). Parallel resistance to source reactance is the numerical damping resistance of 2000 ohms.

2. Transformer rating is $138 / 69-13.8 \mathrm{kV}$ (Yn(auto)D).

3. The energization was considered at no-load condition.

4. The source was assumed to be feeding in the steady-state.

5. The switch was closed at $0 \mathrm{~ms}$, to accommodate for the initialized nonlinear type-93 inductance of the transformer.

6. The analysis was conducted for 3 different residual flux linkage values in the range of 30$50 \%$ of the steady state flux linkage.

7. The peaks of the inrush currents were compared for each residual flux linkage value.

8. For sensitivity with respect to magnetization slope at saturation $\left(\mathrm{L}_{\mathrm{a}}\right)$, the slope values for $\mathrm{L}_{\mathrm{a}}$ chosen were 2, 5.5 and 8. The core chosen was 3-legged core with no residual flux linkage. 
9. The initialized flux linkage leakages are shown for one case in the next section.

10. The complete results for inrush currents are attached in the appendices.

11. The parameters for the hybrid model are attached in the Appendix B.
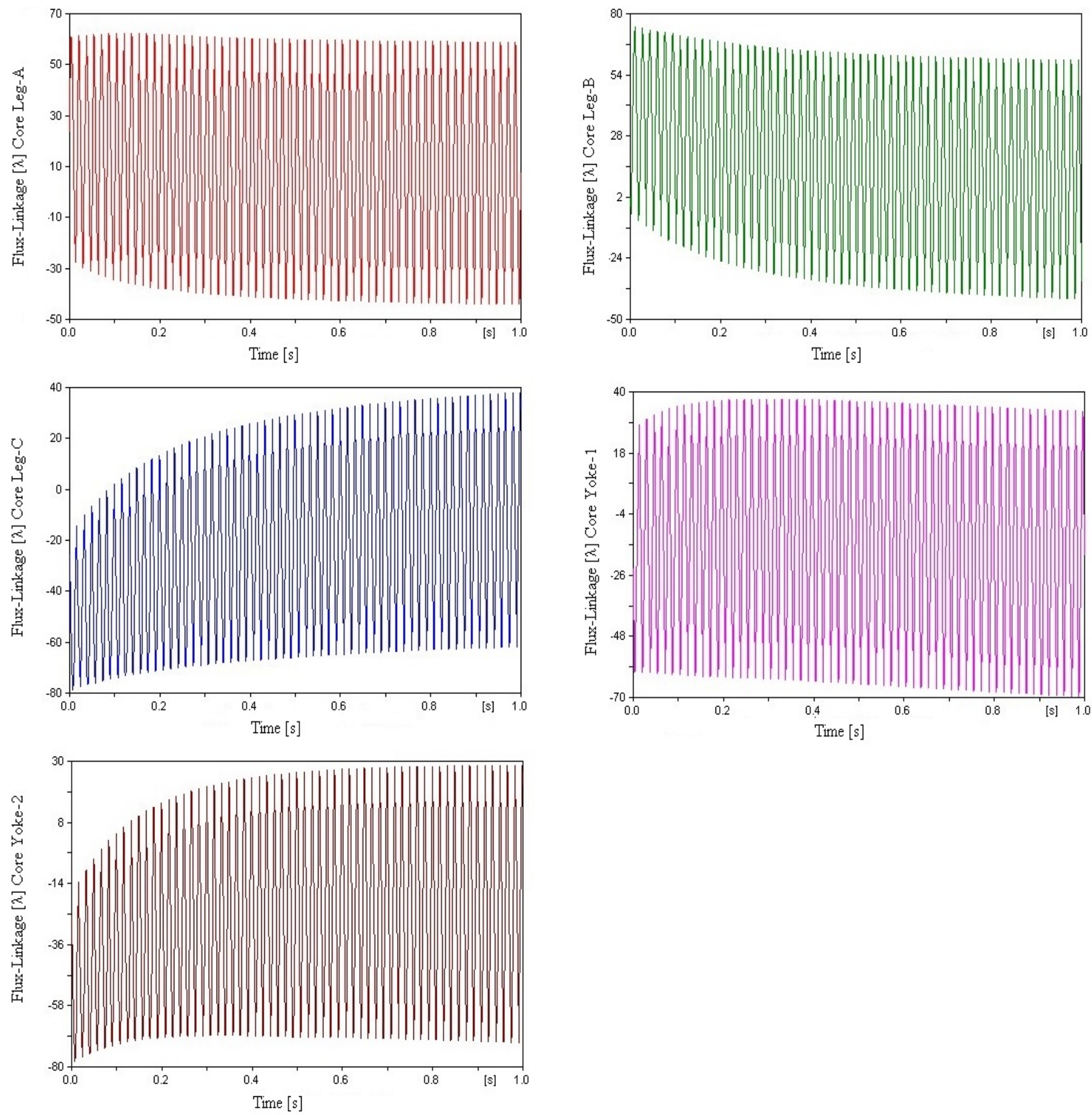

Figure 3.5: Flux linkage with initialized flux linkage 


\subsubsection{ENERGIZATION}

\section{HIGH VOLTAGE SIDE}

\section{Case-1: 3-Legged Type Core}

Comparison between different initialized flux linkages (the method followed is written in flux initialization part) from $30-50 \%$ of the steady state flux linkage is depicted in the waveforms below.
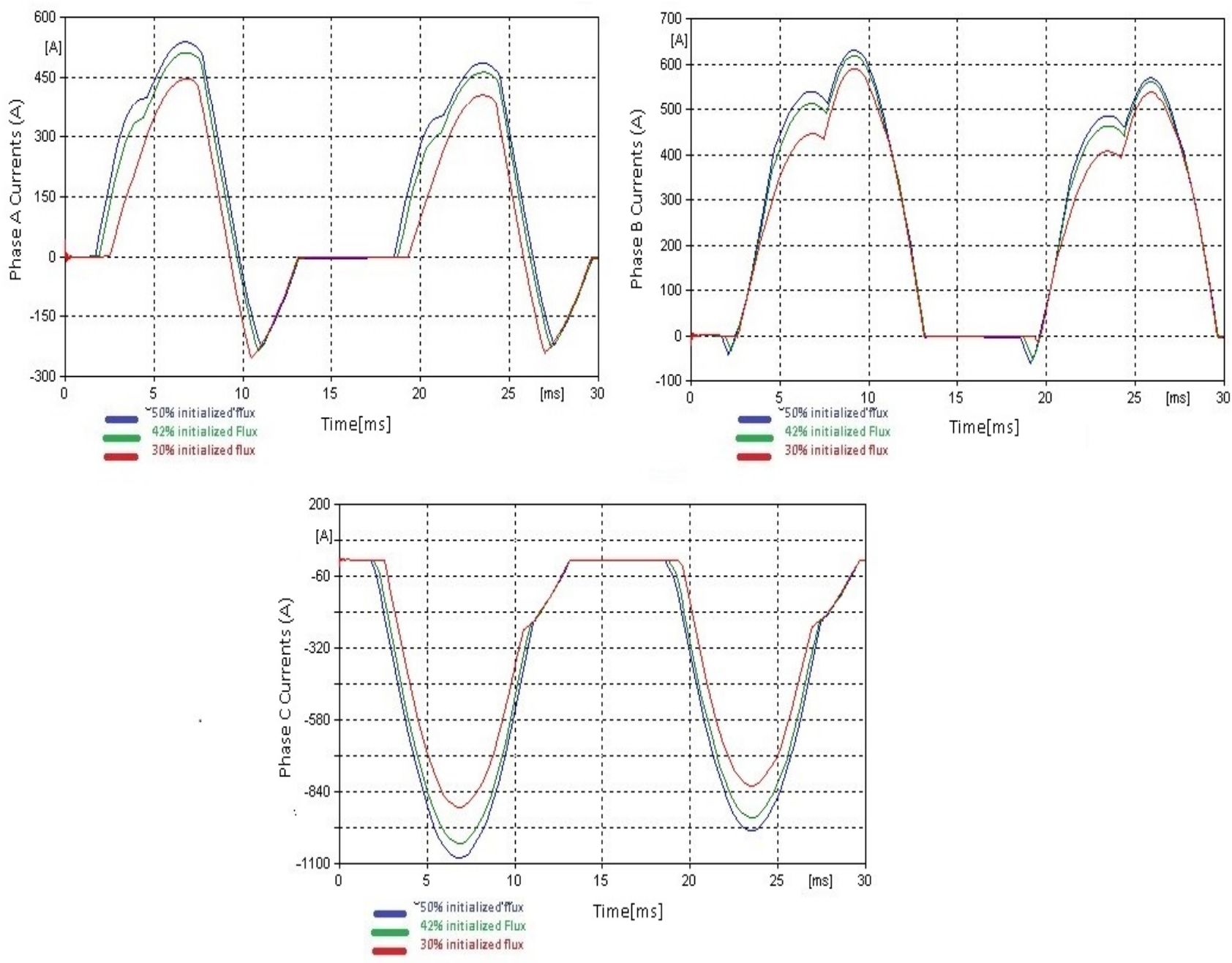

Figure 3.6: Inrush current comparison for 30-50\% initialized flux linkage in triplex core for all phases from $H V$ side 
Case-2 Triplex core transformer
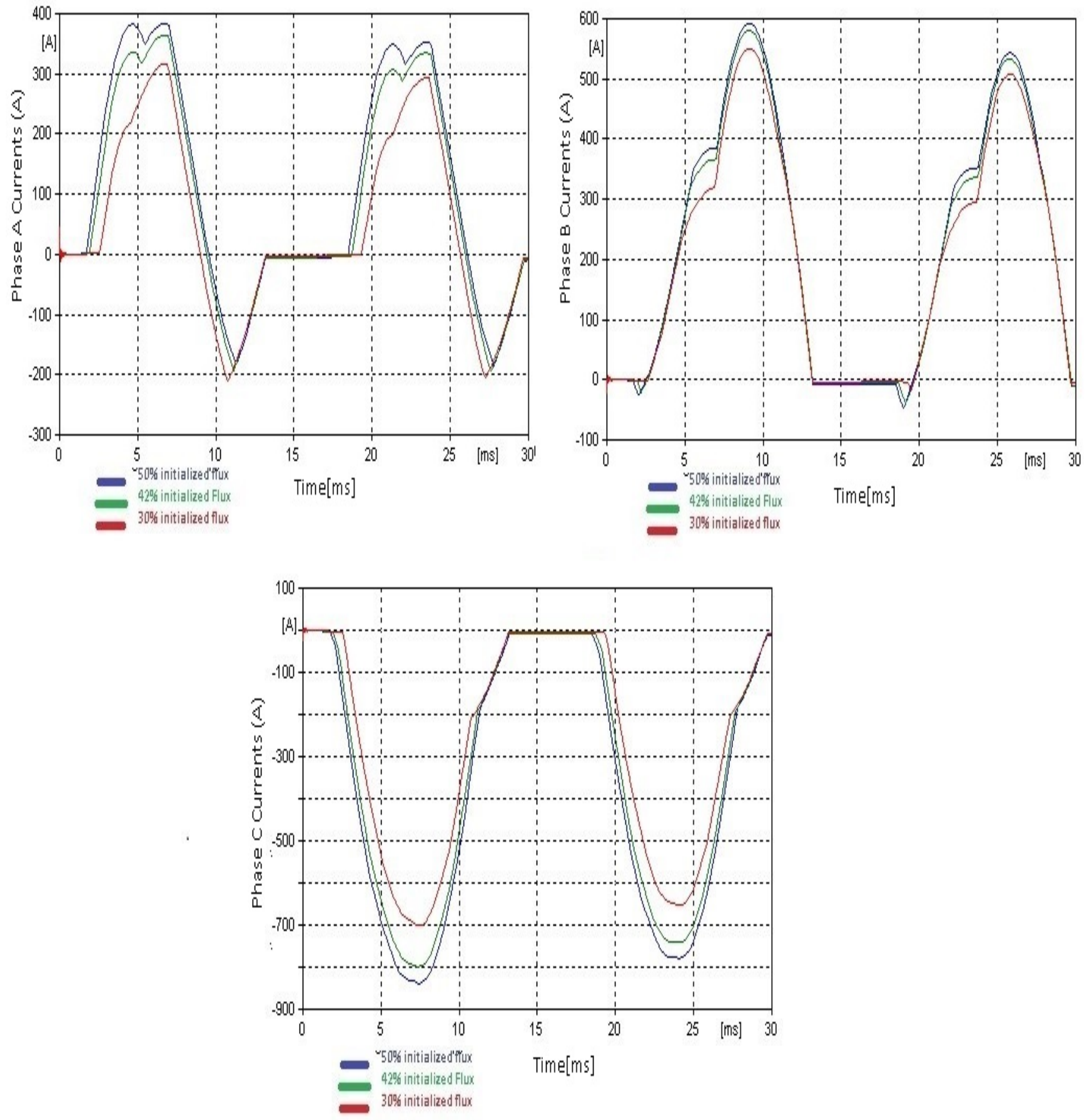

Figure 3.7: Inrush current comparison for 30-50\% initialized flux linkage in triplex core for all phases from HV side 
Table 3.1: Energization from HV side Peak currents for 3-legged core

\begin{tabular}{|l|l|l|l|}
\hline 3-Legged Core & Phase B peak (A) & Phase C peak (A) \\
\hline Initialized Flux linkage & Phase A peak (A) & 630 & -1080 \\
\hline $50 \%$ & 538 & 618 & -1027 \\
\hline $42 \%$ & 511 & 590 & -900 \\
\hline $30 \%$ & 446 & \multicolumn{2}{l|}{} \\
\hline \multicolumn{4}{|l|}{} \\
\hline $50 \%$ & 383 & 592 & -837 \\
\hline $42 \%$ & 364 & 580 & -798 \\
\hline $30 \%$ & 317 & 550 & -701 \\
\hline
\end{tabular}




\section{LOW VOLTAGE SIDE}

Case-1: 3-Legged transformer
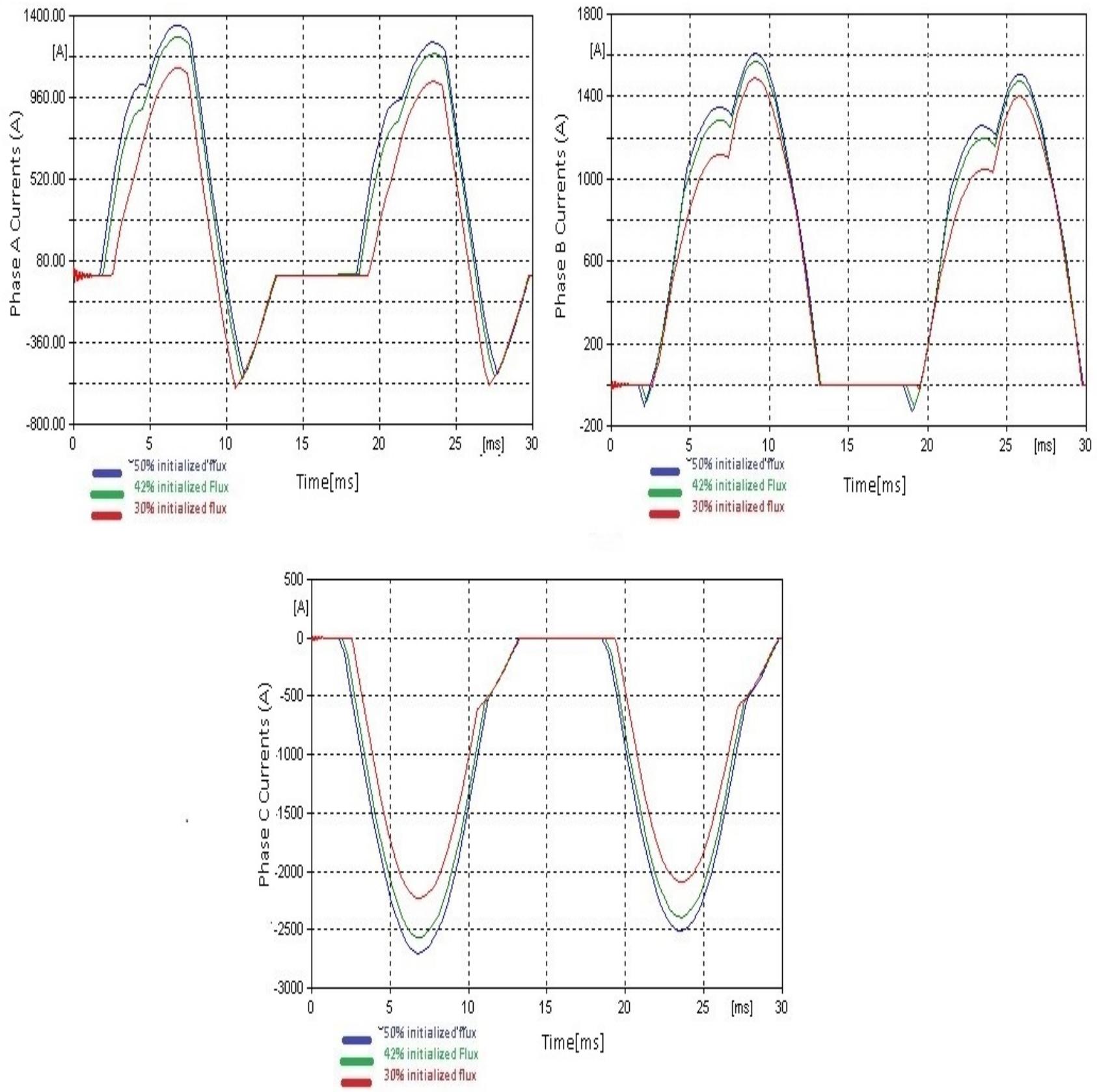

Figure 3.8: Inrush current comparison for 30-50\% initialized flux linkage in 3-legged core for all phases from $L V$ side 
Case-2: Triplex core transformer
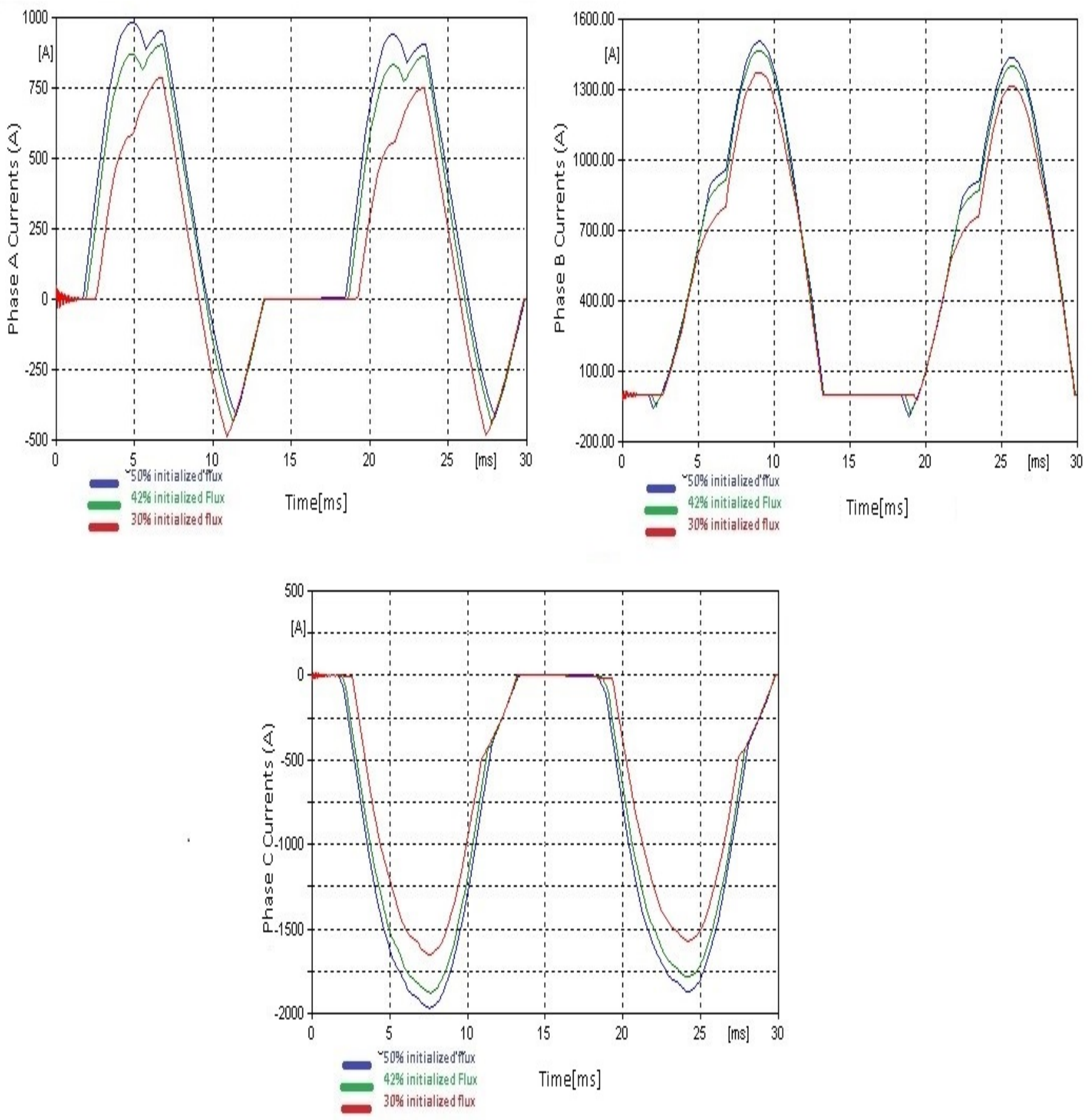

Figure 3.9: Inrush current comparison for 30-50\% initialized flux linkage in Triplex core for all phases from LV side 
Table 3.2: Energization from LV side peak currents for 3-legged and triplex core

\begin{tabular}{|l|l|l|l|}
\hline 3-Legged Core \\
\hline Initialized Flux linkage & Phase A peak (A) & Phase B peak (A) & Phase C peak (A) \\
\hline $50 \%$ & 1350 & 1608 & -2701 \\
\hline $42 \%$ & 1283 & 1573 & -2567 \\
\hline $30 \%$ & 1117 & 1488 & -2235 \\
\hline \multicolumn{5}{|l|}{} \\
\hline $50 \%$ & 952 & 1504 & -1968 \\
\hline $42 \%$ & 904 & 1467 & -1877 \\
\hline $30 \%$ & 784 & 1375 & -1650 \\
\hline
\end{tabular}

\section{Discussion:}

1. The results attached for 3-legged core and triplex core when the energization is done from LV or HV side suggests that the residual flux linkage plays an important part in defining the peak inrush current on energization.

2. Initialization of flux linkage was performed using the mentioned method and is working correctly, this can be extrapolated through the results obtained.

3. It has been observed that more residual flux linkage will lead higher peak inrush current. In addition, the model developed seems capable of predicting the effect of residual flux linkage quite well in general as well as mathematically.

4. Point 3 is observed from the fact that for a 3-legged core transformer energized from LV side with residual flux linkage equal to $50 \%$ of steady state flux linkage draws an inrush current of 1350 A in phase-A compared to 1117 A for 30\% residual flux linkage.

5. The protection guidelines for inrush currents have not been studied in this report but Appendix C can be referenced in order to establish settings for differential relays for addressing problems due to different type of inrush in transformers. 


\subsubsection{SENSITIVITY TO MAGNETIZATION SLOPE AT SATURATION (La)}
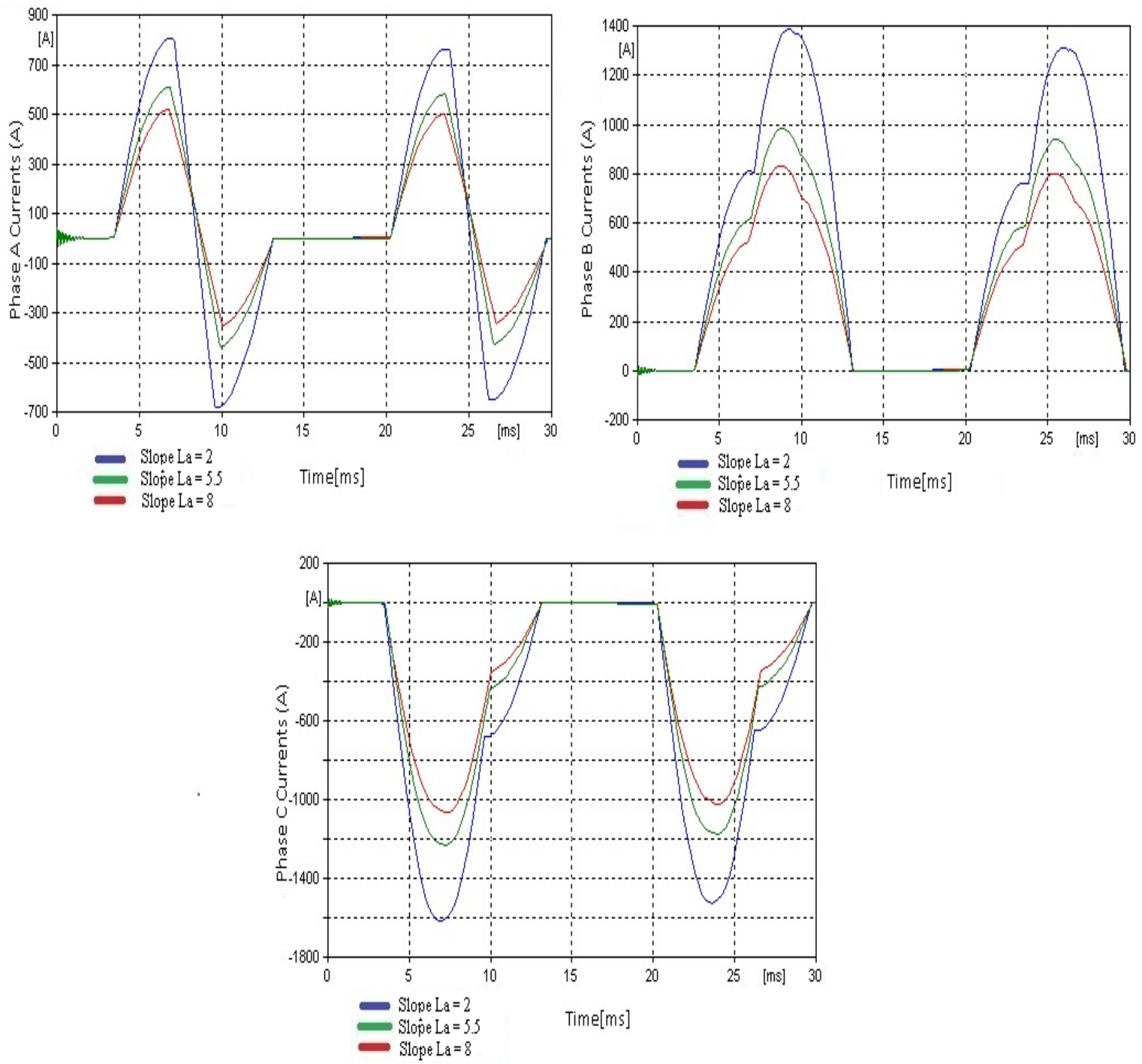

Figure 3.10: Comparison of Inrush with effect of Slope La for 3-legged core and no residual flux linkage 
Table3.3: Sensitivity analysis for slope $L_{a}$

\begin{tabular}{|c|c|c|c|}
\hline $\begin{array}{c}\text { Slope } \\
\mathbf{L}_{\mathbf{a}}\end{array}$ & $\begin{array}{c}\text { Phase-A inrush current } \\
\text { Amplitude (Amps) }\end{array}$ & $\begin{array}{c}\text { Phase-B inrush current } \\
\text { Amplitude (Amps) }\end{array}$ & $\begin{array}{c}\text { Phase-C inrush current } \\
\text { Amplitude (Amps }\end{array}$ \\
\hline $\mathbf{2}$ & 806 & 1385 & -1603 \\
\hline $\mathbf{5 . 5}$ & 609 & 981 & -1235 \\
\hline $\mathbf{8}$ & 515 & 826 & -1068 \\
\hline
\end{tabular}

\section{Discussion:}

The sensitivity analysis gives an idea of how important $\mathrm{L}_{\mathrm{a}}$ or air core inductance of transformer

core is. This value is the final slope of the magnetization curve and can have a significant impact on the peak of inrush currents. Hence the correct data for this slope is necessary or in case the data is not available the estimate function in the core parameters option can be used to approximately estimate the value of $\mathrm{L}_{\mathrm{a}}$. 


\subsection{OVER-EXCITATION}

Over-excitation is another common problem associated with transformers, especially when they are directly fed from a generator. In this section the problem of Over-excitation is simulated and its effects on transformer cores are studied. The ATP model used for this simulation is attached below.

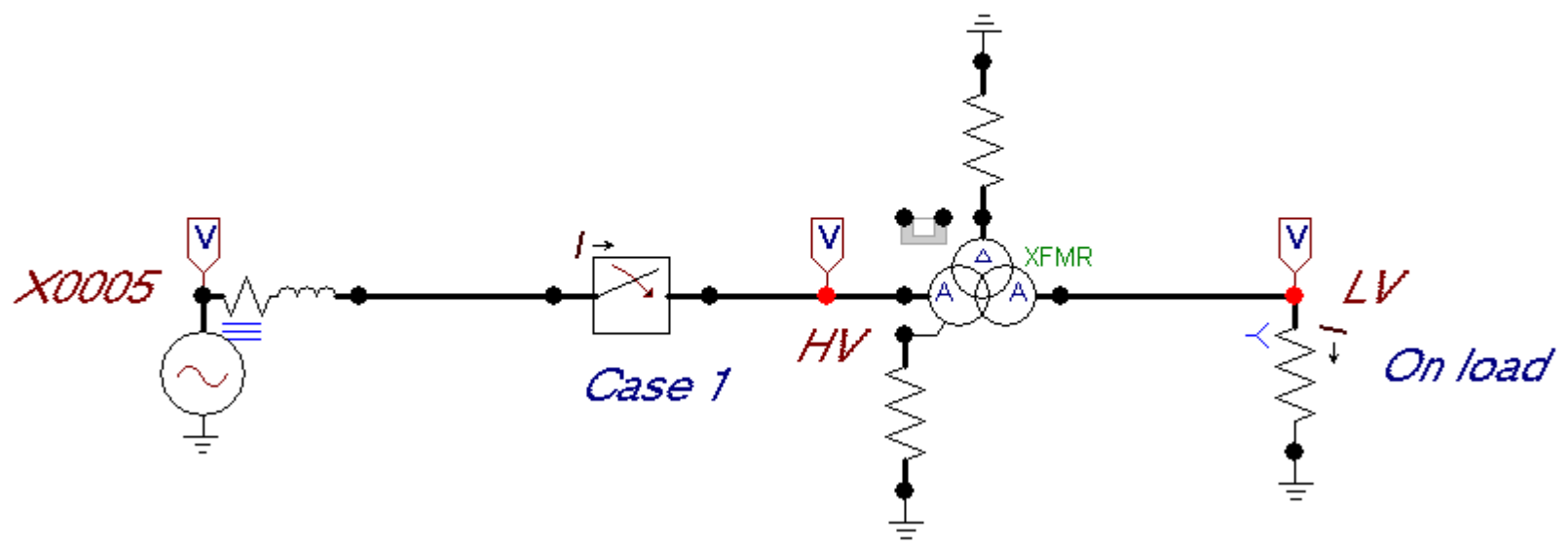

Figure 3.11: ATP model for Over-excitation

Following are a few assumptions made while modeling for over-excitation:

1. Source reactance was considered to be $5 \%$ over the 100 MVA base on HV side.

2. Transformer rating is $138 / 69-13.8 \mathrm{kV}$ (Yn(auto)D).

3. The Sources were assumed to be feeding in the steady state to observe the saturation of core.

4. For frequency response a $50 \mathrm{~Hz}$ frequency was assumed in place of $60 \mathrm{~Hz}$ nominal.

5. For voltage response, the excitation voltage was assumed to be $120 \%$ of the nominal value of $138 \mathrm{kV}$. 
6. The parameters used for the hybrid XFMR model are same as the one used for inrush model and are attached in Appendix B.

7. The harmonic estimation of the excitation is done using the harmonic model available in the ATP GUI which uses Discreet Fourier Transform (DFT) for estimation.

The core response for over-excitation is attached in the results in the coming section.

\subsubsection{FREQUENCY RESPONSE}

\section{$\underline{\text { Triplex Core }}$}
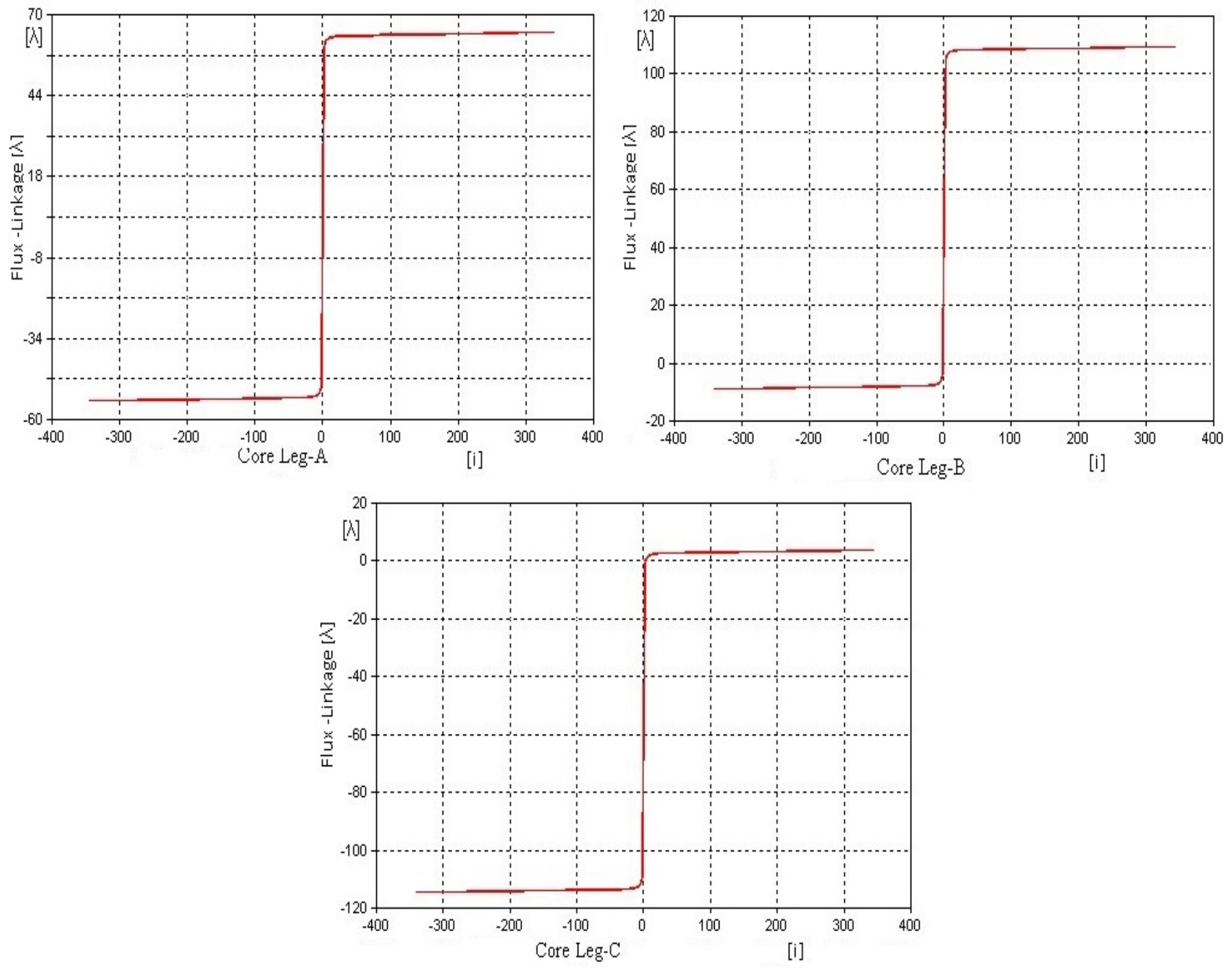

Figure 3.12: $\lambda$-I Characteristic of Triplex core for $50 \mathrm{~Hz}$ under frequency 


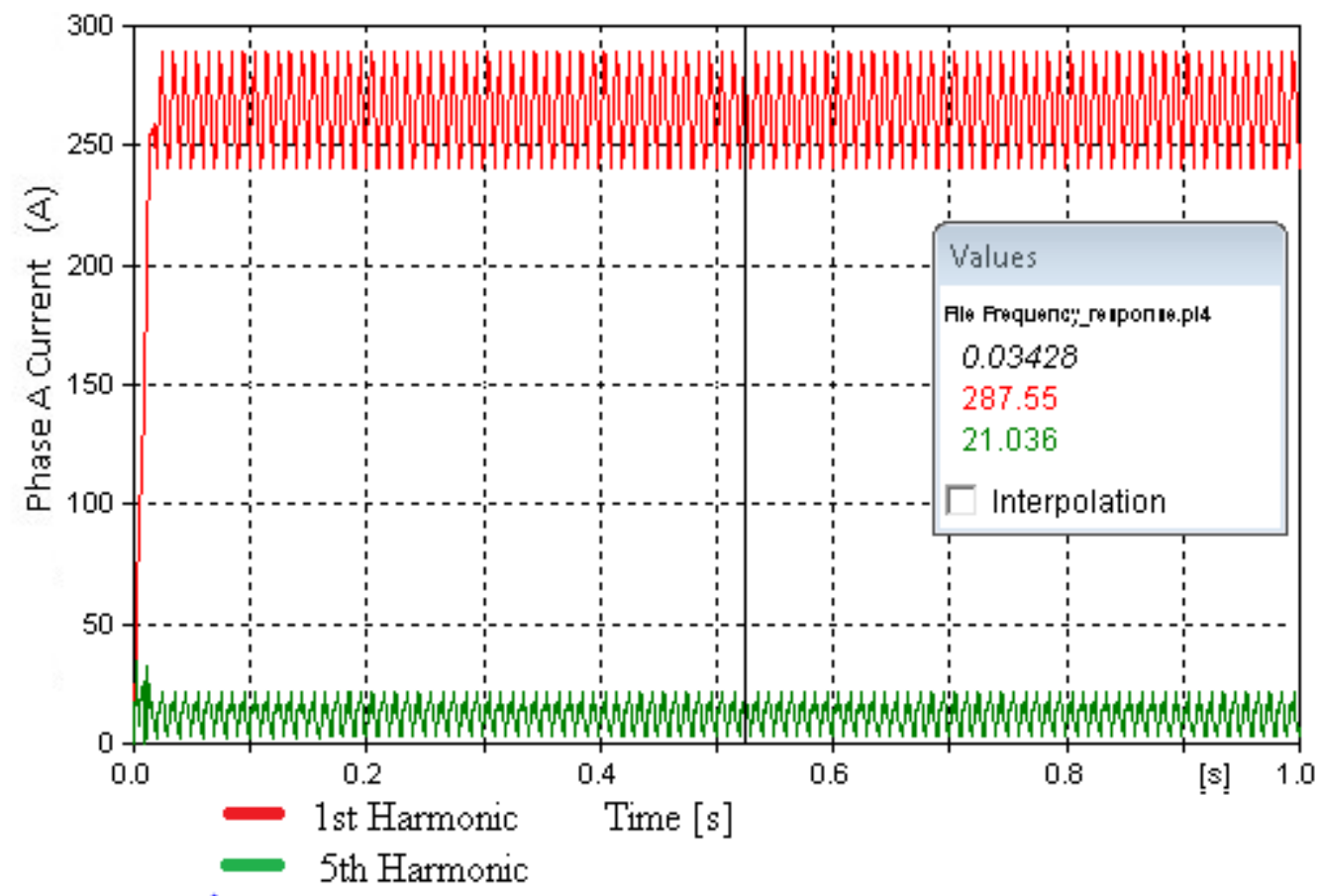

Figure 3.13: $1^{\text {st }}$ and $5^{\text {th }}$ Harmonics as seen by relays in the excitation current for Triplex core for $50 \mathrm{~Hz}$ under frequency

The harmonics were obtained using the harmonics block available in the ATP GUI which uses DFT for its calculations. 


\section{3-Legged Core}
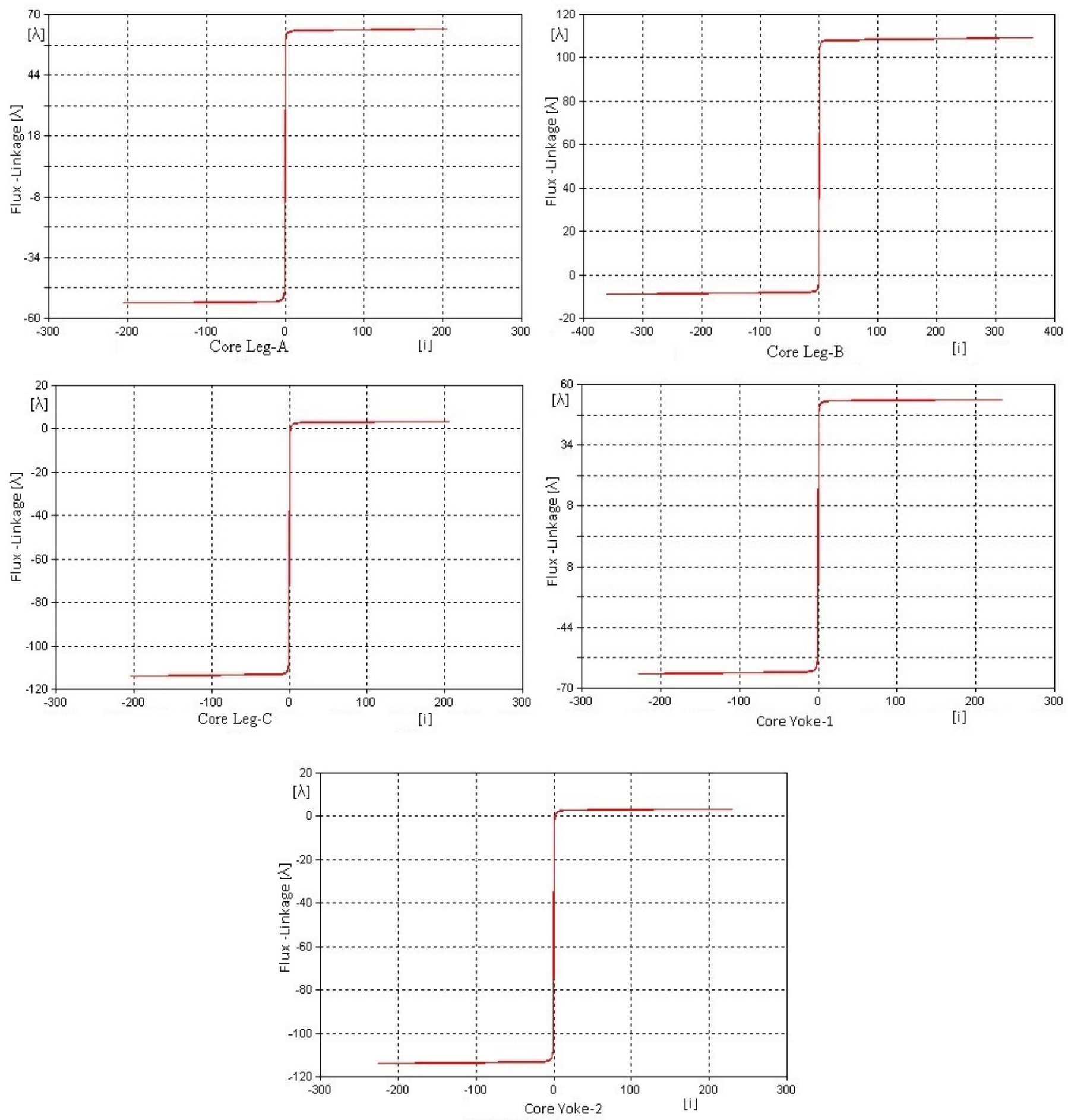

Figure 3.14: $\lambda$-I Characteristic of 3-legged core for $50 \mathrm{~Hz}$ under frequency 


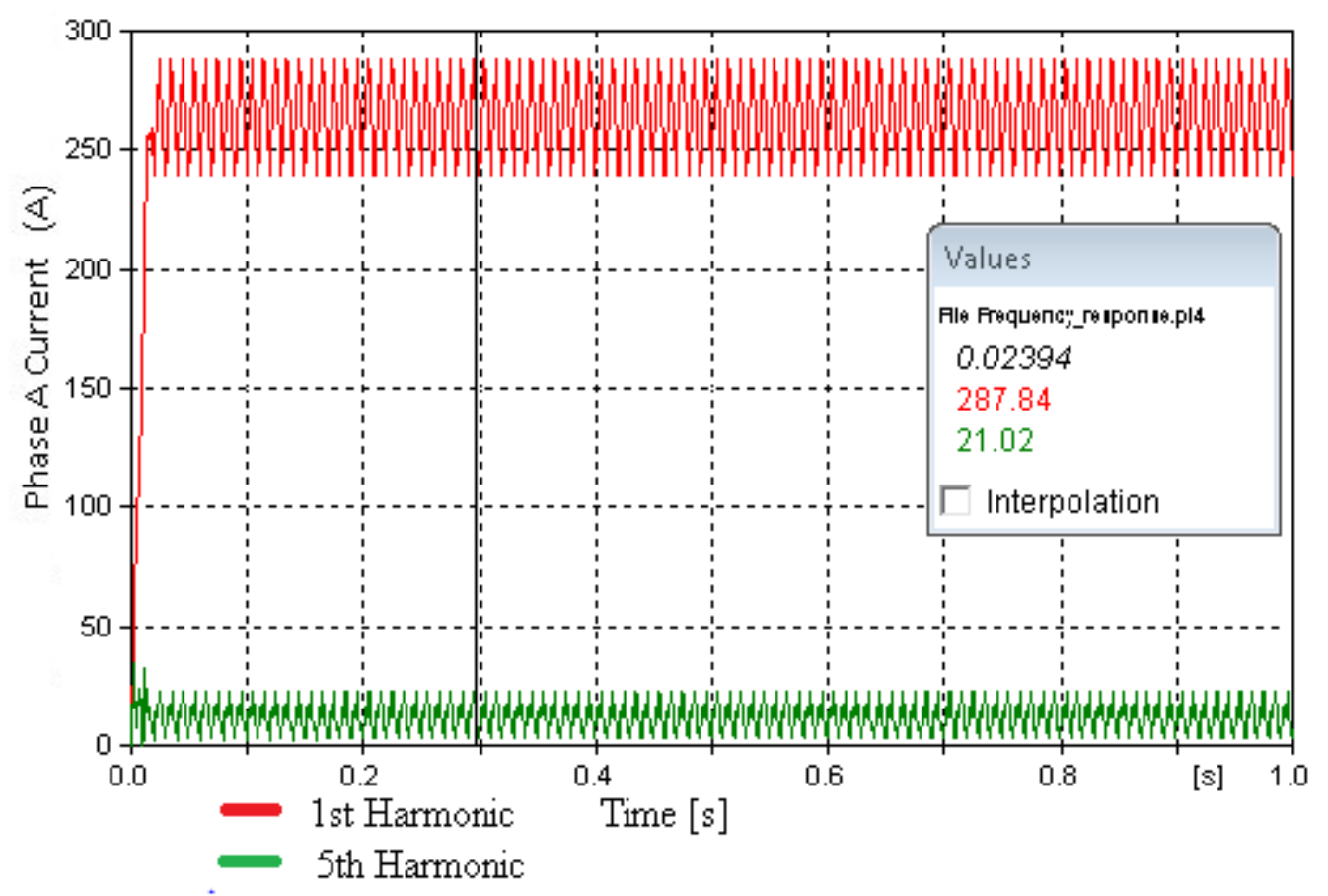

Figure 3.15: $1^{\text {st }}$ and $5^{\text {th }}$ Harmonics as seen by relays in the excitation current for 3-legged core for $50 \mathrm{~Hz}$ under frequency

The harmonics were obtained using the harmonics block available in the ATP GUI which uses

DFT for its calculations.

Table 3.4: Magnetization Current Comparison for under-frequency response

\begin{tabular}{|l|l|l|l|}
\hline \multicolumn{5}{|c|}{ 3-Legged Core } \\
\hline Voltage response & Phase A peak (A) & Phase B peak (A) & Phase C peak (A) \\
\hline $120 \%$ & 225 & 370 & 215 \\
\hline \multicolumn{4}{|c|}{ Triplex Core } \\
\hline $120 \%$ & 340 & 340 & 340 \\
\hline
\end{tabular}

Table 3.5: $1^{\text {st }}$ and $5^{\text {th }}$ Harmonics as seen by relays in the excitation current for $50 \mathrm{~Hz}$ under frequency

\begin{tabular}{|c|c|c|}
\hline \multicolumn{3}{|c|}{ 3-Legged Core } \\
\hline Voltage response & $1^{\text {st }}$ Harmonic $(\mathrm{A})$ & $5^{\text {th }}$ Harmonic (A) \\
\hline $120 \%$ & 288 & 21 \\
\hline \multicolumn{3}{|c|}{ Triplex } \\
\hline $120 \%$ & 287.5 & 21 \\
\hline
\end{tabular}




\subsubsection{OVER-VOLTAGE RESPONSE}

Triplex Core
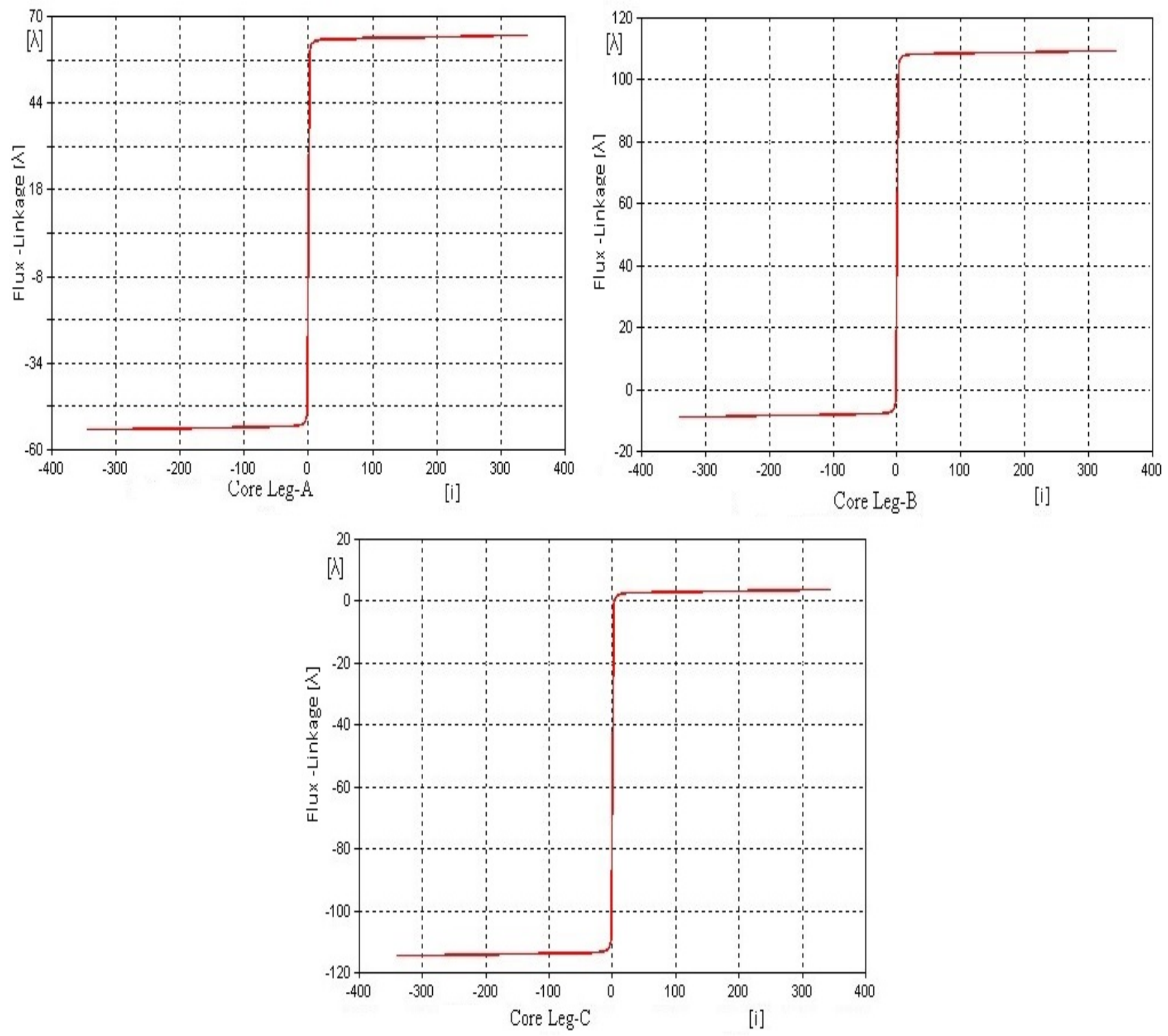

Figure 3.16: $\lambda-I$ Characteristic of Triplex core for $120 \%$ of nominal excitation 


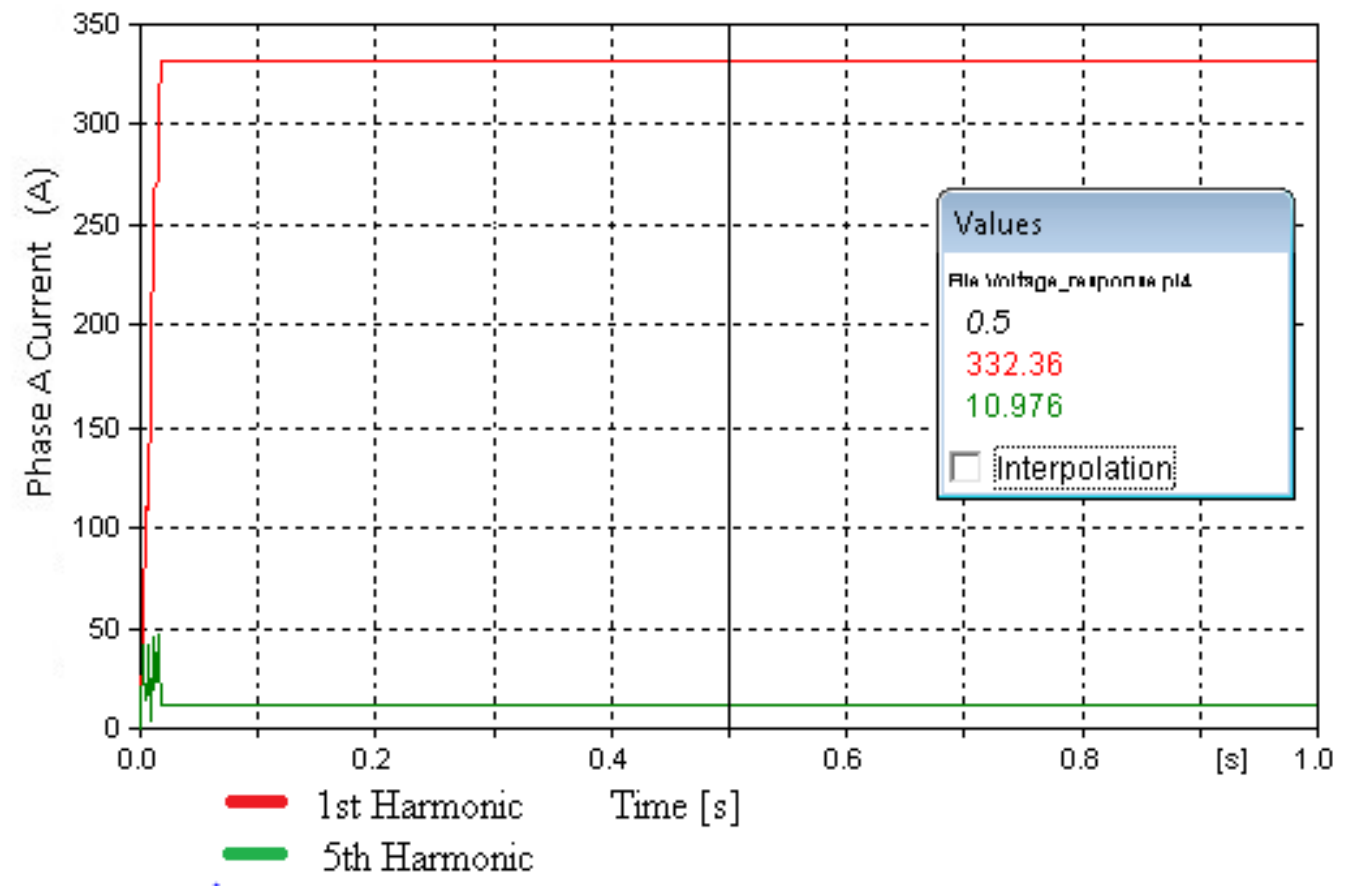

Figure 3.17: $1^{\text {st }}$ and $5^{\text {th }}$ Harmonics as seen by relays in the excitation current for Triplex core for $120 \%$ excitation voltage

The harmonics were obtained using the harmonics block available in the ATP GUI which uses DFT for its calculations. 


\section{3-Legged Core}
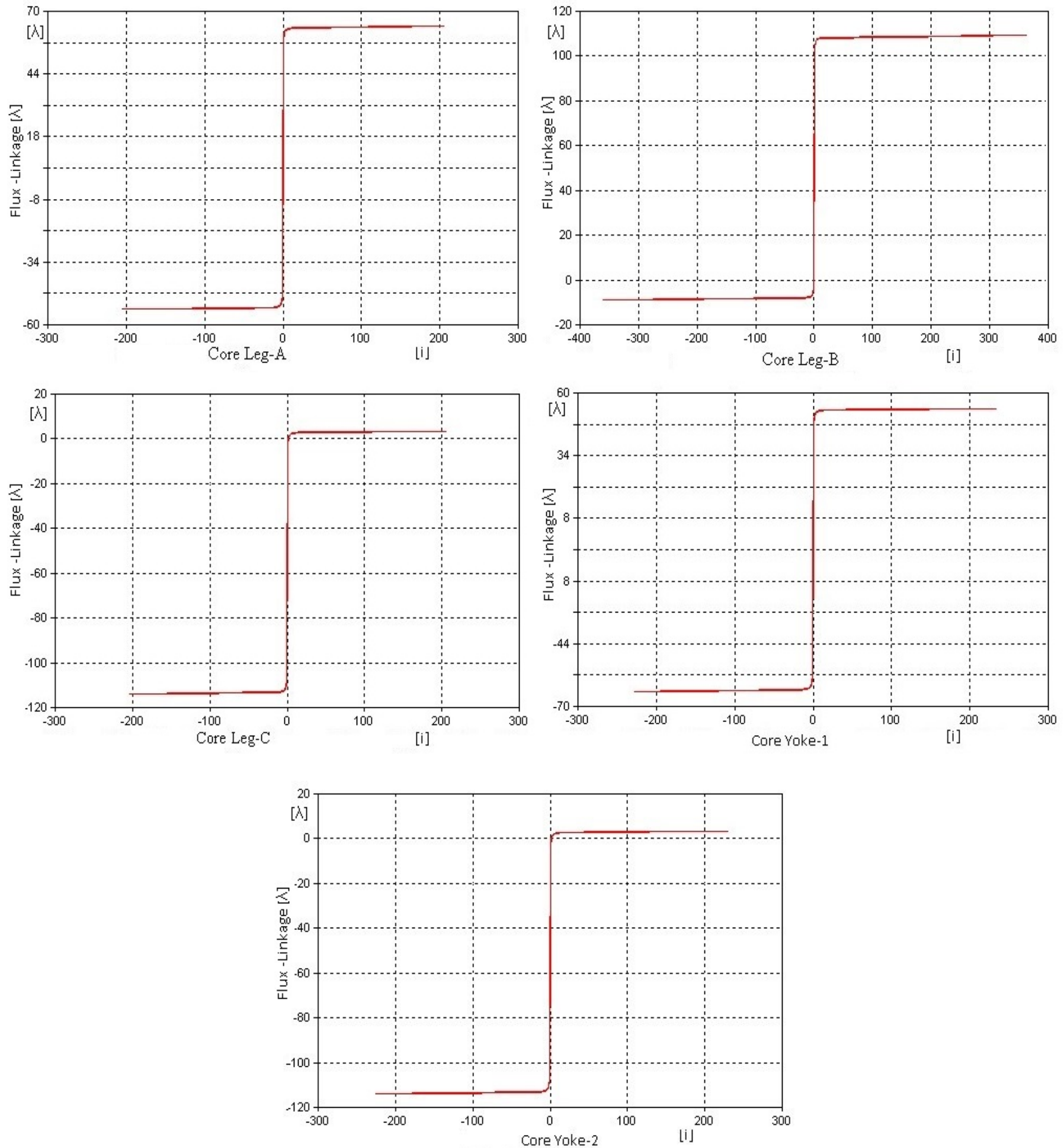

Figure 3.18: $\lambda$-I Characteristic of 3-legged core for $120 \%$ of nominal excitation voltage 


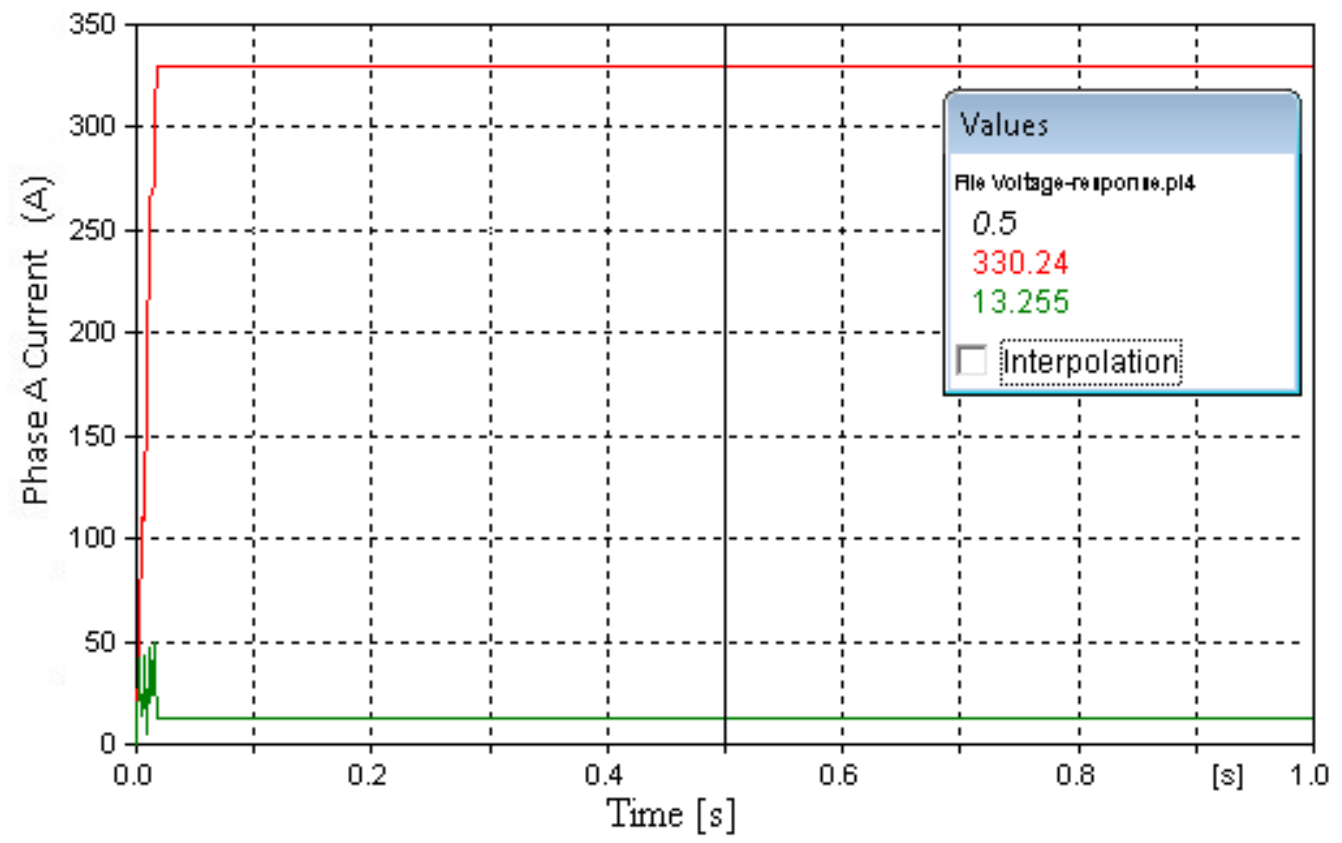

Figure 3.19: $1^{\text {st }}$ and $5^{\text {th }}$ Harmonics as seen by relays in the excitation current for 3-legged core for $120 \%$ excitation voltage

The harmonics were obtained using the harmonics block available in the ATP GUI which uses DFT for its calculations.

Table 3.6: Magnetization Current Comparison for over-voltage response

\begin{tabular}{|l|l|l|l|}
\hline \multicolumn{5}{|c|}{ 3-Legged Core } \\
\hline Voltage response & Phase A peak (A) & Phase B peak (A) & Phase C peak (A) \\
\hline $120 \%$ & 215 & 360 & 205 \\
\hline \multicolumn{4}{|c|}{ Triplex Core } \\
\hline $120 \%$ & 340 & 340 & 340 \\
\hline
\end{tabular}

Table 3.7: $1^{\text {st }}$ and $5^{\text {th }}$ Harmonics as seen by relays in the excitation current for $120 \%$ excitation voltage

\begin{tabular}{|l|l|l|}
\hline \multicolumn{3}{|c|}{ 3-Legged Core (Phase-A) } \\
\hline Voltage response & $1^{\text {st }}$ Harmonic (A) & $5^{\text {th }}$ Harmonic (A) \\
\hline $120 \%$ & $330 \quad$ Triplex & 13.3 \\
\hline \multicolumn{3}{|c|}{11} \\
\hline $120 \%$ & $332 \quad$ & 11 \\
\hline
\end{tabular}




\section{Discussion:}

1. Response of transformer to over-voltage and under-frequency conditions is very similar. The peak currents in each case underlines this fact.

2. Triplex core is observed to be badly impacted by Over-excitation problem in comparison to the 3-legged core. But irrespectively, the cores for either geometry are saturated under over-excitation conditions.

3. The results also suggests a considerable amount of $5^{\text {th }}$ harmonic component, as predicted. This component can be used to detect the over-excitation condition and restrain/block the relay operation.

4. Another sophisticated way of detecting the over-excitation is V/f. This method is also very widely used. 


\subsection{GEOMAGNETICALLY INDUCED CURRENTS MODEL}

As discussed in Chapter 1 and Chapter 2, GICs are quasi-DC signals. Although they are quasiDC most of research that has been conducted on GIC has been with the GIC being purely DC. That is because most of the transient's simulation programs do no support sources with different frequencies. ATP has had a similar problem but in this section a TACS model was developed in order to overcome the problem of multiple frequencies. This TACS model generates a quasi-DC signal for the GIC study. Given below is the code used to generate the quasi-DC signal.

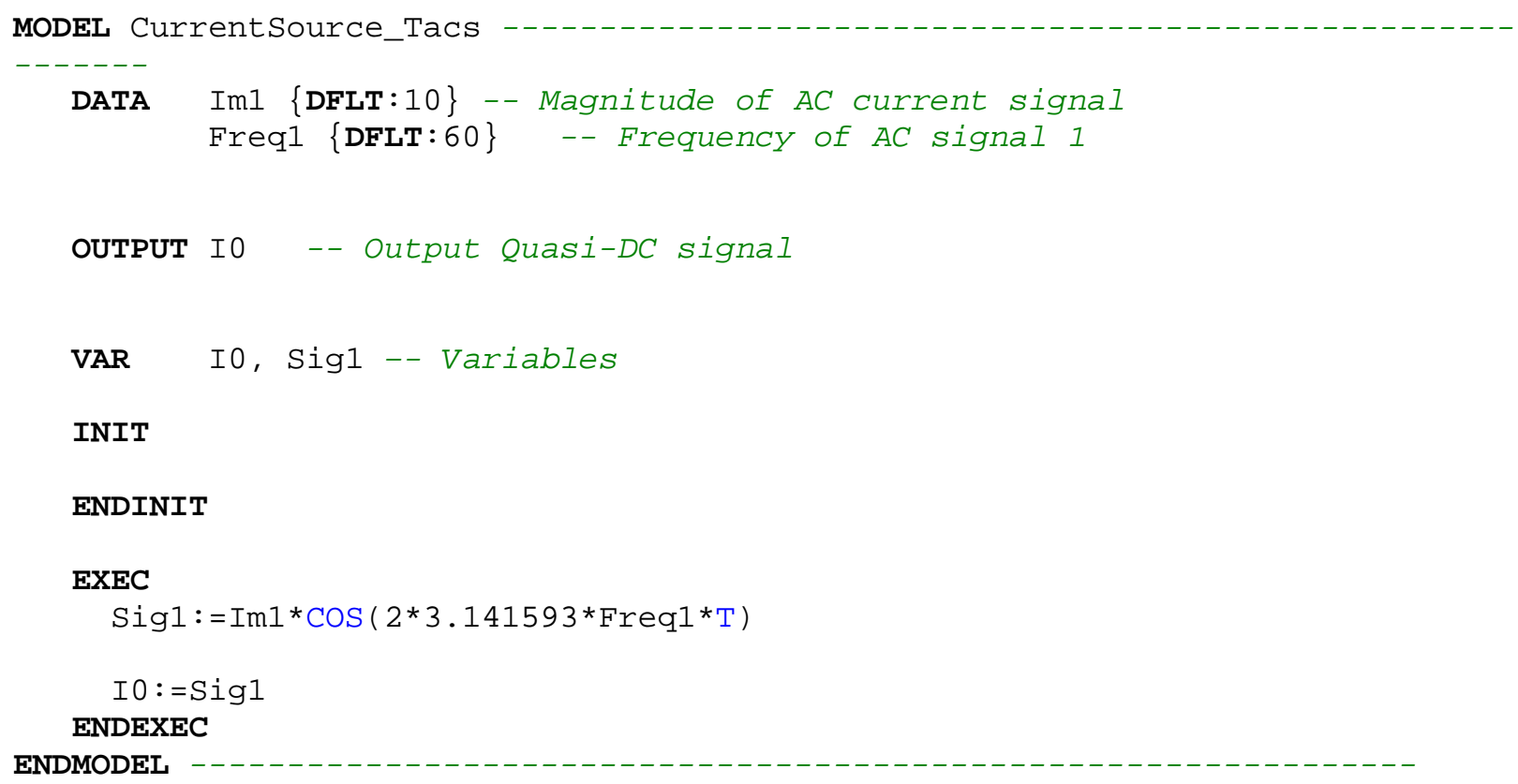

The Model used for GIC study is shown below, it also shows how the GIC has been injected in the system from the TACS source. 


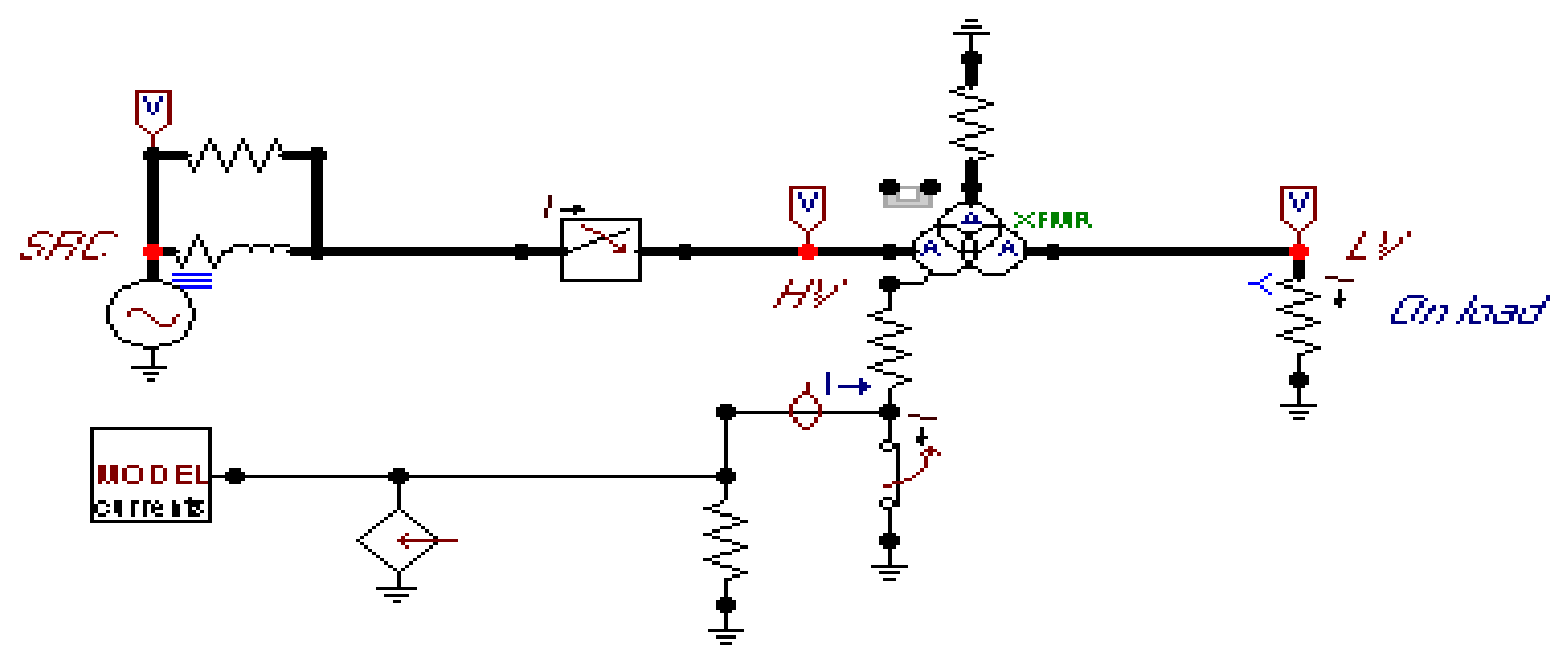

Figure 3.20: ATP model for GIC studies

Following are a few assumptions made while modeling for GIC:

1. Source reactance was considered to be $5 \%$ on the 100 MVA base on HV side. Parallel resistance to source reactance is the numerical damping resistance of 2000 ohms.

2. Transformer rating is 345/118-34.5 kV Yn(auto)D.

3. The parameters for hybrid XFMR model are attached in the Appendix B.

4. The Source was assumed to be feeding in the steady state.

5. GIC of $50 \mathrm{~A}$ at $0.01 \mathrm{~Hz}$ was introduced at $100 \mathrm{~ms}$ through the grounded neutral on $\mathrm{HV}$ side.

6. For sensitivity analysis four different values of GIC i.e. $25 \mathrm{~A}, 50 \mathrm{~A}, 75 \mathrm{~A}$ and $100 \mathrm{~A}$ at $0.01 \mathrm{~Hz}$ were injected at $100 \mathrm{~ms}$.

The results from the model for 3-legged transformer core and triplex core are attached in the next section. The core currents and $\lambda$-i characteristics have been attached as the outputs. 


\subsubsection{GIC WITH 3-LEGGED CORE}
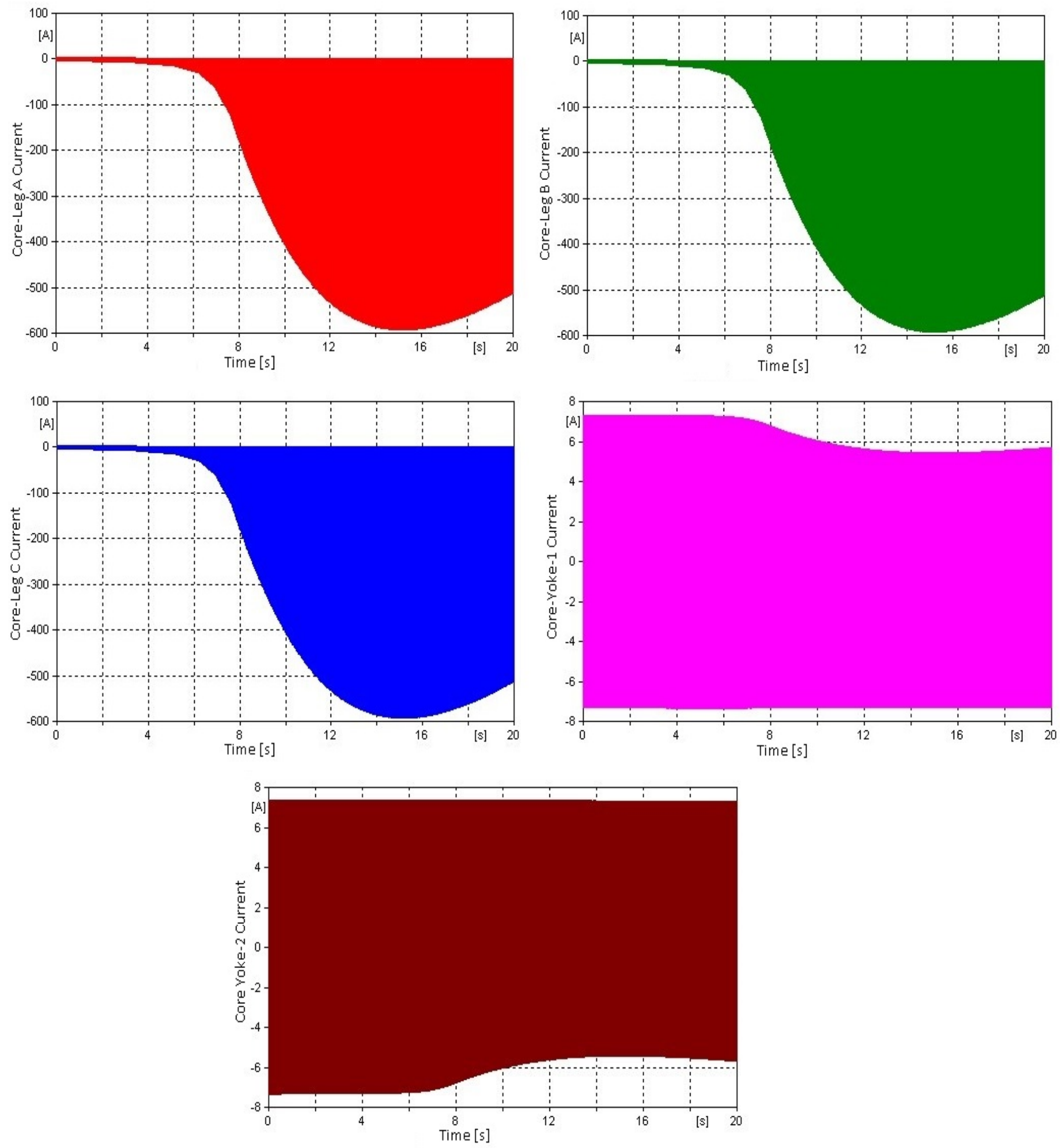

Figure 3.21: Magnetizing Currents in the core of 3-legged xfmr showing half-cycle saturation in core legs 

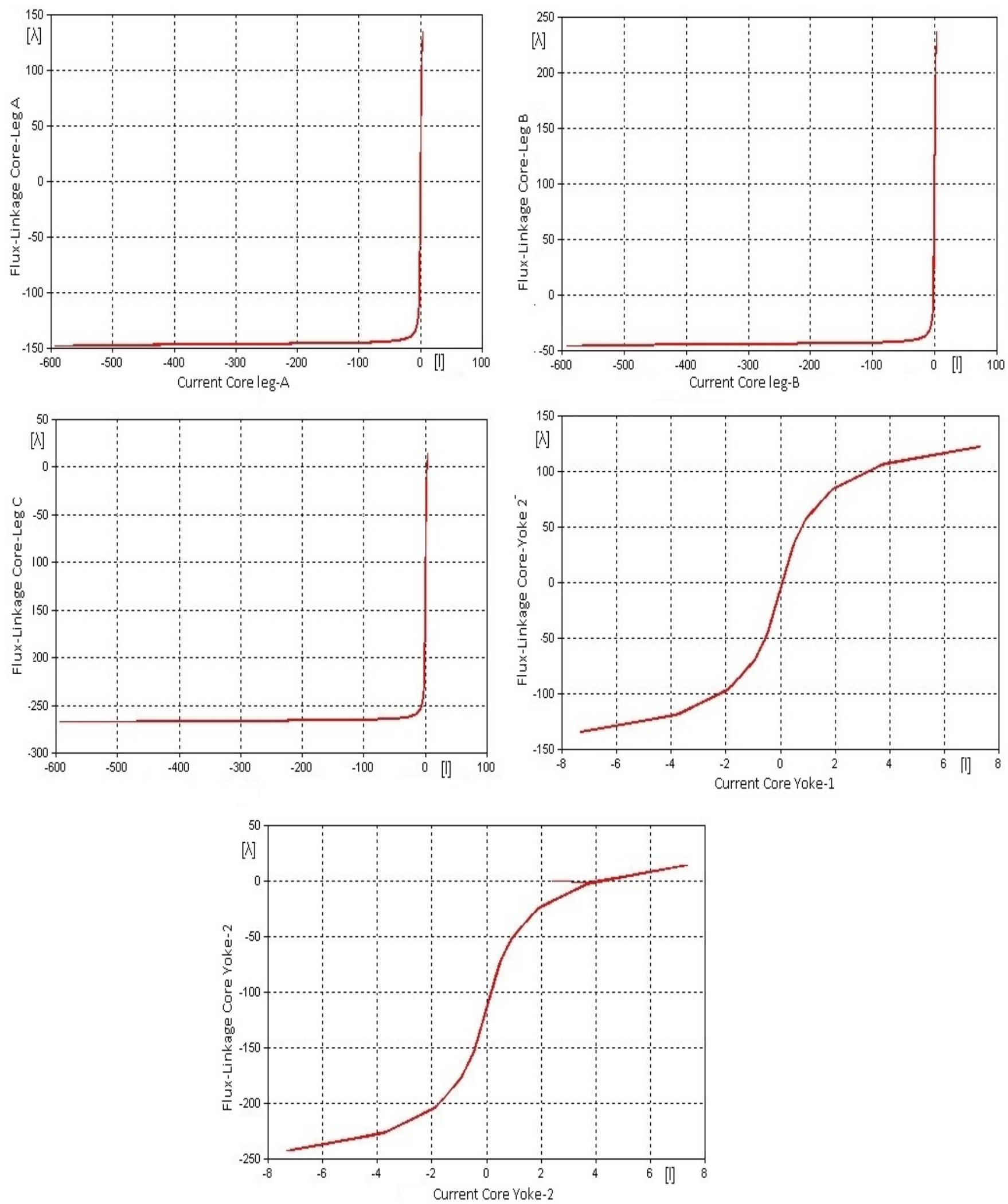

Figure 3.22: $\lambda$-I characteristics for core parts of 3-Legged Transformer 


\subsubsection{GIC WITH TRIPLEX CORE}
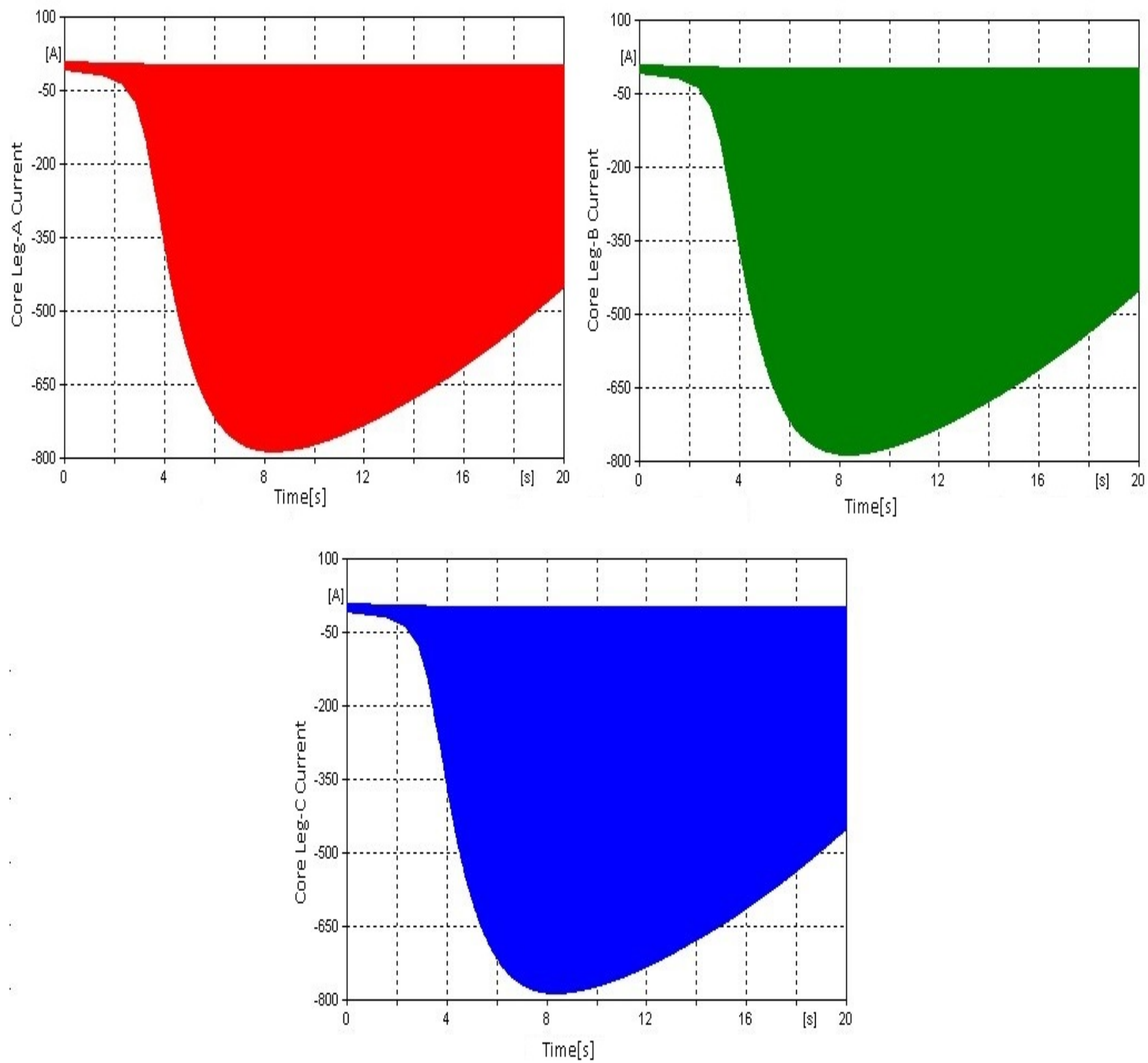

Figure 3.23: Magnetizing Currents in the core of Triplex core xfmr showing half-cycle saturation in core legs 

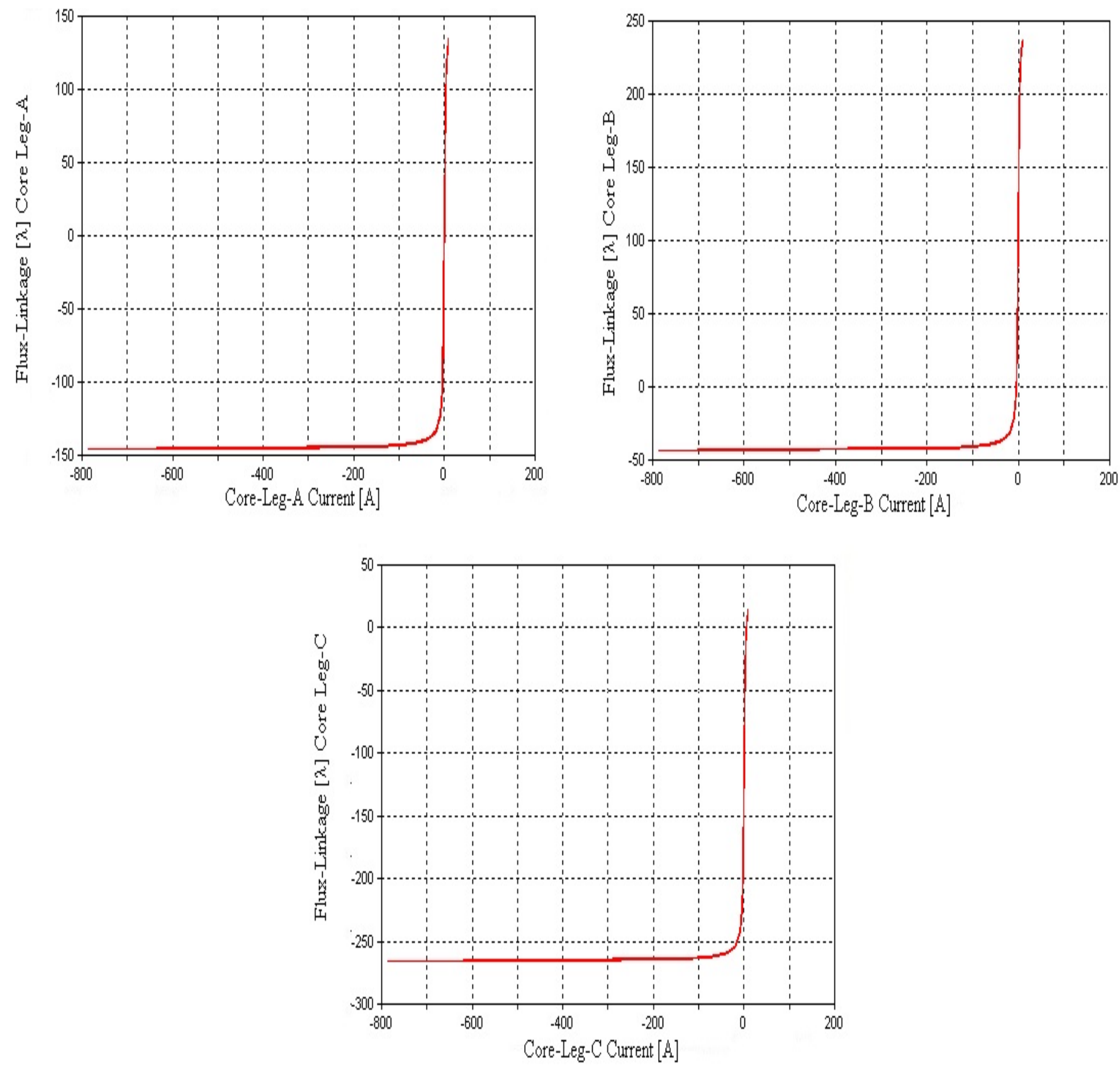

Figure 3.24: $\lambda$-I characteristics for core parts of Triplex core Transformer

Table 3.8: GIC response comparison between 3-legged core and triplex core

\begin{tabular}{|l|l|l|l|}
\hline \multicolumn{5}{|c|}{ 3-Legged Core } \\
\hline GIC at $0.01 \mathrm{~Hz}$ & Core Leg-A Current & Core Leg-A Current & Core Leg-A Current \\
\hline $50 \mathrm{~A}$ & $590 \quad 590$ & 590 \\
\hline \multicolumn{5}{|c|}{ Triplex Core } \\
\hline $50 \mathrm{~A}$ & 775 & 775 & 775 \\
\hline
\end{tabular}




\section{Discussion:}

1. Half-cycle saturation is correctly observed in the results for core leg. This can observed in the $\lambda$-I characteristics obtained and the magnetizing current waveforms.

2. Core saturates earlier and magnetizing current is higher for triplex core in comparison to the 3-legged core.

3. The quasi-DC model is found to be quite effective for GIC studies. 


\subsubsection{SENSITIVITY ANALYSIS}

\section{3-Legged Core}

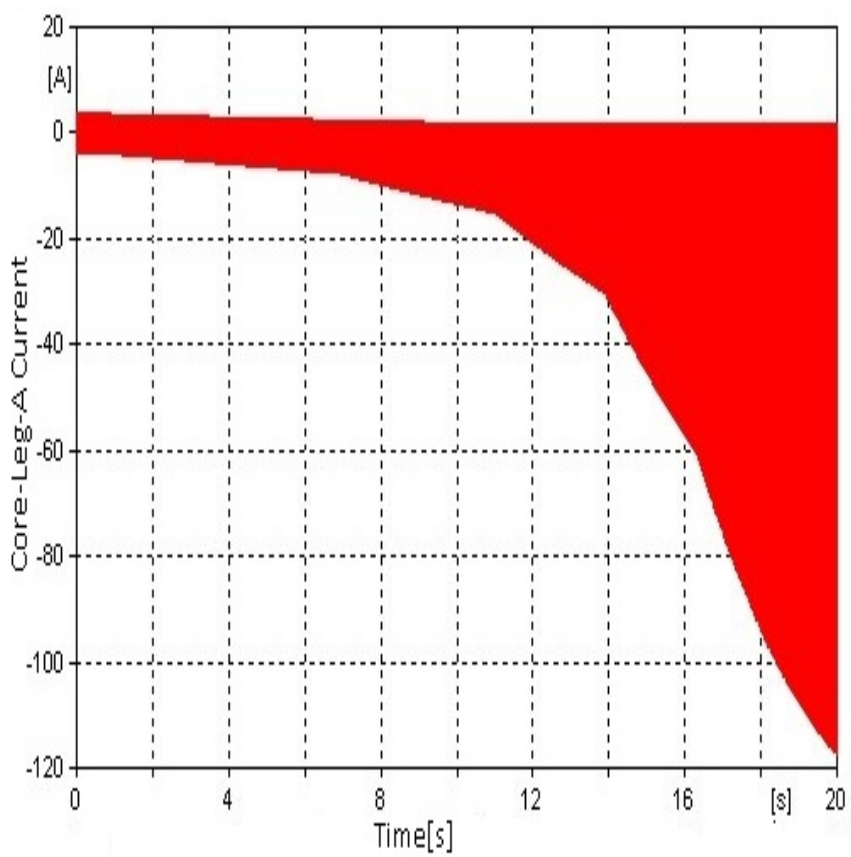

GIC- $25 \mathrm{~A}$ and Frequency $0.01 \mathrm{~Hz}$

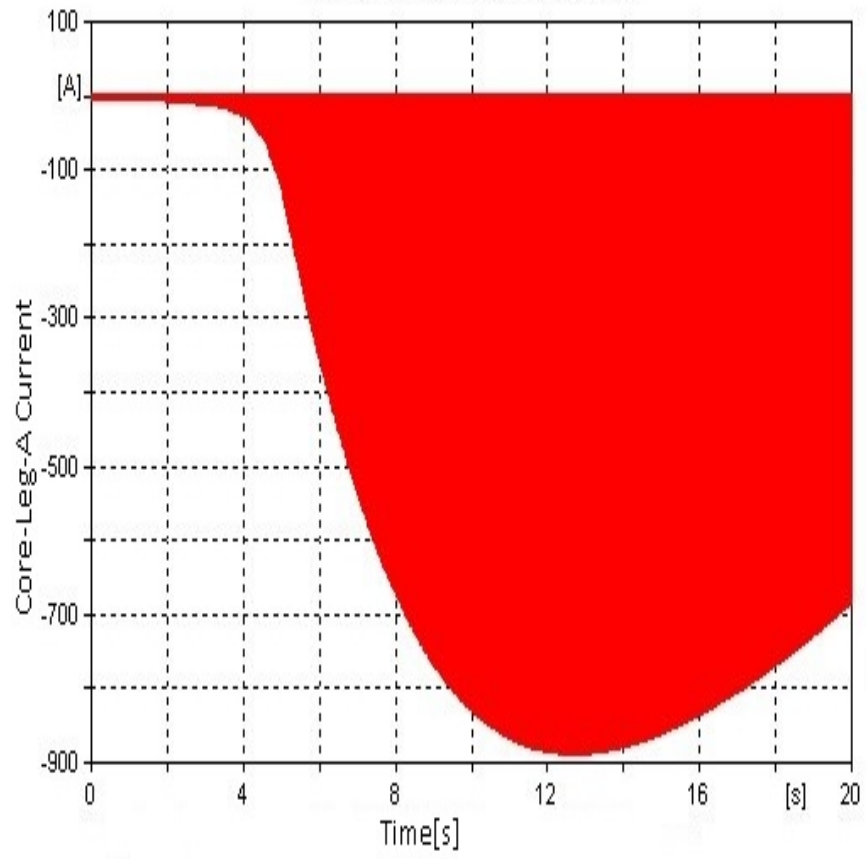

GIC-75A and Frequency $0.01 \mathrm{~Hz}$

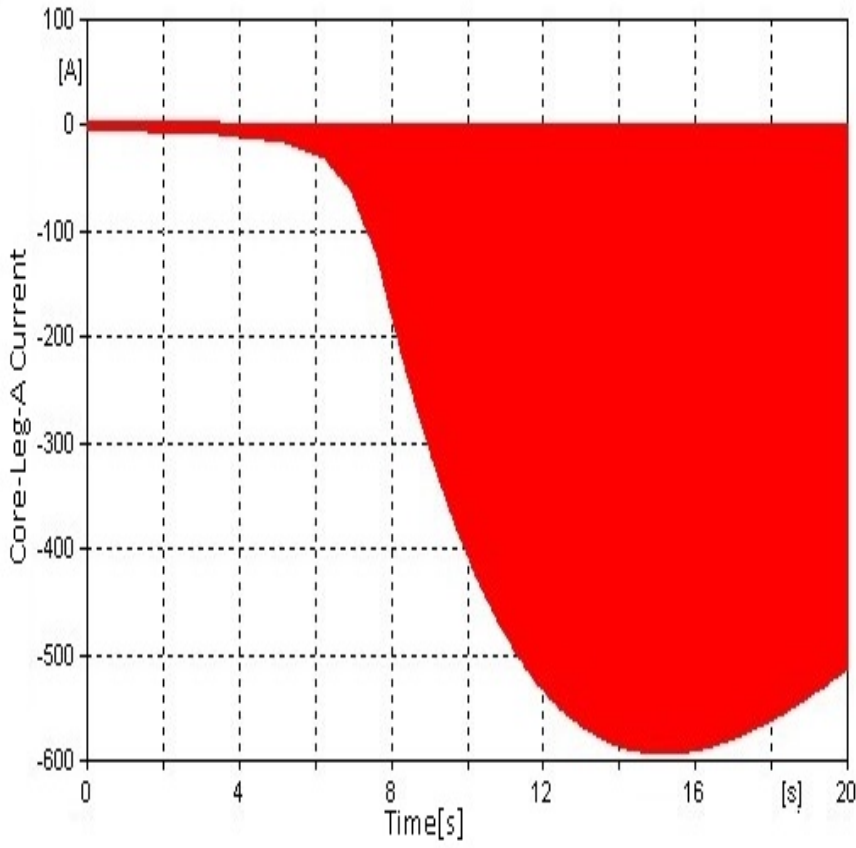

GIC- $50 \mathrm{~A}$ and Frequency $0.01 \mathrm{~Hz}$

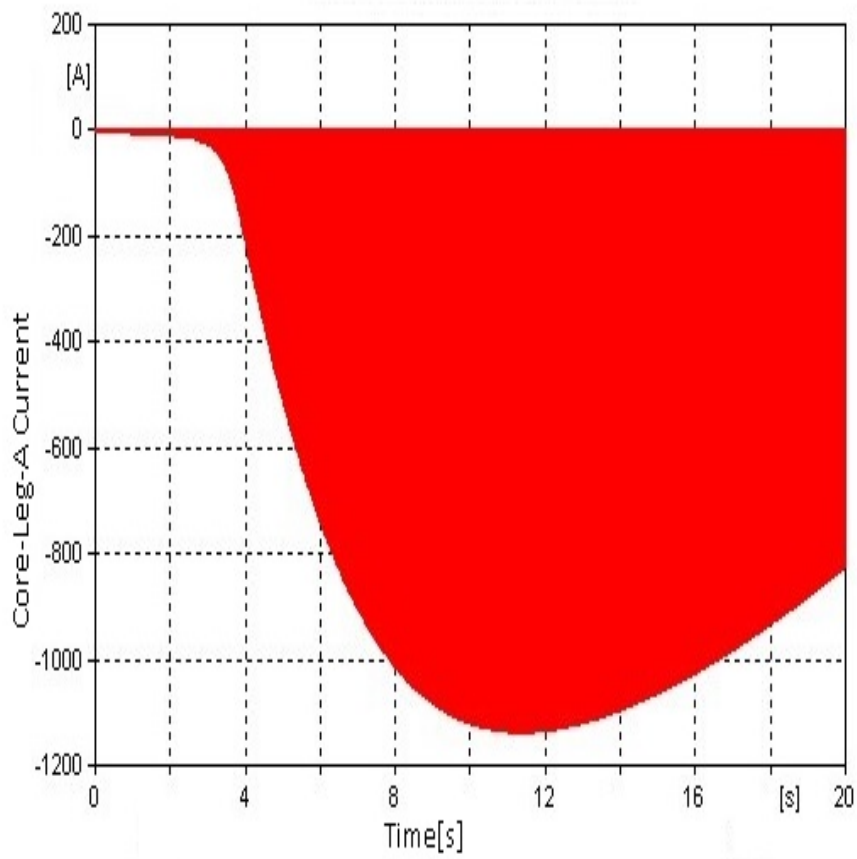

GIC-100 A and Frequency $0.01 \mathrm{~Hz}$

Figure 3.25: Sensitivity analysis for different GIC amplitudes for 3-legged core 
Table 3.9: Sensitivity analysis of 3-legged Transformer Core with respect to GIC level

\begin{tabular}{|c|c|c|}
\hline $\mathrm{GIC}$ ( in Ampere) at $0.01 \mathrm{~Hz}$ & Peak current in core leg-A (A) & Time at Peak current (sec) \\
\hline 25 & 118 & 20 \\
\hline 50 & 595 & 15 \\
\hline 75 & 890 & 13 \\
\hline 100 & 1150 & 11 \\
\hline
\end{tabular}

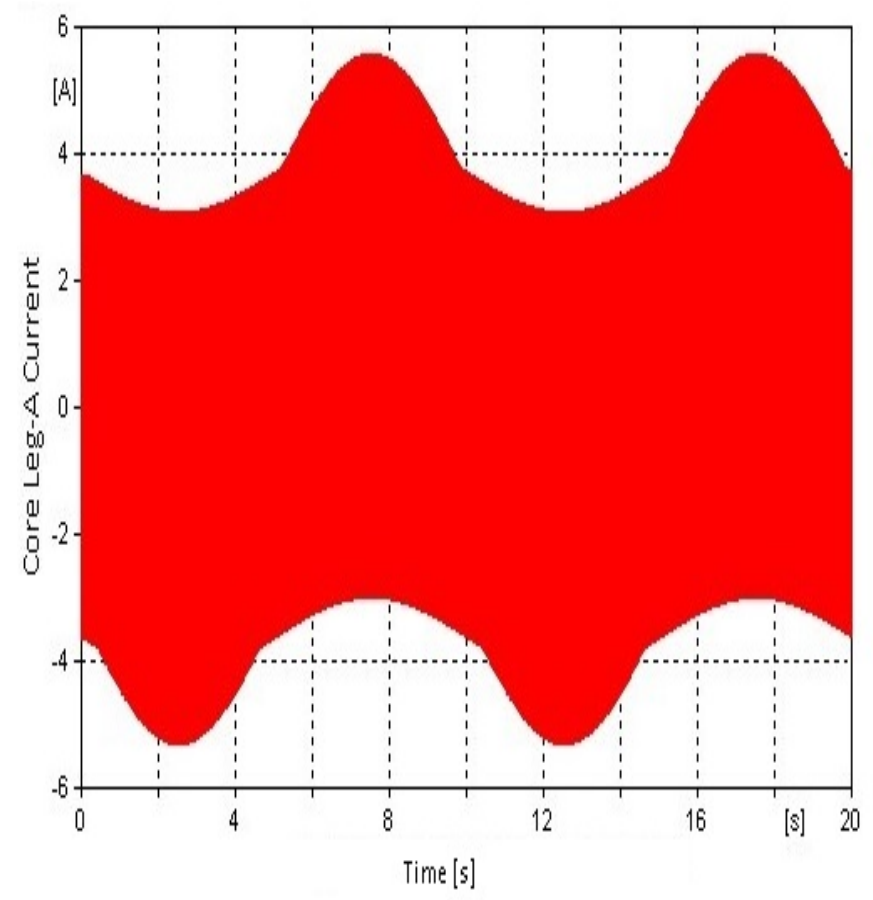

$50 \mathrm{AGIC}$ at $0.1 \mathrm{~Hz}$

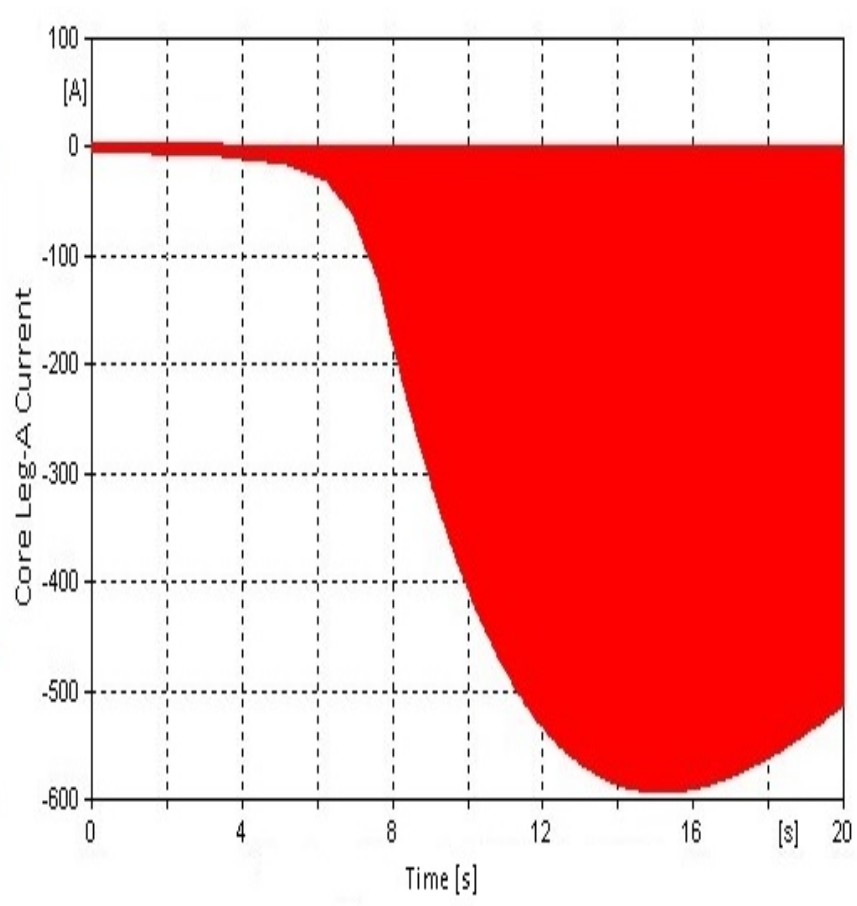

$50 \mathrm{AGICat} 0.01 \mathrm{~Hz}$

Figure 3.26: Sensitivity analysis for different GIC frequencies for 3-legged core

Table 3.10: Sensitivity analysis for different frequencies of GIC for 3-legged core

\begin{tabular}{|l|l|}
\hline GIC Frequency in $\mathrm{Hz}$ at $50 \mathrm{~A}$ & Peak Current in Core Leg- $\mathrm{A}(\mathrm{A})$ \\
\hline 0.1 & 5.5 \\
\hline 0.01 & 595 \\
\hline
\end{tabular}


$\underline{\text { Triplex Core }}$

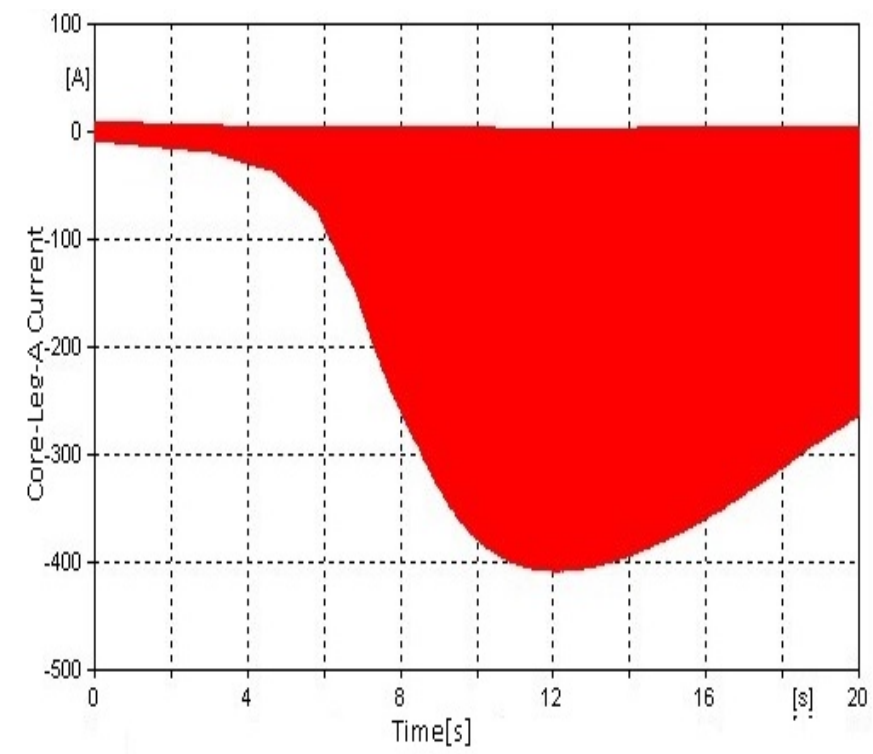

GIC- $25 \mathrm{~A}$ and Frequency $0.01 \mathrm{~Hz}$

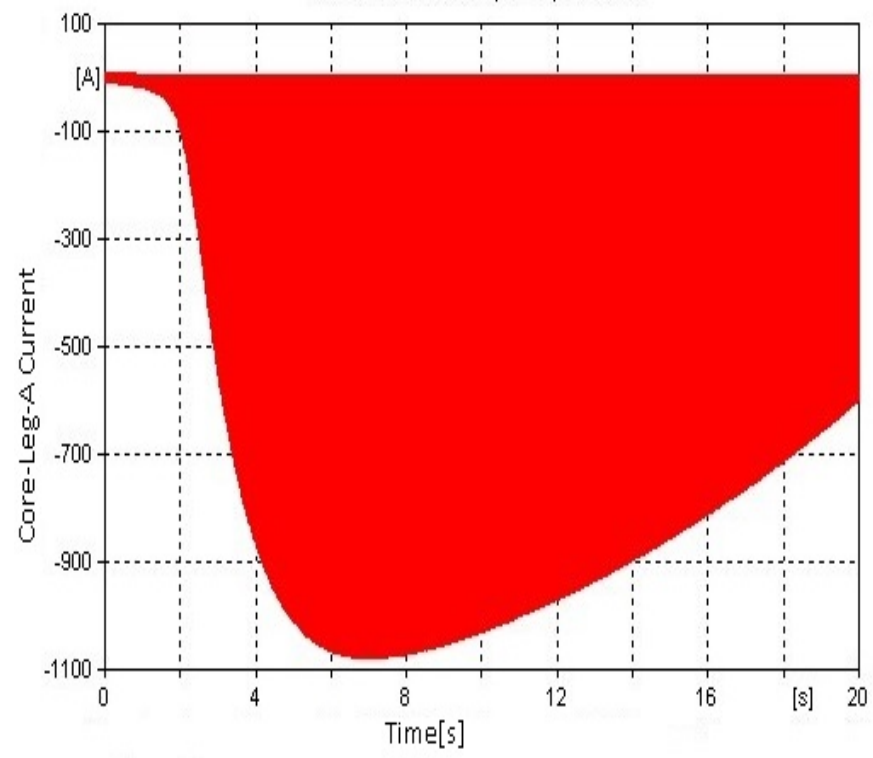

GIC-75A and Frequency $0.01 \mathrm{~Hz}$

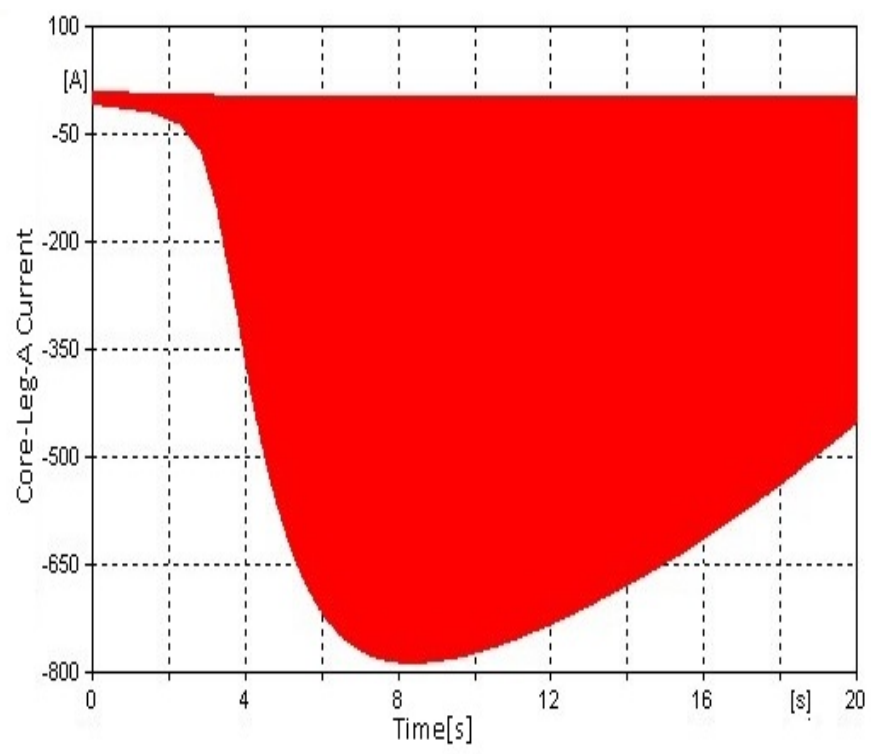

GIC- $50 \mathrm{~A}$ and Frequency $0.01 \mathrm{~Hz}$

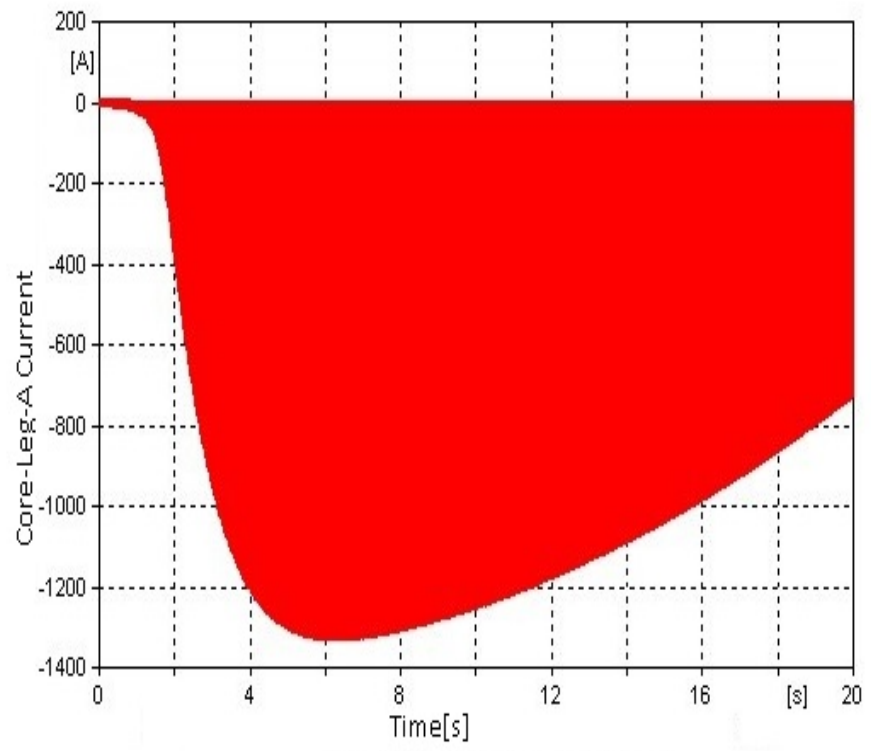

GIC- $100 \mathrm{~A}$ and Frequency $0.01 \mathrm{~Hz}$

Figure 3.27: Sensitivity analysis for different GIC for Triplex core

Table 3.11: Sensitivity analysis of Triplex Transformer Core with respect to GIC level

\begin{tabular}{|c|c|c|}
\hline $\mathrm{GIC}$ ( in Ampere) at $0.01 \mathrm{~Hz}$ & Peak current in core leg-A (A) & Time at Peak current (sec) \\
\hline 25 & 400 & 12 \\
\hline 50 & 790 & 8 \\
\hline 75 & 1075 & 6 \\
\hline 100 & 1350 & 5 \\
\hline
\end{tabular}




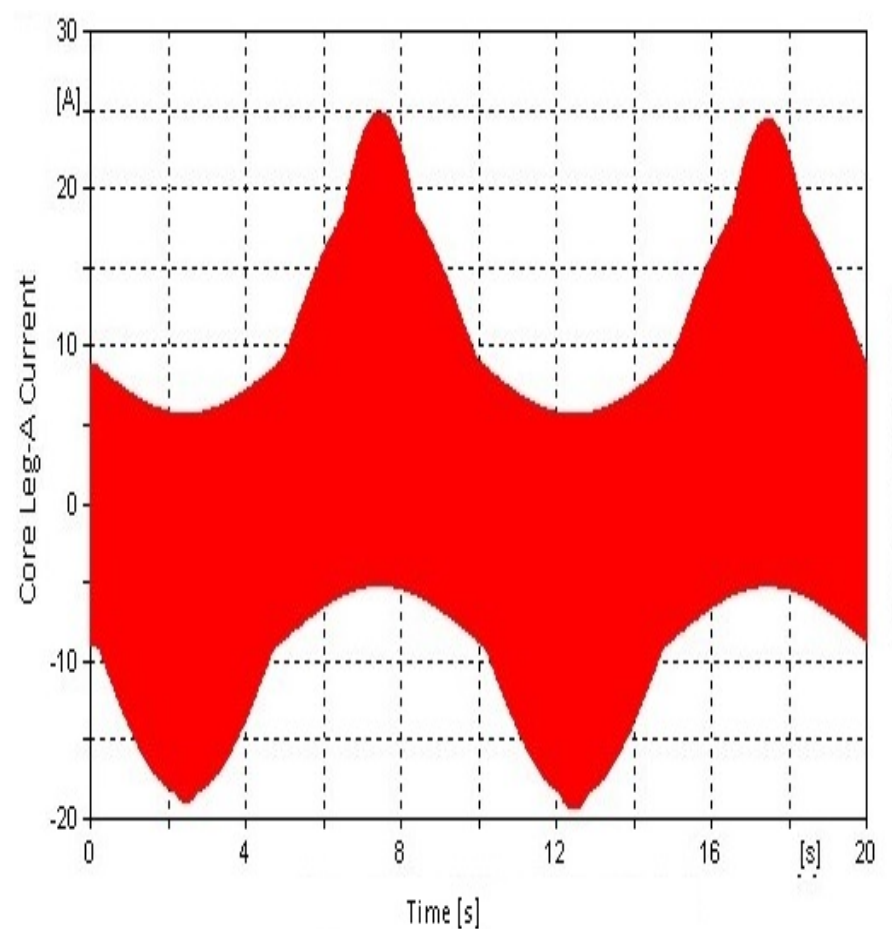

$50 \mathrm{AGICat} 0.1 \mathrm{~Hz}$

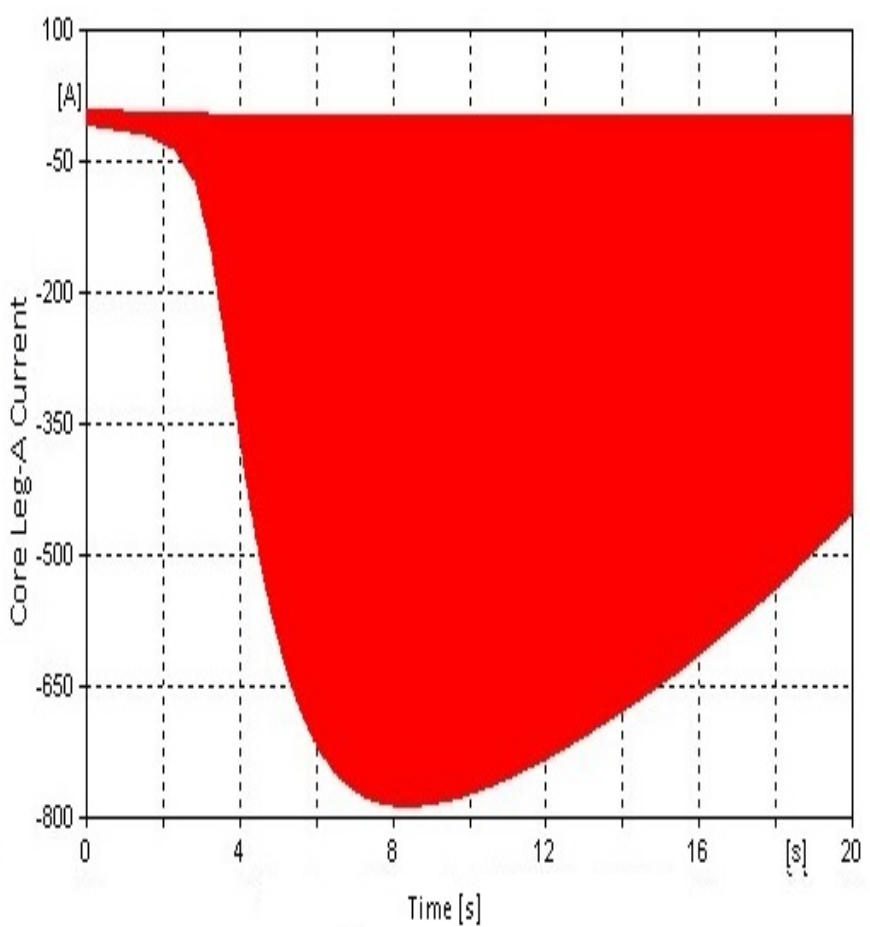

50 A GICat $0,01 \mathrm{~Hz}$

Figure 3.28: Sensitivity analysis for different GIC for Triplex core

Table 3.12: Sensitivity analysis for different frequencies of GIC for Triplex Core

\begin{tabular}{|l|l|}
\hline GIC Frequency in $\mathrm{Hz}$ at $50 \mathrm{~A}$ & Peak Current in Core Leg-A $(\mathrm{A})$ \\
\hline 0.1 & 25 \\
\hline 0.01 & 790 \\
\hline
\end{tabular}




\section{Discussion:}

1. Triplex core seems to be rather severely impacted by GIC compared to the 3-legged core.

2. Higher GIC currents lead to faster saturation and higher peak magnetizing currents, as can be seen in the results above. For a GIC of $25 \mathrm{~A}$ at $0.01 \mathrm{~Hz}$ in a 3-legged core the peak magnetizing current is $118 \mathrm{~A}$ and peak was attained at $20 \mathrm{~s}$, while for a GIC of $100 \mathrm{~A}$ at $0.01 \mathrm{HZ}$, the peak magnetizing current is $1150 \mathrm{~A}$ and peak was reached at $11 \mathrm{~s}$.

3. The sensitivity analysis for different frequencies of GIC suggests that the frequency of GIC plays a pivotal role in transformer core performance. For a triplex core with $50 \mathrm{~A}$ GIC at $0.1 \mathrm{~Hz}$ frequency the peak magnetizing current observed is $25 \mathrm{~A}$ while for $50 \mathrm{~A}$ GIC at $0.01 \mathrm{~Hz}$ the peak current observed is $790 \mathrm{~A}$. It's clear that transformer core is more severely saturated when the frequency of GIC is lower. 


\section{CHAPTER 4 - SUMMARY AND CONCLUSIONS}

\subsection{SUMMARY}

Chapter 1 discussed the motivation behind this report and gave a brief description of inrush currents, effects of geomagnetically induced currents and over-excitation. Chapter 2 delved deeper into these issues through literature surveys of recent papers, journals and other guidelines which formed the basis of ATP modelling and the expected results. This chapter also discussed the specific components that were used in the ATP modelling. Chapter 3 discussed the modelling and implementation of these issues including the development of a quasi-DC source for GIC studies, initialization of residual flux linkage for type-93 inductance and representation of steady-state and residual flux linkage on the plot.

\subsection{CONCLUSIONS}

In the report below results were quantified in Chapter 3.

1. For magnetizing inrush the residual flux linkage can be initialized for a type-93 inductance in XFMR model. Although there is no direct way of initializing this flux linkage via GUI, this can be done in the .atp file of the model with proper syntax.

2. The comparison of inrush currents for different residual flux linkages underlined that the magnetizing inrush issue is worse with higher residual flux linkage. For a 3-legged core transformer energized from LV side with residual flux linkage equal to $50 \%$ of steady state flux linkage, it draws an inrush current of $1350 \mathrm{~A}$ in phase-A compared to $1117 \mathrm{~A}$ for $30 \%$ residual flux linkage. 
3. Visualization of steady state flux linkage with residual flux linkage is tricky and there should be a direct way showing it via GUI of ATP. Although, visualization of this flux linkage has been done in Chapter 3 and can be done using a similar syntax.

4. Sensitivity analysis with respect to slope of magnetization curve in saturation region quantified the importance of getting this slope right as it can greatly influence the inrush currents in full saturation region. For slope $L_{a}$ equal to 2 the peak inrush observed was 806 A while for slope equal to 8 the peak inrush observed was 516 A.

5. For GIC, half-cycle saturation of core legs can be seen in the results.

6. The developed quasi-DC model for GIC is a very good tool for studying GIC in the future and could be used to produce more realistic analysis of GIC.

7. A lot depends on the amount of GIC in the circuit. For higher values of GIC, core saturation will be faster and current peaks will be higher, the results for which have been quantified in the sensitivity analysis with respect to the GIC injected. For a GIC of 25 A at $0.01 \mathrm{~Hz}$ in a 3-legged core the peak magnetizing current is $118 \mathrm{~A}$ and peak was attained at $20 \mathrm{~s}$, while for a GIC of $100 \mathrm{~A}$ at $0.01 \mathrm{HZ}$, the peak magnetizing current is $1150 \mathrm{~A}$ and peak was reached at $11 \mathrm{~s}$.

8. Another observation was that the frequency of the GIC is an important factor in core saturation. This is intuitive since $\lambda(t)=\int_{0}^{t} v(t) d t$, so a lower frequency voltage will yield higher magnitude $\lambda$. A GIC with a higher frequency will not saturate the core as much compared to a lower frequency GIC of the same amount. For a triplex core with $50 \mathrm{~A}$ GIC at $0.1 \mathrm{~Hz}$ frequency the peak magnetizing current observed is $25 \mathrm{~A}$ while for $50 \mathrm{~A}$ GIC at $0.01 \mathrm{~Hz}$ the peak current observed is $790 \mathrm{~A}$. 
9. Frequency response and voltage response in over-excitation suggests that it can potentially saturate the core if kept unattended for a longer period of time, but because Over-excitation is generally a short period phenomenon, it is often harmless and relay operation should be blocked if Over-excitation is non-persistent.

10. For the detection of over-excitation, $5^{\text {th }}$ harmonic component can be used for blocking/restraining operation of differential relays.

\subsection{REPORT CONTRIBUTIONS}

Below are a few contributions on the research report:

1. A model way of initializing the type 93 true nonlinear inductance for inrush studies was developed for ATP, this would help in future studies on inrush currents for transformer energization.

2. A source for GIC was developed in order to study the exact effects of GIC on power transformers. This would help in further studies and analysis involving quasi-DC GIC on power system and power transformers.

3. Sensitivity analysis for GIC helped understand the effect of GIC amplitudes on the core saturation.

4. Sensitivity analysis for GIC involving different frequencies of GIC helped understand that lower frequencies of GIC can saturate core at lower amplitudes if GIC. 


\subsection{FUTURE RECOMMENDATIONS}

Below are a few recommendations on future scope of work:

1. The flux linkage initialization process should be made using the ATP GUI, it is a bit complex to figure out the proper syntax inside of the .atp file.

2. Flux linkage visualization that includes the initialized flux linkage offset is very complex and needs a straight-forward GUI function.

3. Controlled switching needs to be studied more with the initialized flux linkage.

4. GIC studies could be extended onto the power system, it would be really interesting to see how exactly the other power system equipment’s would be affected by GIC.

5. Var absorption during GIC should be studied in more detail in time domain, it will be interesting to see more on relationship between var absorption and GIC. 


\section{$\underline{\text { REFERENCES }}$}

[1] V.D. Abertson, J.M. Thornson, S.A. Miske, "The effects of geomagnetic storms on electric Power," IEEE PES summer meeting and EHV/UHV conference, Vancouver, Canada, July 15-20,1973.

[2] R. Girgis, K. Vedante, "Effects of GIC on Power transformer and Power systems," Transmission and Distribution Conference and Exposition (T\&D), 2012 IEEE PES.

[3] NERC "Application guide on computing geomagnetic induced currents in Bulk Power systems," Northern American Reliability Corporation, December 2013.

[4] N. Chiesa, A. Lotfi, H. K. Høidalen, B. A. Mork, Ø. Rui, T. Ohnstad, "Five leg transformer model GIC studies," International Conference on Power Systems Transients (IPST2013) in Vancouver, Canada July 18-20, 2013.

[5] R. Girgis, K. Vedante,’Impacts of GIC on Power Transformers,” IEEE Electrification magazine, December, 2015.

[6] L. Marti, J. Berge, R. Varma "Determination of geomagnetically induced current flow in a transformer from reactive power absorption" IEEE Trans. Power Del. vol. 28 no. 3 pp. 1280-1288 Jul. 2013.

[7] L. Marti, J. Berge, R. Varma "Laboratory Validation of the Relationship Between geomagnetically Induced Current (GIC) and Transformer Absorbed Reactive Power" IEEE Trans. Electric power and energy Conference, 2011. 
[8] S. Arabi, M. M. Komaragiri, M. Z. Taranawecky "Effects of geomagnetically-induced currents in power transformers", IEEE, Can. Elec. Eng. J. vol. 12 no. 4 pp. 165-170 1987.

[9] Wenqi G, Y. Wang, Z. Zhao, X. Yang, Y. Li "Residual Flux in the Closed Magnetic Core of a Power Transformer,” Power Engineering Conference (UPEC), 2015 50th International Universities, 2015 IEEE.

[10] Q. Qi, X. Yin, Z. Zhang, Y. Wang, Y. Ye "Study on complex inrush caused by transformer energization and its influence on current differential protection,” IEEE Transactions on Applied Superconductivity, 2014 IEEE.

[11] R. González, A. Bachiller, J. Antonio, J. Alvarez, “Controlled switching strategies for transformer inrush current reduction: A comparative study”, Electric Power Systems Research, Vol 145, 2017 ScienceDirect.

[12] N. Chiesa, H. K. Høidalen "Modeling of nonlinear and hysteretic iron-core inductors in ATP" Proc. EEUG Meeting Eur. EMTP-ATP Conf. pp. (s) 12 2007-Sep.

[13] J..Grainger, W. Stevenson,” Power system analysis”, Tata Mcgraw Hill, 2003.

[14] L.Ganatra, P.Mysore, K.K. Mustaphi, A.Mulawarman, B.A. Mork, G.Gopakumar, “Application of Reclosing Schemes in the Presence of Capacitor Bank Ringdown,” Proceedings, American Power Conference, Chicago, IL, April 6-9, 1999.

[15] N. Sharma, H. Gaikwad, "Isolation of Inrush currents for a Transformer Differential relay”, Michigan technological University, 2018.

[16] H. Saadat,” Power system analysis”, Tata Mcgraw Hill, 1999. 
[17] IEEE std. C37.106,” IEEE Guide for Abnormal Frequency Protection for Power Generating Plants”, IEEE Power Engineering Society, 2003, IEEE.

[18] A. Kazemi, C. Labuschagne, "Protecting Power Transformers From Common Adverse Conditions”, 32nd Annual Western Protective Relay Conference, October 2005.

[19] K. Behrendt, N. Fischer, C. Labuschagne, "Considerations for Using Harmonic Blocking and Harmonic Restraint Techniques on Transformer Differential Relays,” Schweitzer Engineering Laboratories, Inc., 2006.

[20] “IEEE Guide for a Generator Protection,” IEEE Std C37.102-2006 (Revison of IEEE Std C37.102-1995), pp. 1-177, 2006.

[21] B, A. Mork, F. Gonzalez, D. Ishchenko, D. L. Stuehm, J. Mitra, “Hybrid Transformer Model for Transient Simulation—Part I: Development and Parameters”, IEEE Transactions on Power Delivery, 2007 IEEE.

[22] B, A. Mork, F. Gonzalez, D. Ishchenko, D. L. Stuehm, J. Mitra, “Hybrid Transformer Model for Transient Simulation—Part II: Laboratory Measurements and benchmarking”, IEEE Transactions on Power Delivery, 2007 IEEE.

[23] B. A. Mork, F. Gonzalez-Molina, D. Ishchenko, "Parameter estimation and advancement in transformer models for EMTP simulations. Task/activity MTU-7: Model performance and sensitivity analysis,” Technical report, submitted to BPA, Portland, OR, May 2004. 
[24] H. K. Høidalen, B. A. Mork, F. Gonzalez, D. Ishchenko, N. Chiesa, "Implementation and verification of the Hybrid Transformer model in ATPDraw," Electric Power Systems Research, vol. 79, no. 3, pp. 454-459, Mar. 2009.

[25] B. A. Mork, F. Gonzalez-Molina, D. Ishchenko, "Parameter estimation and advancement in transformer models for EMTP simulations. Task/activity MTU-6: Parameter estimation,” Technical report, submitted to BPA, Portland, OR, Dec. 2003.

[26] Three-Phase Transformer Inductance Matrix Type (Two Windings), The Mathworks, Inc. [Online]. Available: http://www.mathworks.com/help/physmod/sps/powersys/ref/threephasetransformerind uctancematrixtypetwowindings.html 


\section{APPENDICES}

A

\section{Complete Results for Magnetizing Inrush from HV side}

Case-1:3-legged core
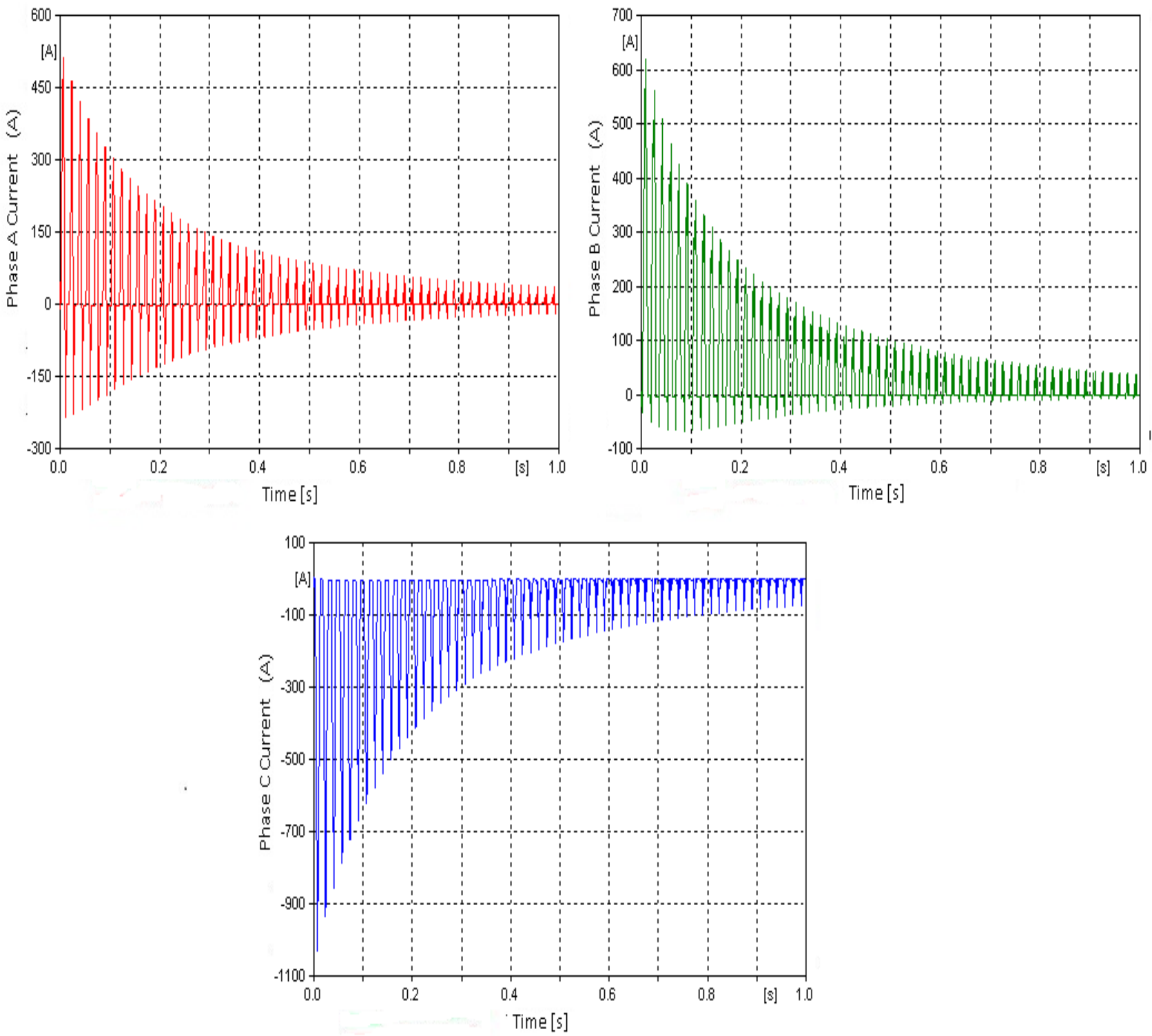

Figure A.1: Inrush Currents in Phase-A, Phase-B and Phase-C with 42\% residual flux linkage for 3legged core from $\mathrm{HV}$ side 

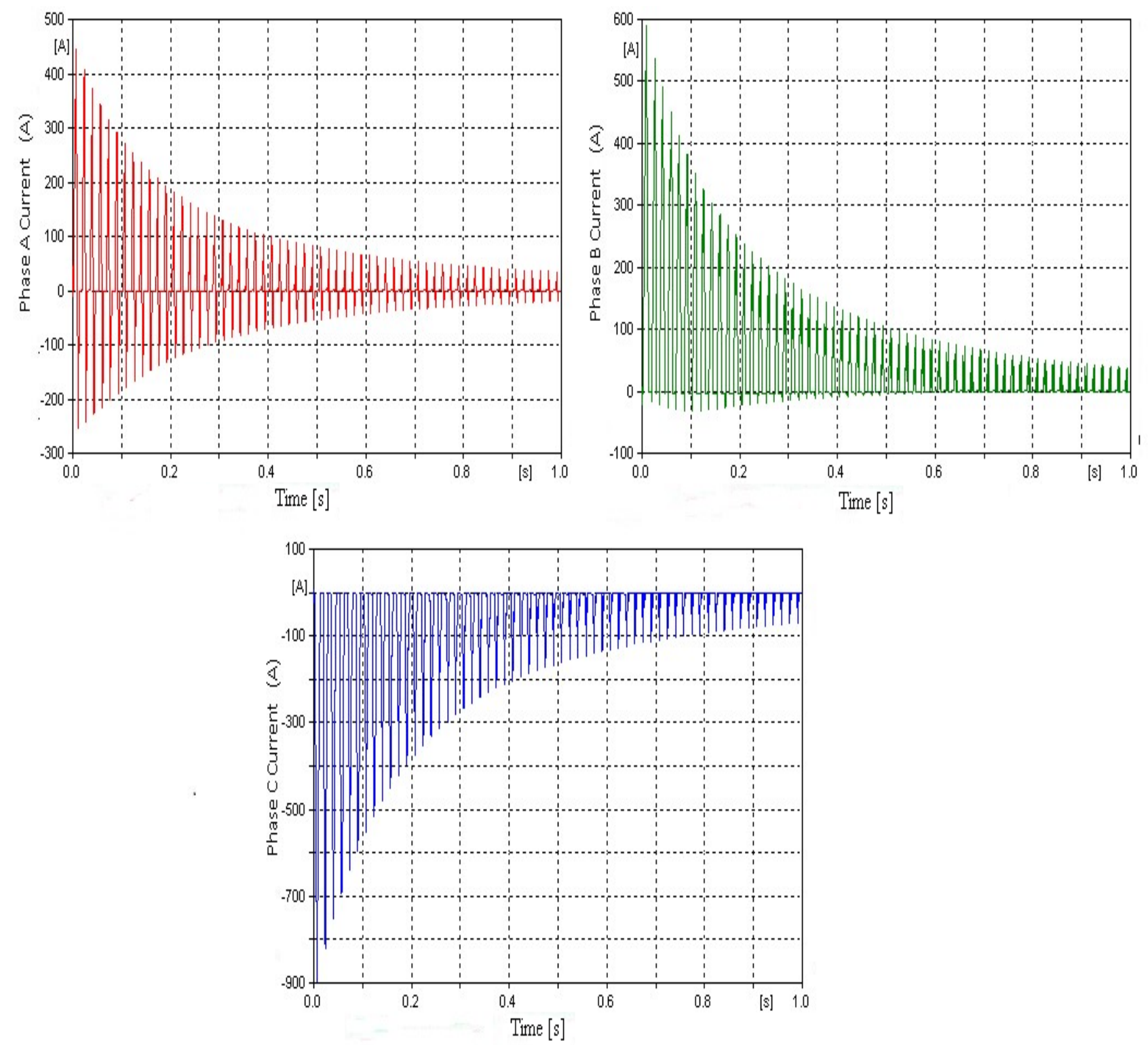

Figure A.2: Inrush Currents for Phase A, Phase B and Phase C at 30\% residual flux linkage 3-legged core from $\mathrm{HV}$ side 

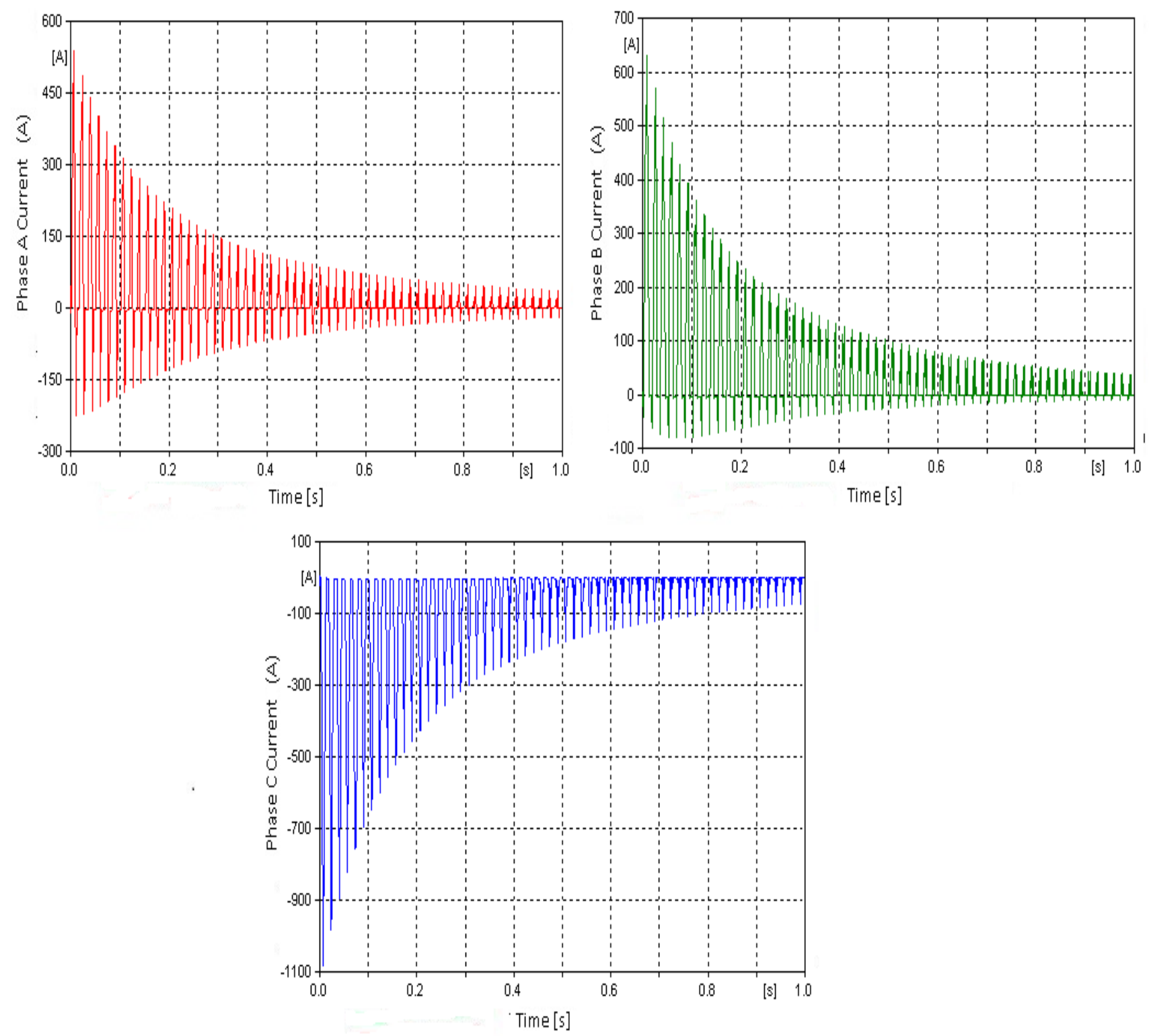

Figure A.3: Inrush Currents for Phase A, Phase B and Phase C at 50\% residual flux linkage 3-legged core from $\mathrm{HV}$ side

The above results show higher peak inrush currents for higher residual flux linkages. They also show the inrush current decay for each case. 
Case-2 Triplex core transformer
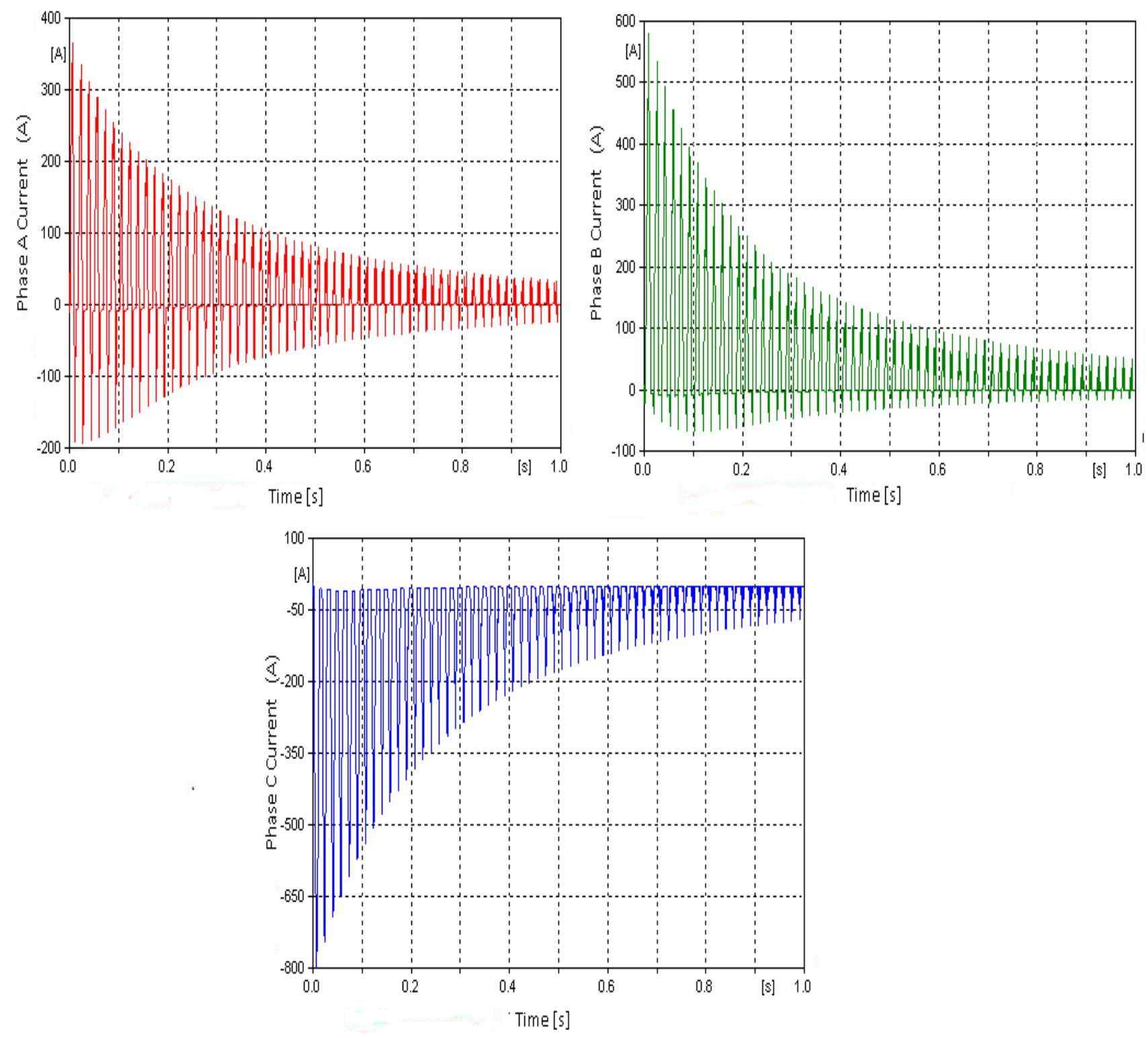

Figure A.4: Inrush Currents for Phase A, Phase B and Phase C at 42\% residual flux linkage for Triplex core from $\mathrm{HV}$ side 

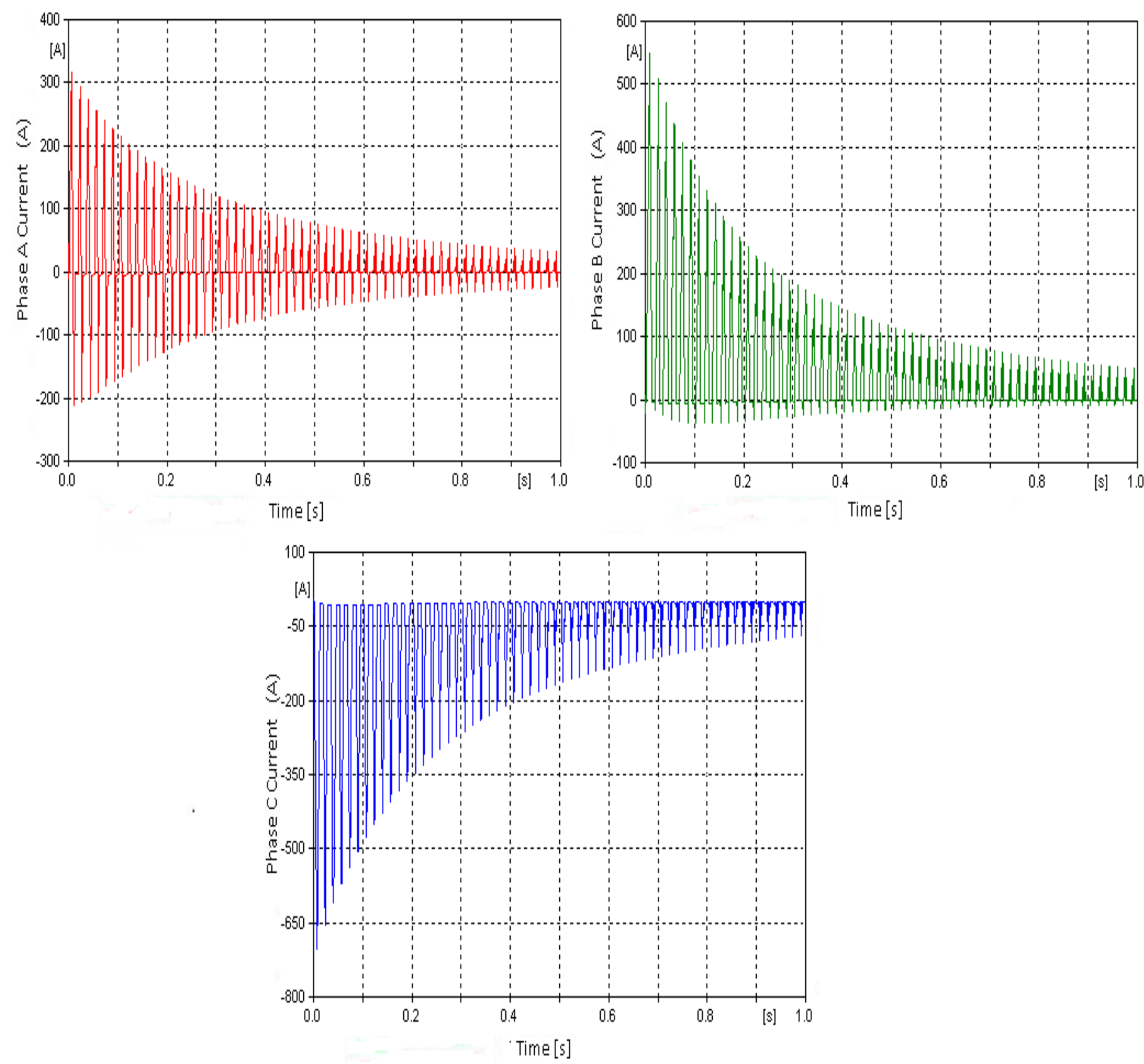

Figure A.5: Inrush Currents for Phase A, Phase B and Phase C at 30\% residual flux linkage for Triplex core from $\mathrm{HV}$ side 

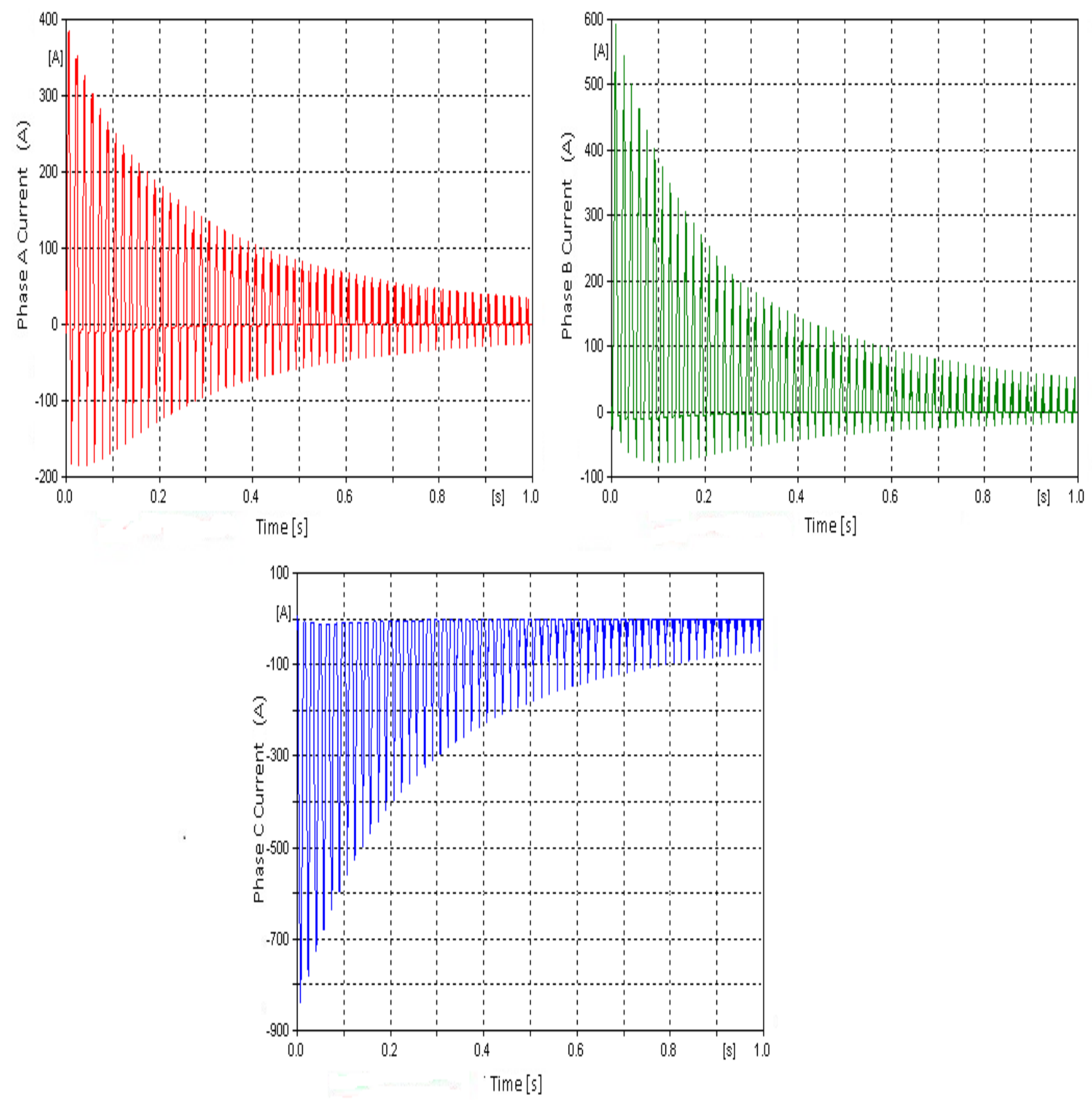

Figure A.6: Inrush Currents for Phase A, Phase B and Phase C at 50\% residual flux linkage for Triplex core from $\mathrm{HV}$ side

The above results show higher peak inrush currents for higher residual flux linkages. They also show the inrush current decay for each case. 


\section{Complete Results for Magnetizing Inrush from LV side}

\section{Case-1: 3 -legged transformer}
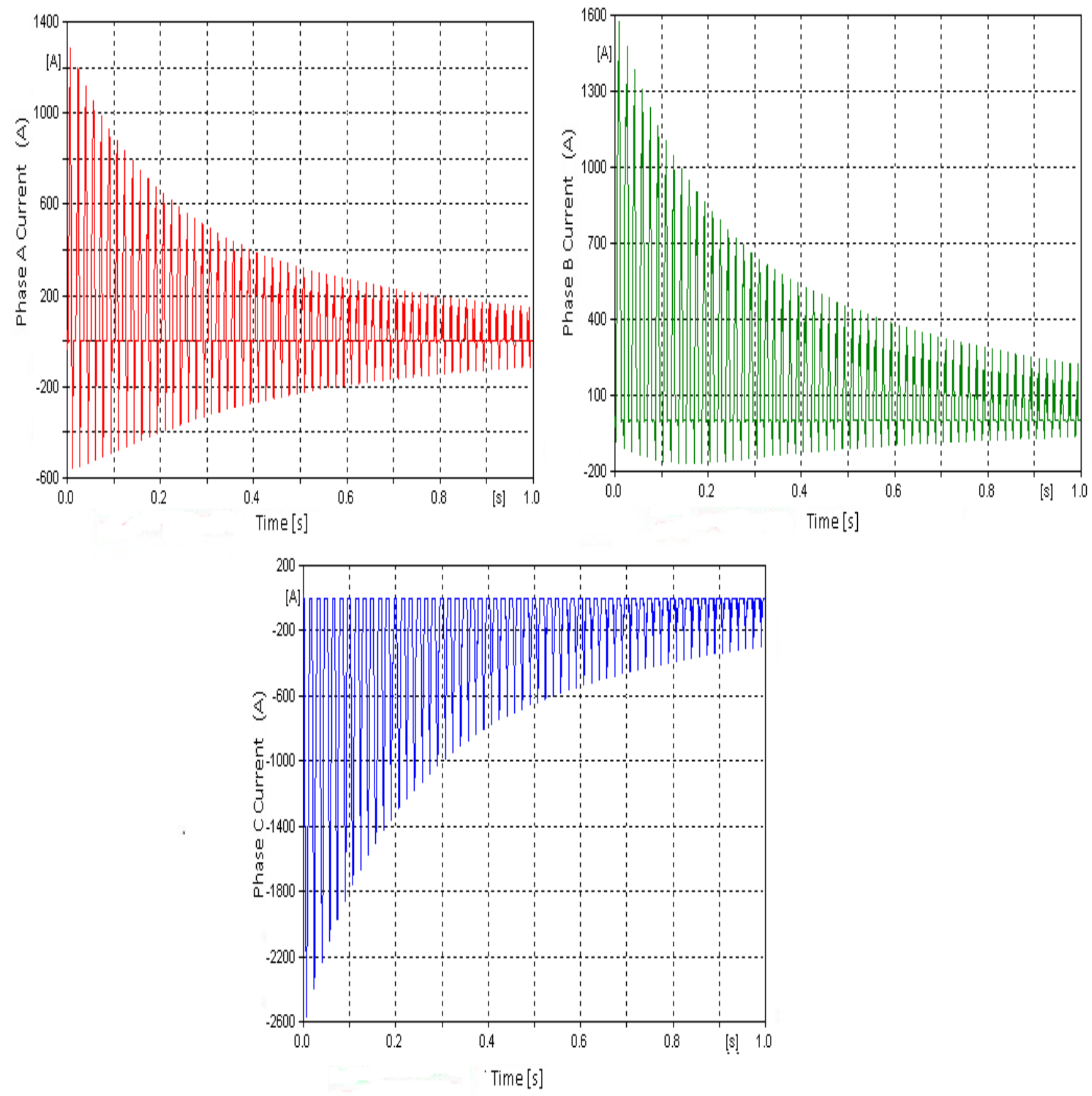

Figure A.7: Inrush Currents for Phase A, Phase B and Phase C at 40\% residual flux linkage for 3-legged core from $L V$ side 

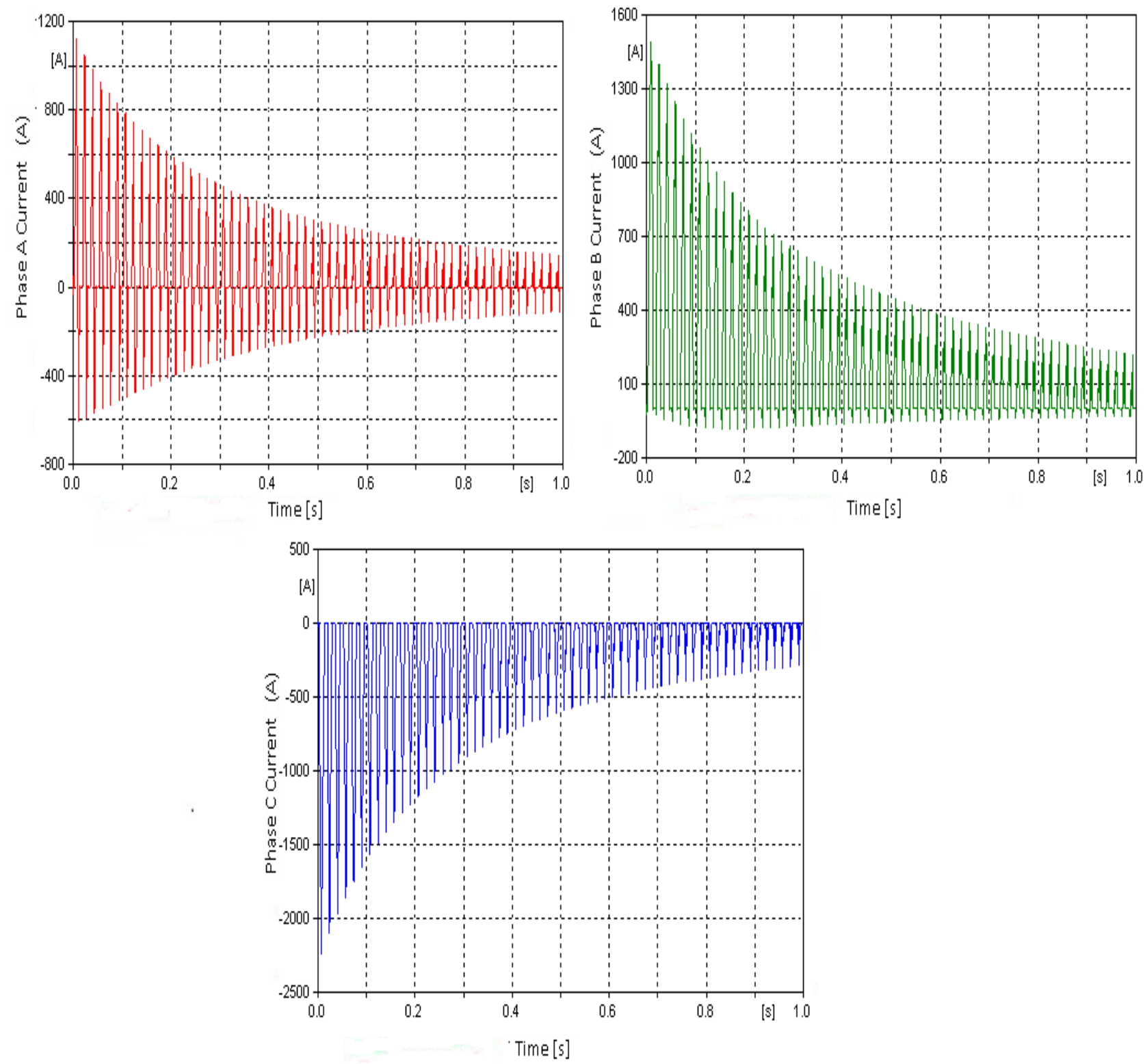

Figure A.8: Inrush Currents for Phase A, Phase B and Phase C at 30\% residual flux linkage for 3-legged core from $L V$ side 

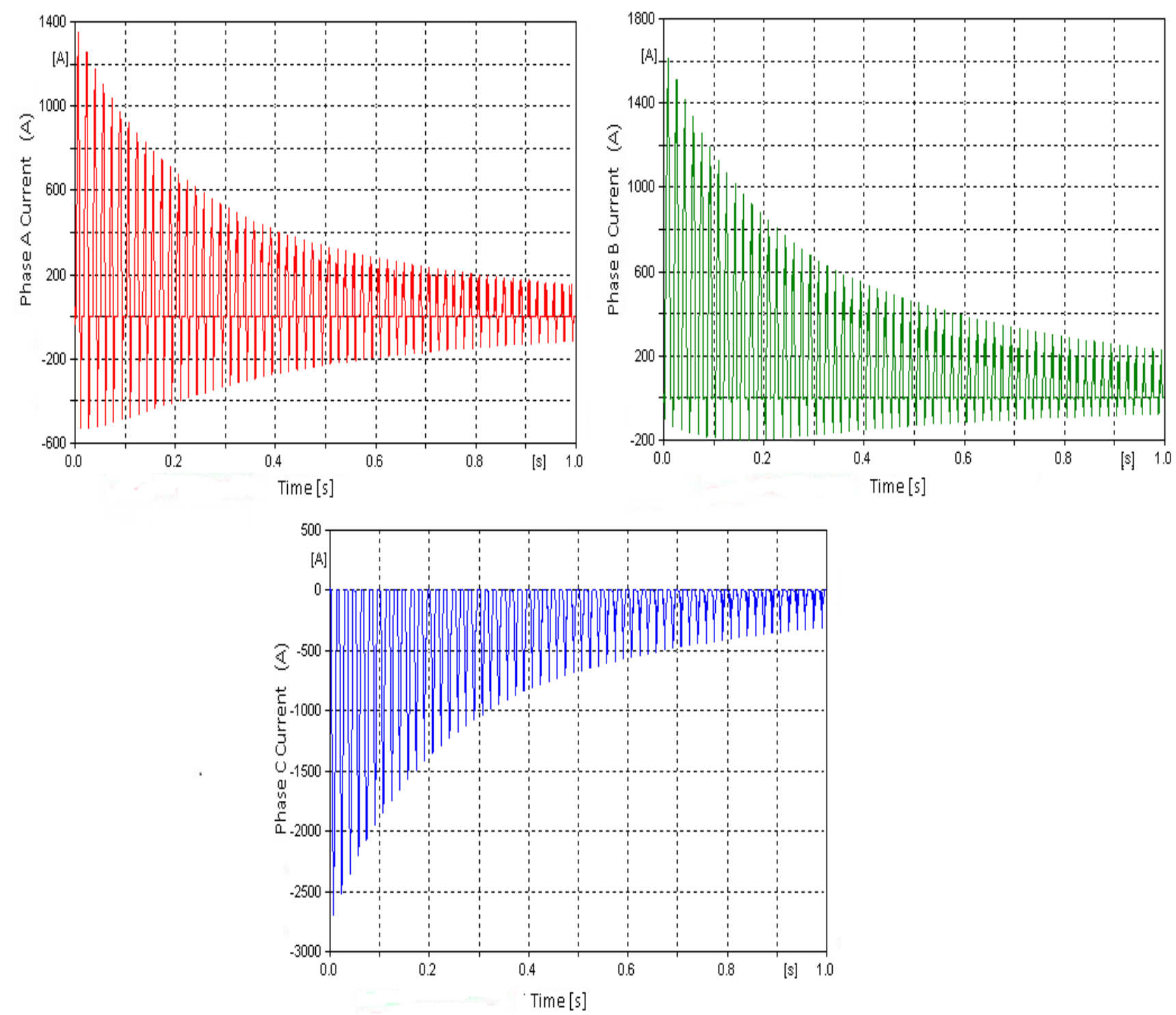

Figure A.9: Inrush Currents for Phase A, Phase B and Phase C at 50\% residual flux linkage for 3-legged core from $L V$ side 
Case-2: Triplex core transformer
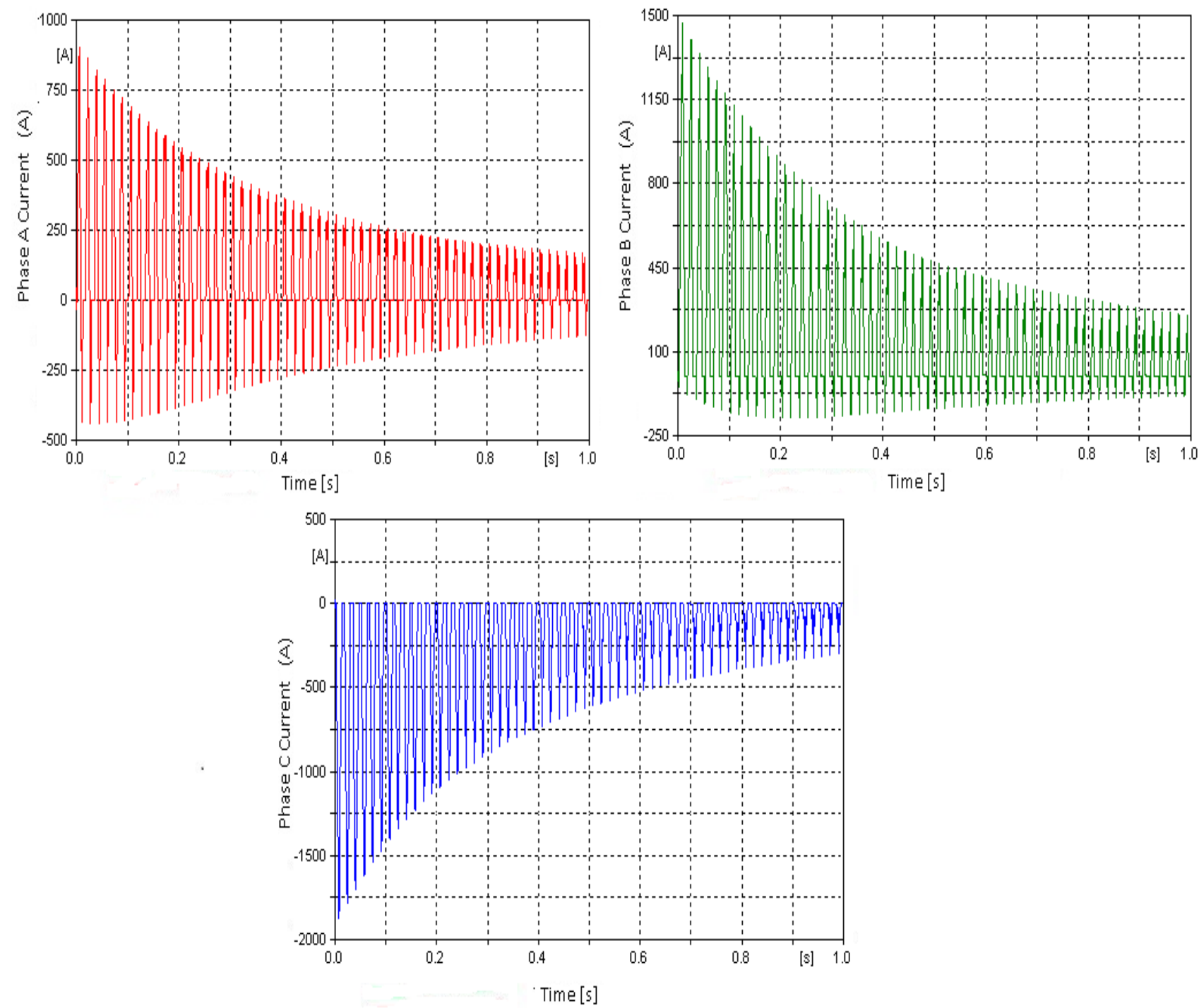

Figure A.10: Inrush Currents for Phase A, Phase B and Phase C at 40\% residual flux linkage for Triplex Core from $L V$ side 

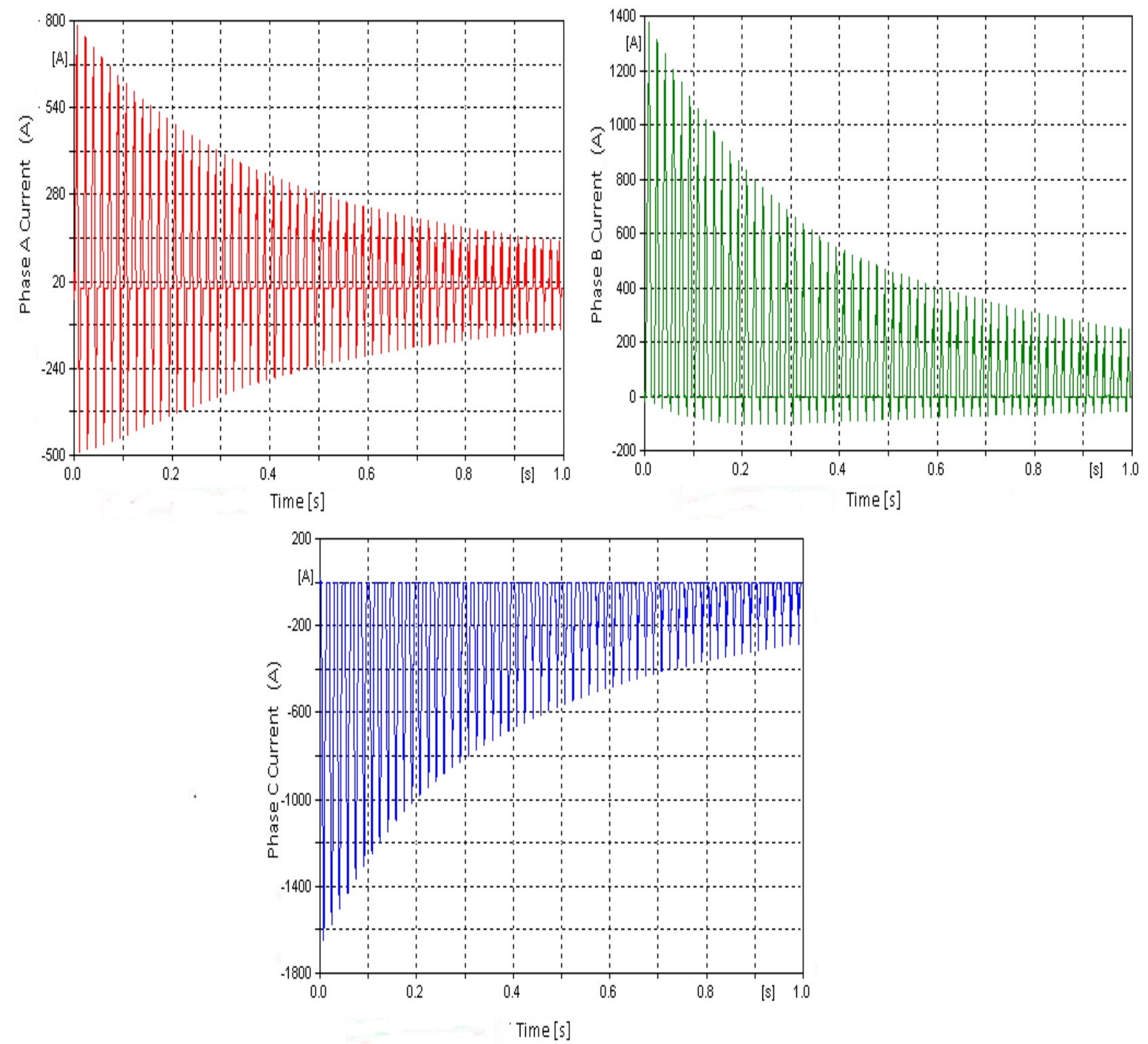

Figure A.11: Inrush Currents for Phase A, Phase B and Phase C at 30\% residual flux linkage for Triplex Core from $L V$ side 

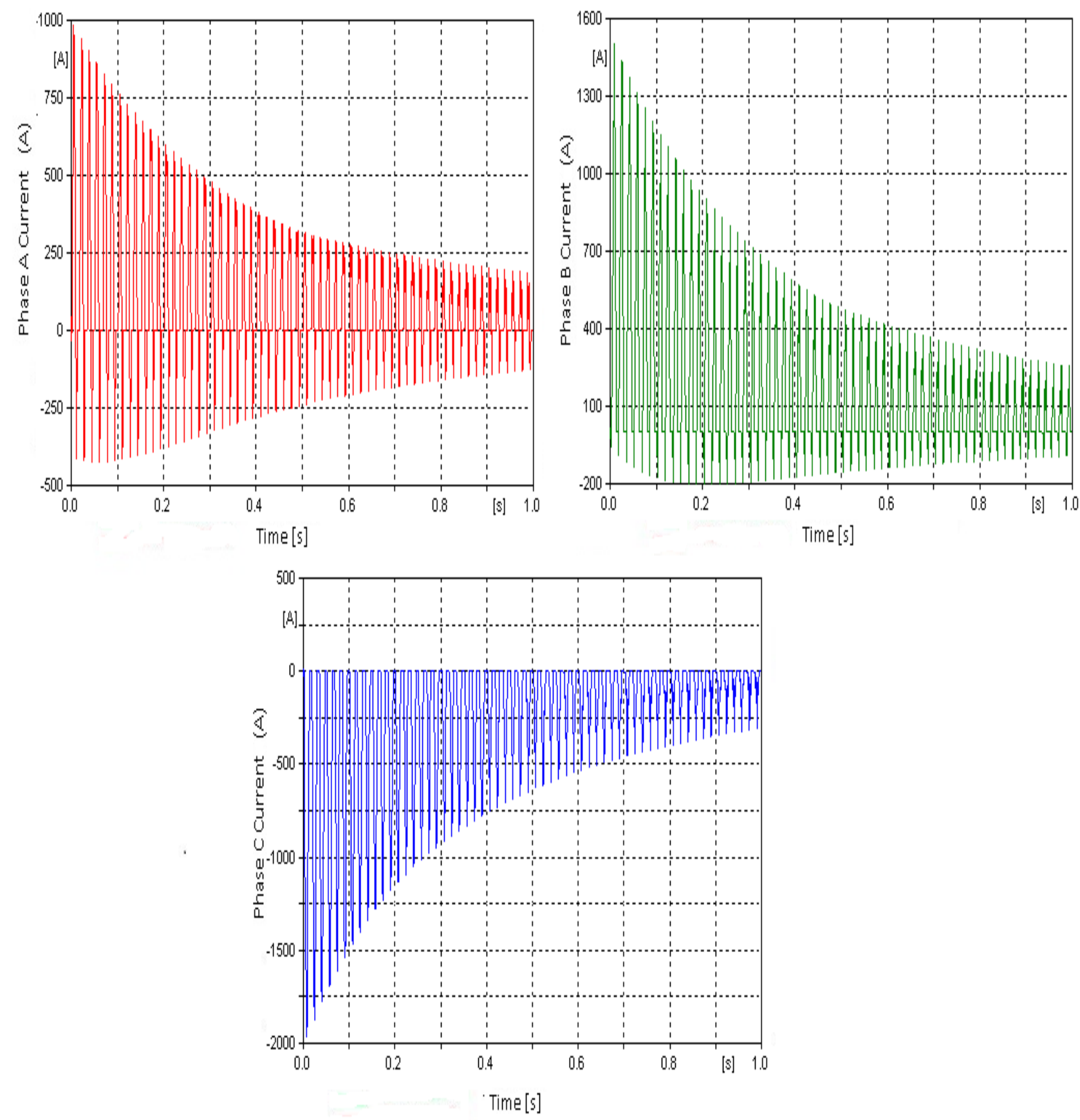

Figure A.12: Inrush Currents for Phase A, Phase B and Phase C at 50\% residual flux linkage for Triplex Core from $L V$ side

The above results show higher peak inrush currents for higher residual flux linkages. They also show the inrush current decay for each case. 
B

Transformer parameters for Inrush and Over-excitation models

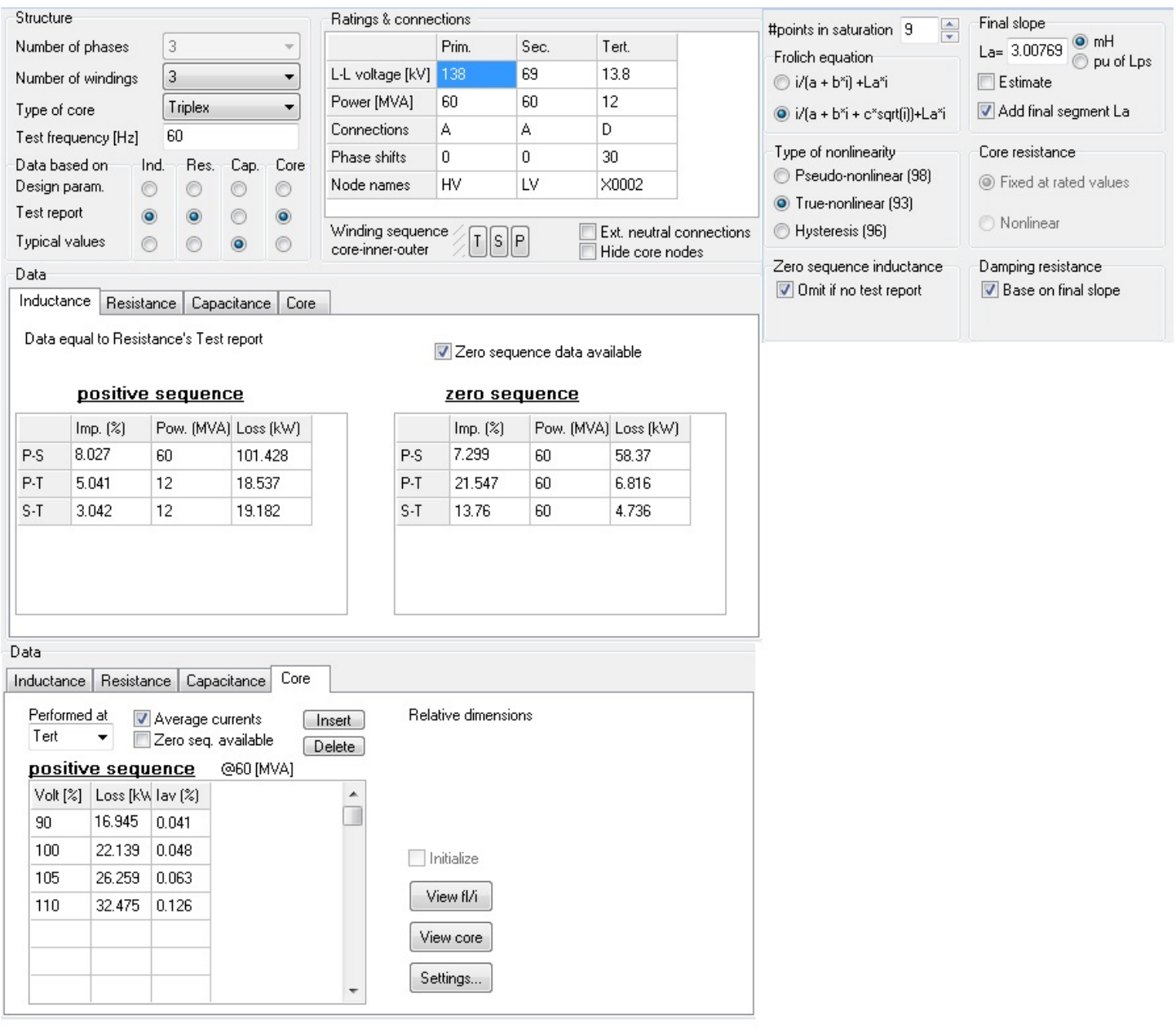

Figure B.1: Parameters for Hybrid XFMR model used in inrush and Over-excitation modelling

Note: For 3-legged core just changed the transformer core to 3-legged stacked. 
$\underline{\text { Transformer parameters for Inrush and Over-excitation models }}$

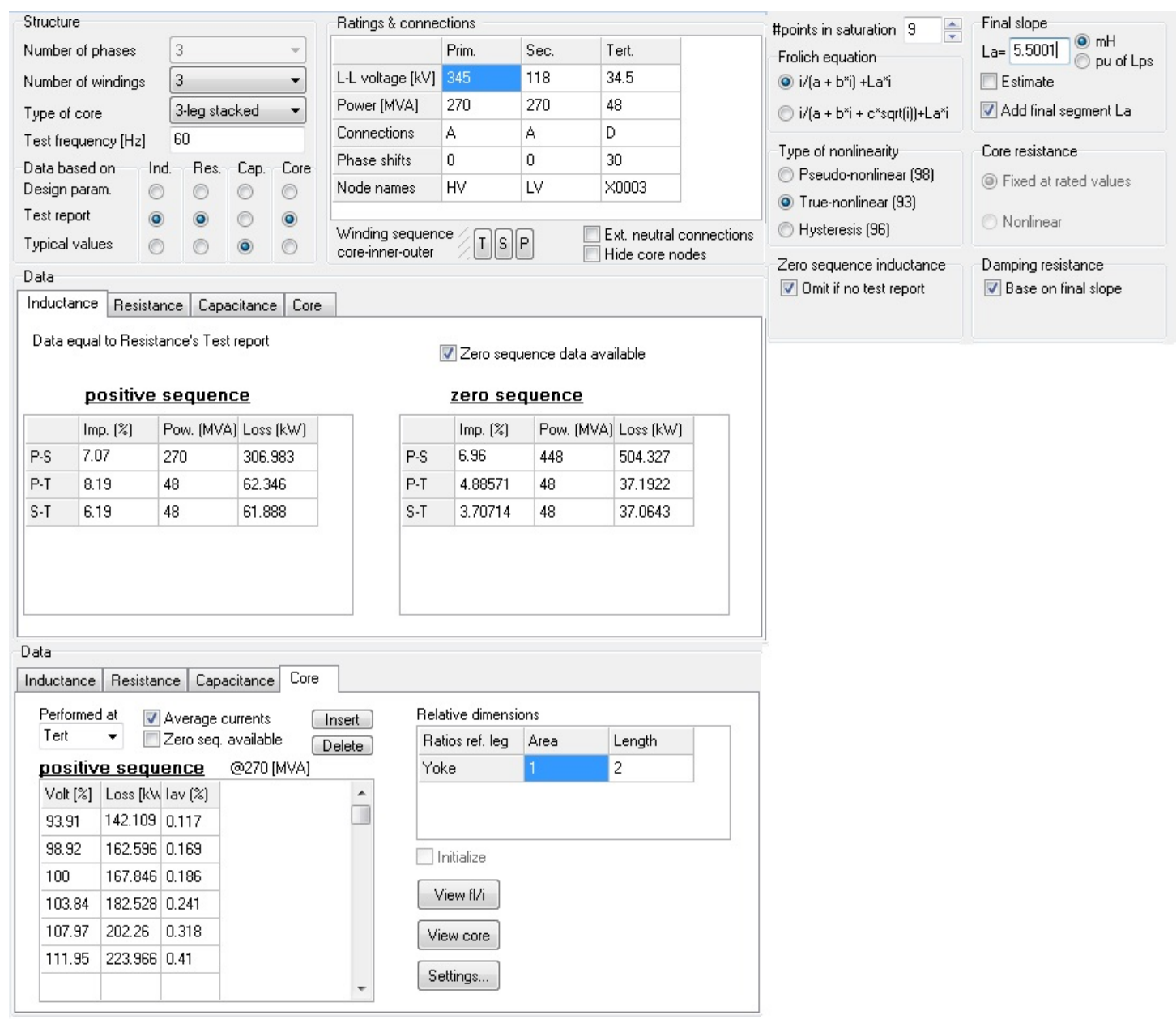

Figure B.2: Parameters for Hybrid XFMR model used in inrush and Over-excitation modelling

Note: For 3 single phase transformer arrangement just changed the type of core to Triplex 
C

Report for isolation of inrush currents for differential relays 


\section{Isolation of Magnetic Inrush problem in Transformer Differential Relays}

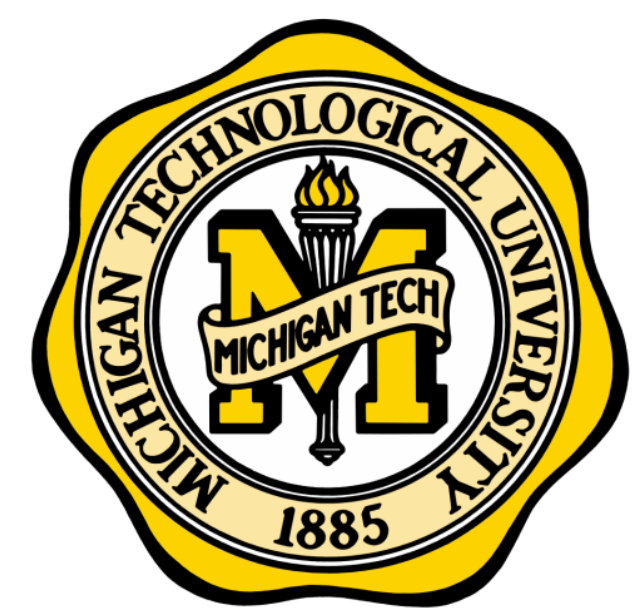

\section{TEAM PROJECT:}

EE 5220 - Power System Transients

\section{INSTRUCTOR:}

DR. BRUCE MORK

\section{TEAM:}

Nishchal Sharma

Harshada Gaikwad 


\section{Executive Summary}

Transformers are a very important part of the power system infrastructure and protecting them is of a great importance in order to keep the power system stable. A very common problem associated with transformers is of the inrush currents. There can be three kinds of inrush currents, namely energization inrush, sympathetic inrush and recovery inrush. In this report we studied different inrush phenomenons by modeling them on ATP using hybrid transformer model and used the generated current data for development of a differential relay setting that can detect and restrain the relay operation when inrush is detected. The setting developed was downloaded in SEL-787 transformer differential relay and tested with the same data that was generated after simulation on ATP. We used harmonic restraint for blocking the operation in case of inrush while making sure the relay operates for actual transformer faults. All the cases were tested and results were found to be satisfactory. 


\section{Statement of Contribution:}

I wrote Journal paper review, made simulation models for energization, recovery inrush in ATPDraw, developed relay setting files for SEL for HIL testing, and literature survey, development and implementation, conclusion and future recommendation part in the report was covered by me.

Nishchal Sharma

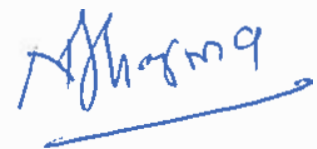

Presentation for JPR, simulation file for sympathetic inrush in ATPDraw, HIL testing with Nishchal Sharma, in the report I covered introduction, proposed approached, modelling, HIL, results and analysis part.

Harshada Gaikwad 189 
Table of Content

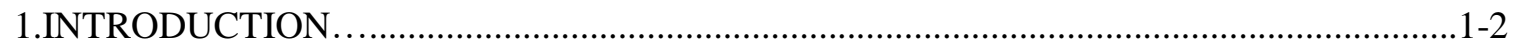

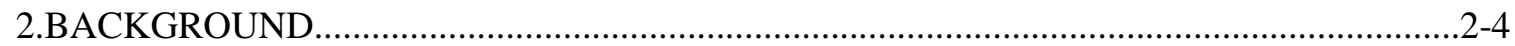

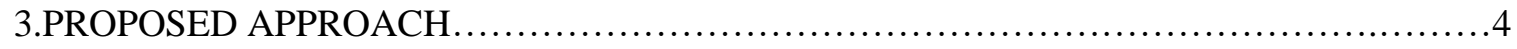

3.1 OVERVIEW OF APPROACH.................................................. $4-5$

3.2 DEVELOPMENT AND IMPLEMENTAATION ..................................

4.IMPLEMENTATION AND MODELLING OF TRANSFORMER MAGNETIC INRUSH......7

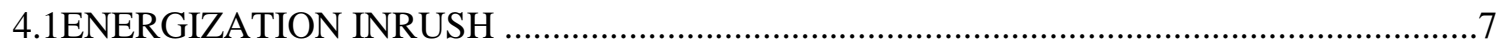

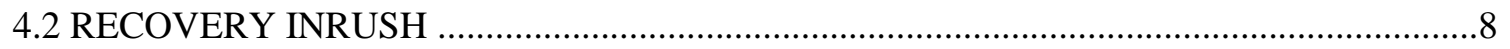

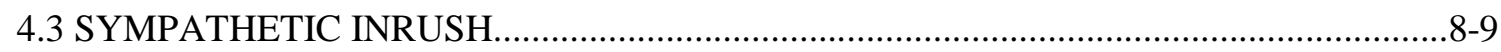

5. HARDWARE IN LOOP TEST ON SEL-787 …............................................................

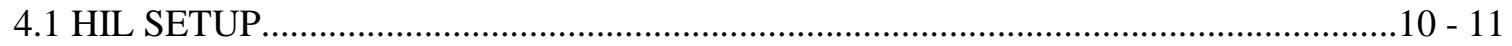

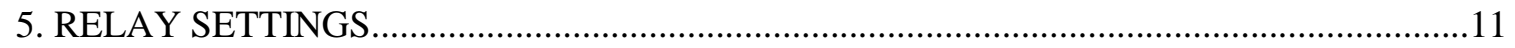

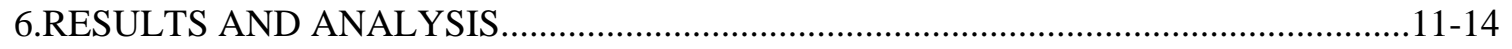

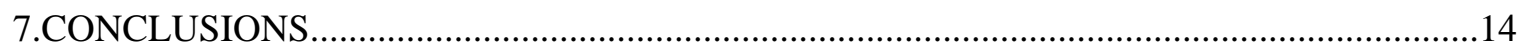

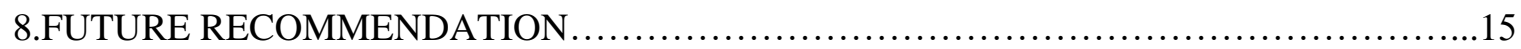

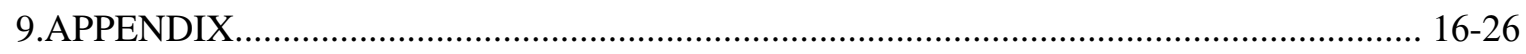

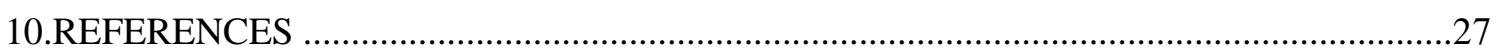




\section{Introduction}

Power transformers are more prominent to electrical transients after the transmission line. The primary of the transformer draws a very high current from the source which is transient in nature when power transformer is switched on without any load on secondary. Inrush current does not create any permanent faults in the transformer, but they can lead to unnecessary tripping of circuit breakers at the time of charging of transformer. Inrush current occurs during energization of the transformer, in power transformer, the magnitude of inrush current is two to five times the rated load current. The magnitude of inrush current is depended on the transformer design and installation parameters. Also, inrush current shape and magnitude is dependent on several other factors like network topology, transformer construction, winding coupling, and residual flux. The inrush current exceeds saturation current, the inrush current affects the magnetic property of transformer's core. The focus is modeling of the transformer where inrush current during energization of the transformer is an issue related to relay settings, voltage harmonic distortion, and inrush mitigation. [1]

Magnetizing inrush current can be categorized as current during energization, current during recovery, and sympathetic inrush current. During energization, inrush current is present after a last instance of deenergization and it can lead to heavy current flow in the transformer. Recovery inrush current occurs when the voltage is stabilizing after the occurrence of a fault. Sympathetic inrush current can occur when the transformer is nearly energized. This phenomenon occurs when a transformer is switched on in power system which contains other transformers which are already energized. The inrush current finds a parallel path in the previously energized path. This is known as sympathetic inrush current. [1][4]

At extreme saturation, UMEC and XFMR model have limitations, models cannot retain a residual flux value after de-energization, and simulations are restricted to zero residual flux initial condition. So, developed model overcomes all the constraints. Transformers need to install with certain protective relays depending on the size of transformer and load capacity. The empirical protection scheme for transformers is differential protection scheme. Differentiating between transformer magnetizing inrush condition and the internal fault condition is one of the key issues while dealing with protection scheme for power transformers. One of the methods used to discriminate was based on deactivating or delaying the relay to compensate transients, which were inefficient as transformers might expose to fault for longer duration which would damage the transformer furthermore, power flow can be used to detect inrush current, and, some researchers have proposed fuzzy logic technique to detect inrush current. [1][2]

The models have been developed and explained in sections and simulated results are compared with hardware in the loop on SEL - 787 differential relay. The choice of protection scheme is mainly 
dependent on the size of the transformer, its application and detection time required. We have shown the protection approach using transformer differential scheme to eliminate malfunction due to magnetizing inrush current during energization, re-energization, and sympathetic inrush current.

\section{Background}

The models used for simulation can be XFMR and UMEC, but, we chose to work with the XFMR model from ATP. The models UMEC and XFMR have limitations related to the accuracy of extreme saturation and the proper representation of the hysteretic behavior of the core. These Transformers also do not have any direct mechanism to initiate residual flux and while it's possible it is very complex to initialize these transformers for residual flux. A new transformer model based on the hybrid model of ATP. The construction of the transformer chosen was for a 3-legged type transformer. The Author starts from its core construction and develops its Hopkinson's equivalent as well as the duality transform model, which was then used as the Hybrid Model. [1]

The residual flux can't be initialized in existing model and it is because the model mainly comprises of linear resistances and inductances. The residual flux is just trapped energy inside the transformer core, now because these models are just linear expressions of the real transformers and there is no way energy can remain trapped inside of these components in absence of capacitor, hence residual flux is not possible with the existing model. The developed model is validated with the analytical equations and the data available from the manufacturer. The sensitivity analysis is done to know the effect of parameters on inrush current. Residual flux can greatly affect the magnetic inrush and author states that for a variation of $20 \%$ of the residual fluxes, a mean variation of $9 \%$ for ungrounded-wye and $14 \%$ for grounded-wye is experienced in the inrush first peak was one of the major findings, also, capacitances can be estimated from direct capacitance measurements at the transformer terminals, but these measurements are highly susceptible to error. [1]

The residual flux is calculated from below equation.

$\lambda(t)=\lambda_{m} \sin (w t+\phi)-\lambda_{m} \sin \phi+\lambda(0)$

Where,

$\lambda(0)$ is residual flux

The model developed gives out satisfactory results and performs well when compared to the empirical data from the field, also, the capability of this model to predict residual fluxes with different disconnection 
conditions should be further verified. The model is highly effective and has been found to be very useful in different studies. [1]

The paper has explained the mitigation techniques used to enable per phase control switching based on a residual magnetic flux estimation. Paper has briefly explained the results of reconstruction process for sympathetic inrush in the Slovenian power system. Wide area monitoring systems are used for the measurements. From the study author has found out that measurements provide misleading information about an actual situation. Also, qualitative observations of phasor parameters are reasonable until electrical variables are purely sinusoidal. For non-sinusoidal, inrush current waveforms RMS value calculated by PMU are not close to the actual values, it doesn't imply that the event cannot be recognized by the operator's observation of RMS current waveform. [2]

When loaded parallel transformer exists in the substation, the winding current of an operational transformer carries magnetizing as well as load current. It is necessary to know such events to be aware of their occurrence in the system. The WAMS measurements, as well as the over-current protection relay, indicated sympathetic inrush occurred between two parallel 400/110 kV transformers in Slovenian power system, due to the magnetization of a second transformer in parallel to fully loaded transformer in the substation. [2]

The model topology includes reflecting an actual core structure, includes leakage core and coils. The model also represents the internal core and coil arrangements which can be applied for delta, wye, auto or zig-zag connections. [3]

While designing the hybrid model, components can be connected normally in the circuit only ground nodes cannot be directly grounded when the capacitance is considered, several components cannot be connected to the same bus, and switches should be used to maintain unique names for nodes in both cases. Also, the line to line voltage rating, power transformer MVA rating, type of coupling and phase shift between windings should be specified. Three settings are referred to the hybrid transformer primary (P) on the left side, secondary on the right side (S), and tertiary winding at the top (T). Primary and secondary nodes can be swapped with an edit-flip option if necessary. While designing hybrid transformer, if the sequence is not mentioned then inner winding has the lowest voltage. [3]

Triplex, 3-legged stacked core, 5-legged stacked core, and shell form core are the different types of cores that can be configured. The structure and calculation of core model would be dependent on the type of 
core. Saturation characteristics for outer legs will be available in the 5-legged core, and zero sequence behavior can be observed in the 3-legged core. [3]

Non- linear inductance type 98 or type 96 can be used. As type 98 inductance can move from one segment to next in one-time step, so, a large number of segments needs smaller time steps. We have selected type 96 inductance for a hybrid transformer, 50\% of loss in the core is included in the hysteresis and the rest in a constant parallel resistor. [3]

The base paper has developed ATPDraw model with a hybrid transformer, but, Author has not considered a type of inductor. We have developed model with the hybrid transformer with 96 inductor to know the effect of non-linearized inductor on the circuit. A model has been developed by Author which can be used to study the effect of inrush currents and extreme saturation. The model can be used to initialize and understand the effect of residual flux, similarly, we have developed a model for three different cases i.e. energization, recovery inrush, and sympathetic inrush with the differential relay. [1][2]

The model gives a good platform for testing inrush currents in 3 phase 3 legged transformers with an added advantage of simulating with residual fluxes, but it seemingly does not take into consideration or does not explain the effect of different non-linearized inductors i.e. type 96, type 98 etc. on the results, the different values of residual fluxes can affect the inrush currents, how the residual fluxes should be input for the transformer. The author has not discussed on what range of values for residual flux is acceptable and if there is any way i.e. analytically that values of residual fluxes are balanced. [1]

\section{Proposed Approach}

\subsection{Overview of proposed approach}

The transformer model has been selected for simulation is Hybrid transformer as per the reference paper. The hybrid model supports 3-phase transformers with two or three windings coupled as Wye, Delta or Auto. Final slope of inductance is important for the calculation of inrush current. Inductance, resistance, and core are selected as test report, and capacitance value is kept as typical values. The hybrid model data in detailed is shown in appendix figure (10). We have used 3-legged stacked cores model for developing ATP simulation model for three type of inrush i.e. energization, re-energization, and sympathetic inrush current. [3] 
For the energization case, the inrush current flowing is very high when excitation is done at zero crossing of voltage. We have used 96 inductors as $50 \%$ of losses of the core are included in hysteresis. The energization can lead to false tripping of differential relays. When the fault occurs, there would be a significant drop in voltage and energization of the transformer. The recovery inrush occurs when the circuit breaker clears the fault and during re-energizing, the recovery inrush would flow through the circuit as excitation of the transformer would increase after clearing the fault. The relay may potentially see it as another fault and trip again. For recovery inrush, we have simulated with a load on transformer side. Sympathetic inrush occurs when one transformer is already operating and another transformer with no load is added and the current finds a parallel path to flow through the circuit. All the simulations were carried out keeping in mind the scenarios mentioned.

The currents from all the above simulations gave us good analytical data to extrapolate and implement a setting for the SEL-787 relay which can isolate the inrush current situation completely and can avoid any kind of nuisance relay operation due to inrush of any kinds.

\subsection{Development and Implementation}

\section{Parameter}

\begin{tabular}{|l|l|l|l|}
\hline \multicolumn{1}{|c|}{ Cases } & \multicolumn{1}{|c|}{ Source voltage } & Inductance (ohms) & Resistance (ohms) \\
\hline Case $1,2,3$ & $138 \mathrm{kV}$ & 8.516 & 4.251 \\
\hline
\end{tabular}

Table 1.1

For all the cases voltage, source reactance is same, the source impedance chosen was $5 \%$ on the base of 100 MVA. For case 1 energization, worst case is considered at voltage zero crossing.

For case 2 recovery inrush, two switches are connected as after fault clearance by one switch (circuit breaker), a large inrush would flow through the circuit. For case 3 sympathetic inrush, two transformers connected to each has its own switch at HV side of the transformer. The detailed parameters structure is shown in (11).

\section{For Hybrid Model}

While designing the hybrid model transformer 3-leg stacked core, the values for resistance and inductances are same and capacitance was set to typical values. For all the three cases i.e. energization, 
recovery inrush and sympathetic inrush, model parameters are same with $138 \mathrm{kV}$ primary side voltage, 69 $\mathrm{kV}$ secondary side voltage and $13.8 \mathrm{kV}$ tertiary voltage. Core values selected for a model are shown in appendix figure (11).

\begin{tabular}{|l|l|l|}
\hline CT Ratio & LV & HV \\
\hline & 600 & 300 \\
\hline
\end{tabular}

Table (1)

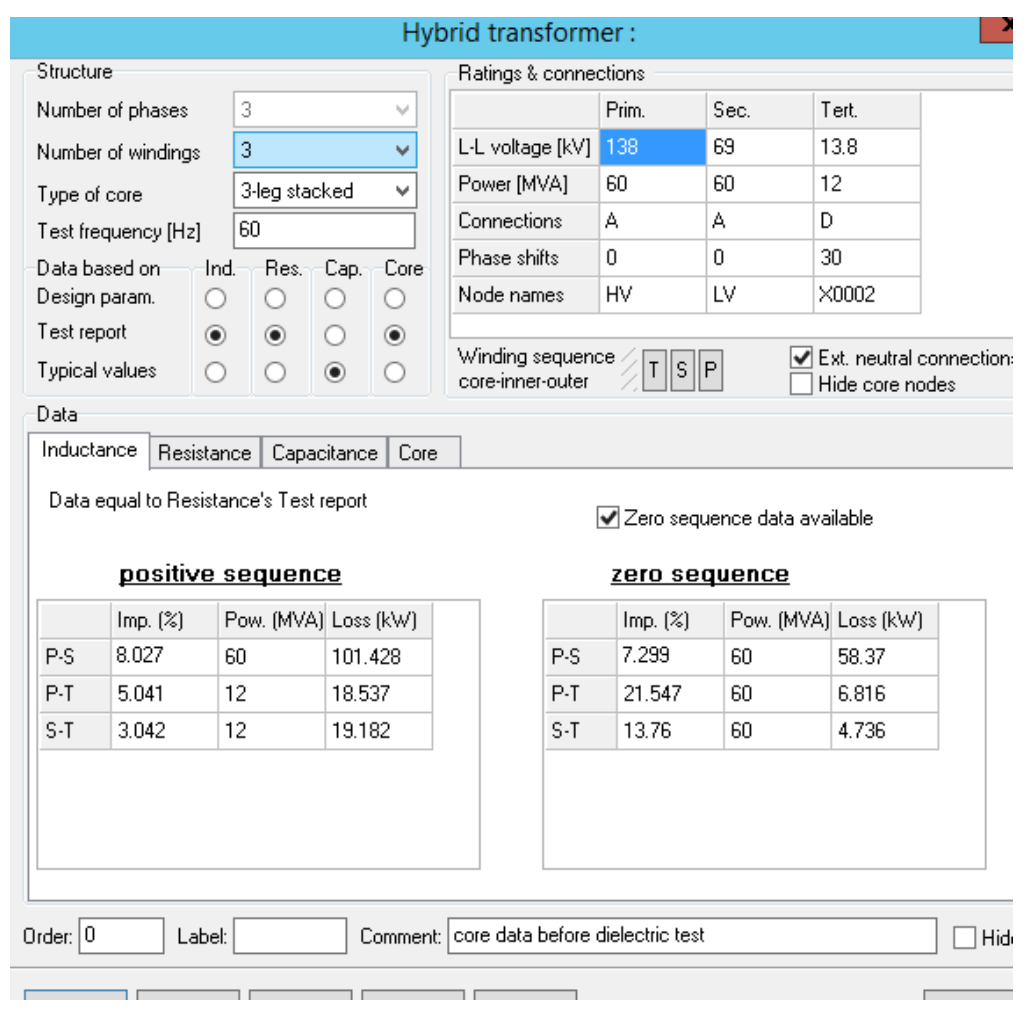

(1) Hybrid Transformer data 


\section{Implementation and Modelling of Transformer Magnetic Inrush}

1. Case Study - ATP model for energization

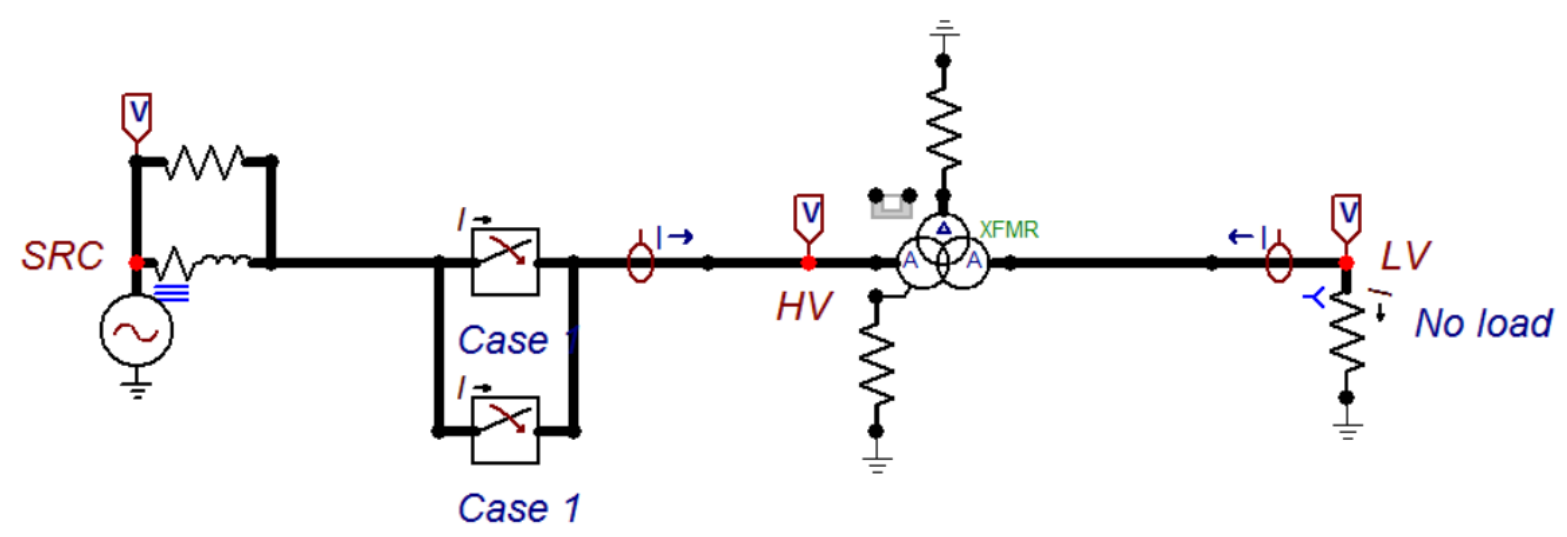

(2) Energization (3 phase transformer)

Transformer energization can create a high value of transient inrush current when the transformer's cores saturated which includes DC components as well. To study the effect of energization, 3 phase transformer model have been developed in ATP. EMTP model consists of 3 phase power transformer, lines, generator, cables and circuit breakers with source impedance connected to HV side. For the energization case, the secondary of the transformer is at no load, the highest inrush current flows during the energization of the transformer. When the inrush current flows, we would get the harmonics and accordingly the differential relay won't operate. We energized and reenergized the transformer in the same simulation, as type 96 inductance in transformer retains the value of residual flux in accordance of time of de-energization. For the transformer energization case one switch has been connected to the HV side.

2. Case Study - ATP model for Recovery inrush

When a fault occurs, voltage drops significantly as transformer excitation decreases. After a fault is cleared by a circuit breaker, the voltage recovers, and the transformer is excited by the normal voltage again and hence, inrush current is observed from the source to transformer. In this case, transformer keeps on operating at initial load value. 


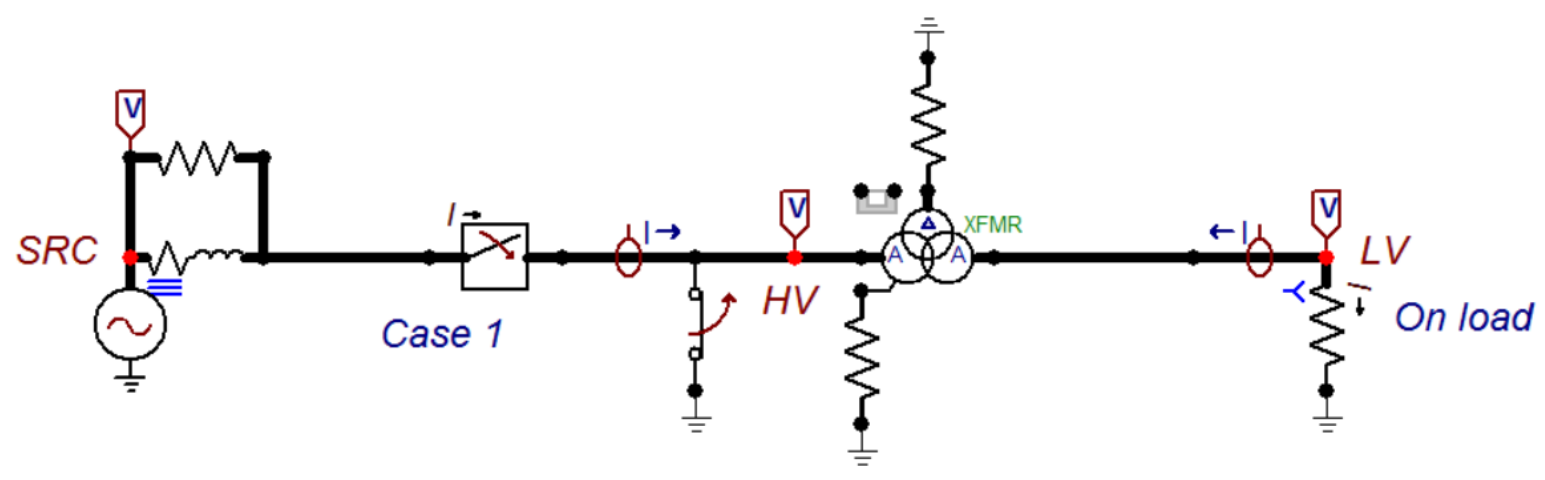

(3) Recovery inrush

During this period, the transformer would have large inrush current for a shorter time and differential relay should not trip during recovery inrush. From the current flowing in the circuit, the harmonics $\left(2^{\text {nd }}\right)$ generated would restrain, hence the differential relay won't operate.

3. Case Study - ATP model for Sympathetic Inrush Current

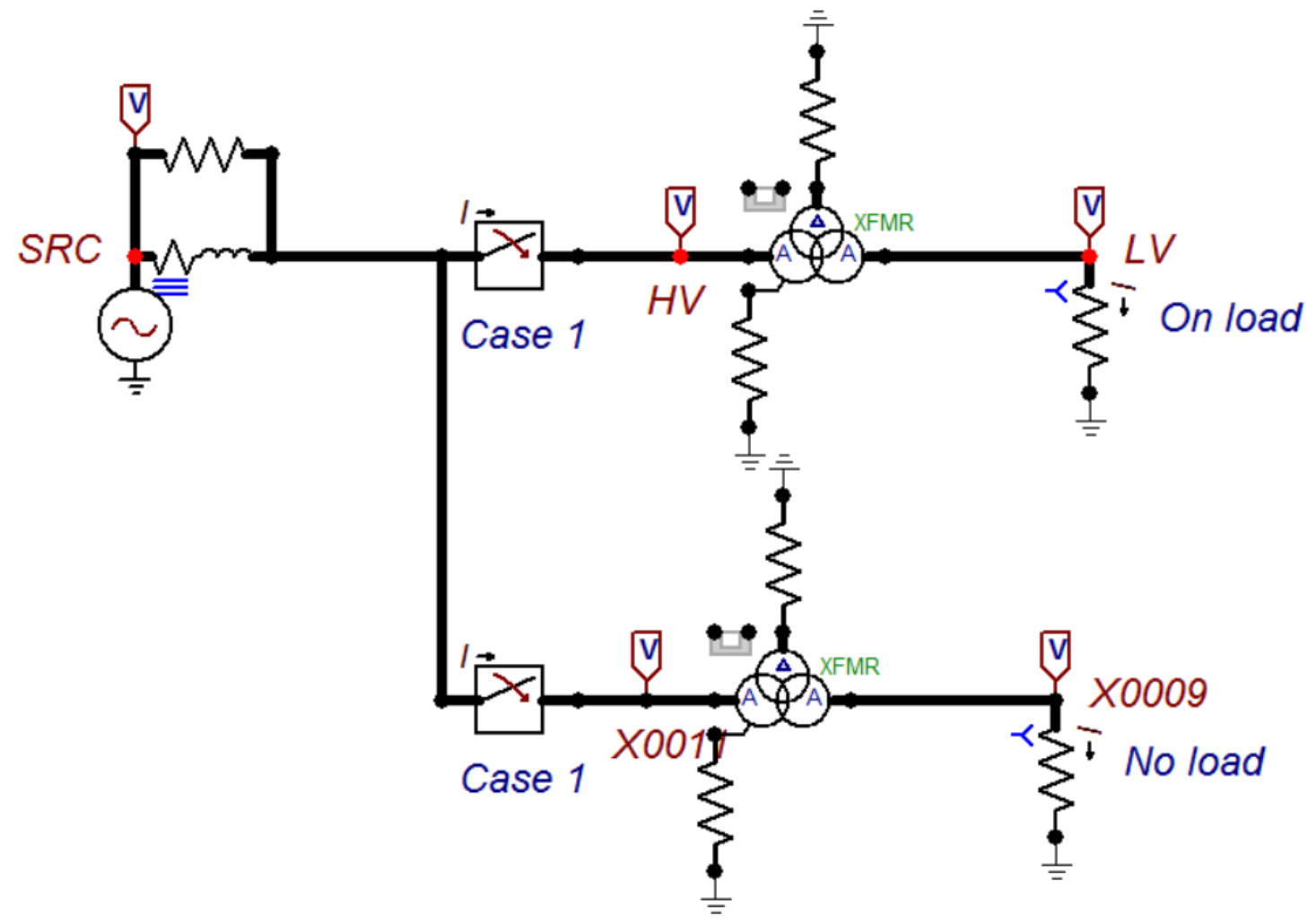

(4) Sympathetic Inrush 
Sympathetic inrush occurs when two transformers are connected in parallel and one of the transformers is on loaded and another transformer is added in the network then the inrush current finds a parallel path in the previously energized transformer. The current flowing through this path would be known as sympathetic inrush current. For simulation, two transformers are connected in parallel, one is a fully operational mode with a load connected on the secondary side and another transformer is newly added with no load. Both transformers would have respective inrush current flowing, while new transformer would see energization inrush and operating transformer as sympathetic inrush. In either case, inrush current would reach in $2^{\text {nd }}$ harmonics and can be used to restrain or blocking operation. Sympathetic inrush stays for longer period as compared to other type of inrush but is not as serious as energization inrush.

\section{Hardware in Loop (HIL)}

Hardware in the loop (HIL) testing using 787 differential relay was carried out to verify the results with doble power simulator in the lab. Refer relay settings files attached for logic created in SEL 787 relay in the appendix (14). The hardware in loop simulation was carried out for 4 cases to know whether relay correctly operates. We used the ATPDraw current values of HV and LV side for hardware in the loop testing. The values of current on either side were extracted and COMTRADE format.

\section{Case 1: Energization}

For the energization case, we added current probe on HV and LV side of the transformer, and the values obtained from the HV and LV side current were then saved in PL4 format, converted into COMTRADE version and transferred to doble power simulator with COMTRADE file uploaded. When the large inrush flows, the transformer is energized the relay does not trip during energization. The input value of current and settings are shown in the appendix. $2^{\text {nd }}$ harmonic obtained for energization case is $131.40 \%$, the differential relay did not trip. 


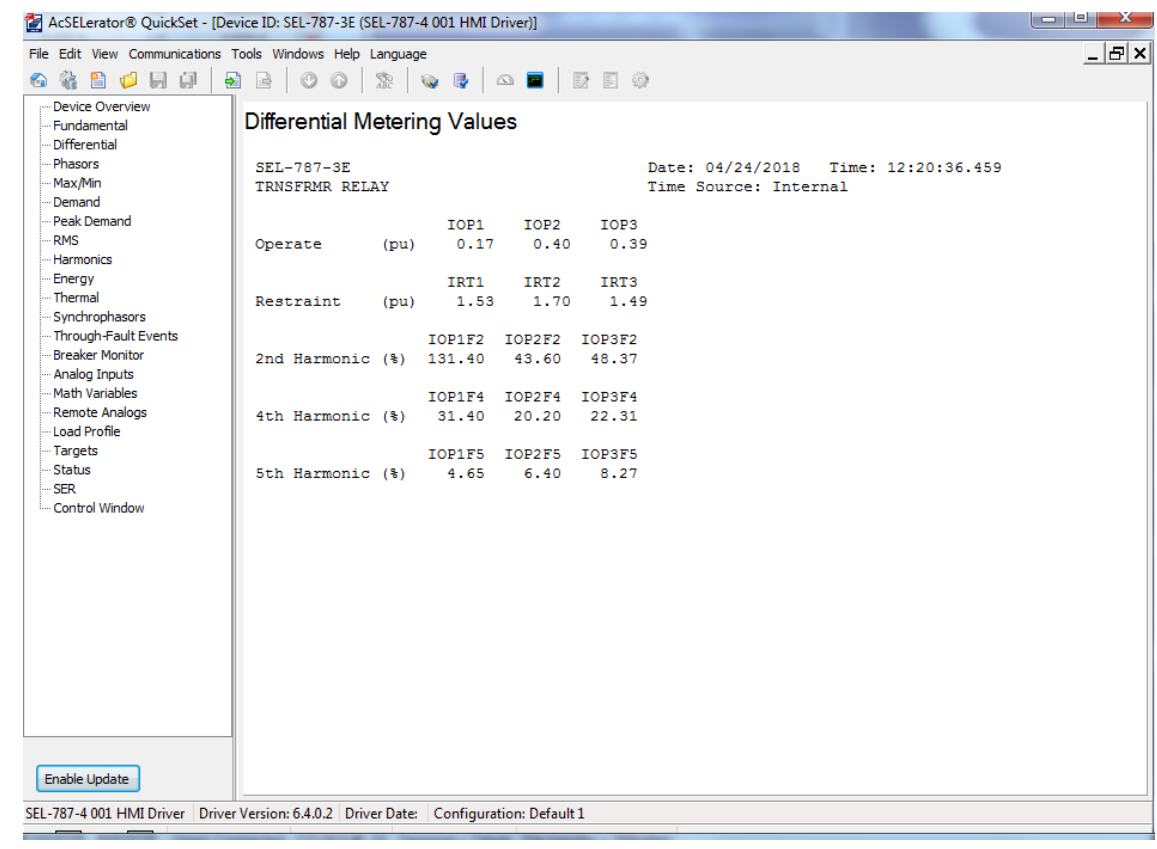

(5) Energization

Case 2: Recovery Inrush

The same process was carried out for recovery inrush to transfer current of HV and LV side to doble power simulator. The relay did not trip even when the transformer has large inrush for some time after clearing the fault. The ATPDraw model developed for recovery inrush gave satisfactory results. The percentage of the second harmonic was $34.85 \%$ which was used to restrained tripping of the differential relay during recovery inrush. The input data and results obtained for recovery inrush are attached in appendix (17).

Case 3: Sympathetic Inrush

As per the logic developed in ATPDraw, one transformer is fully loaded and another transformer with no load was connected, the current of these both transformers obtained were sent to doble power simulator, new settings were created in Doble simulator, when a large inrush flowed through the circuit, the differential relay did not trip, hence the experiment carried out with relay in lab was successful. The results obtained from differential relay are shown in below figure, the $2^{\text {nd }}$ harmonic obtained is used to restrain the differential relay from tripping. The input data used for the doble power simulator from ATPDraw is attached in appendix (18). 


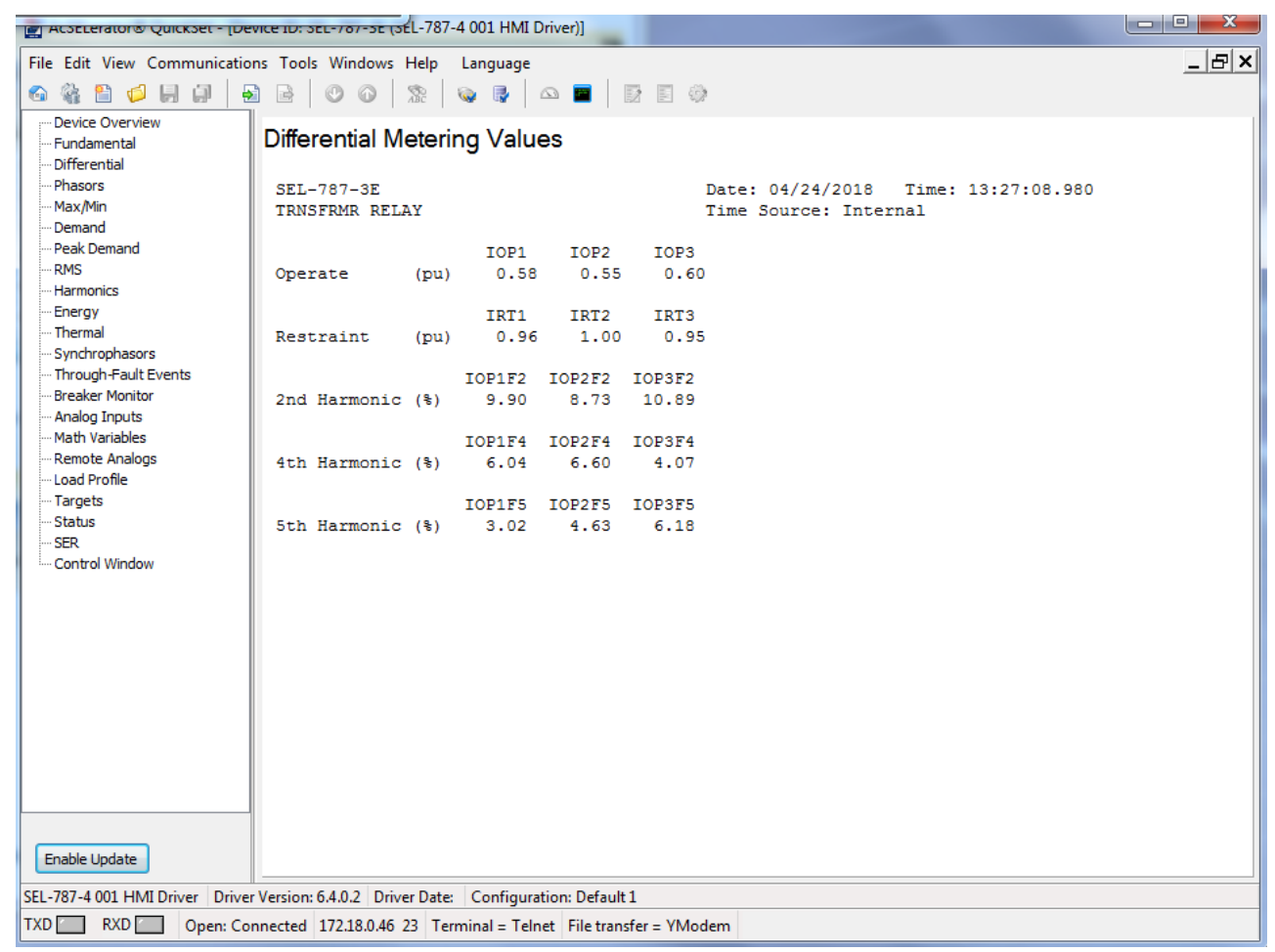

(6) Harmonics for sympathetic inrush

Case 4: Normal Fault condition

Differential relay should be able to identify fault from inrush. We applied fault current in doble simulator and the relay tripped when the fault current is applied. The figure in the appendix shows the amplitude of fault current.

\section{Results:}

\section{Case 1 - Energization:}

The results obtained form ATPDraw as shown in the below figure, the current during the initial excitation period is high and decreases with time. When the inrush current flows, the harmonics obtained are used to restrain and the differential relay won't operate. When energization case was simulated in a lab with 787 differential relay, the relay did not trip during energization condition. 


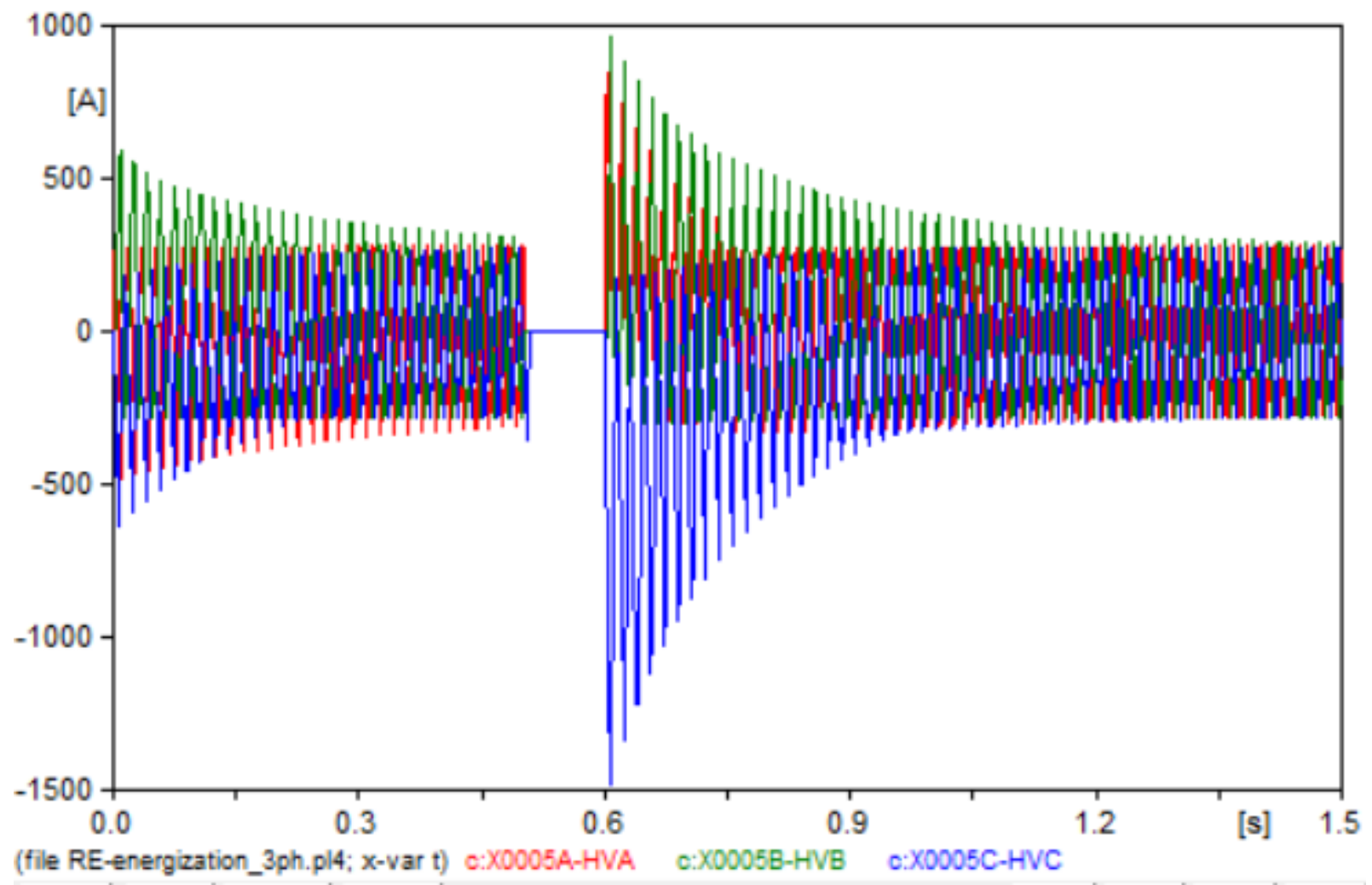

(7) Current during Energization

Case 2 - Recovery Inrush

Current shown below is for HV side of the transformer for recovery inrush. During recovery inrush, voltage recovers after a fault and the transformer is excited by normal voltage again and as shown in the below figure inrush is observed again. When same was performed on SEL 787 in lab results were satisfactory with no tripping of the differential relay. 


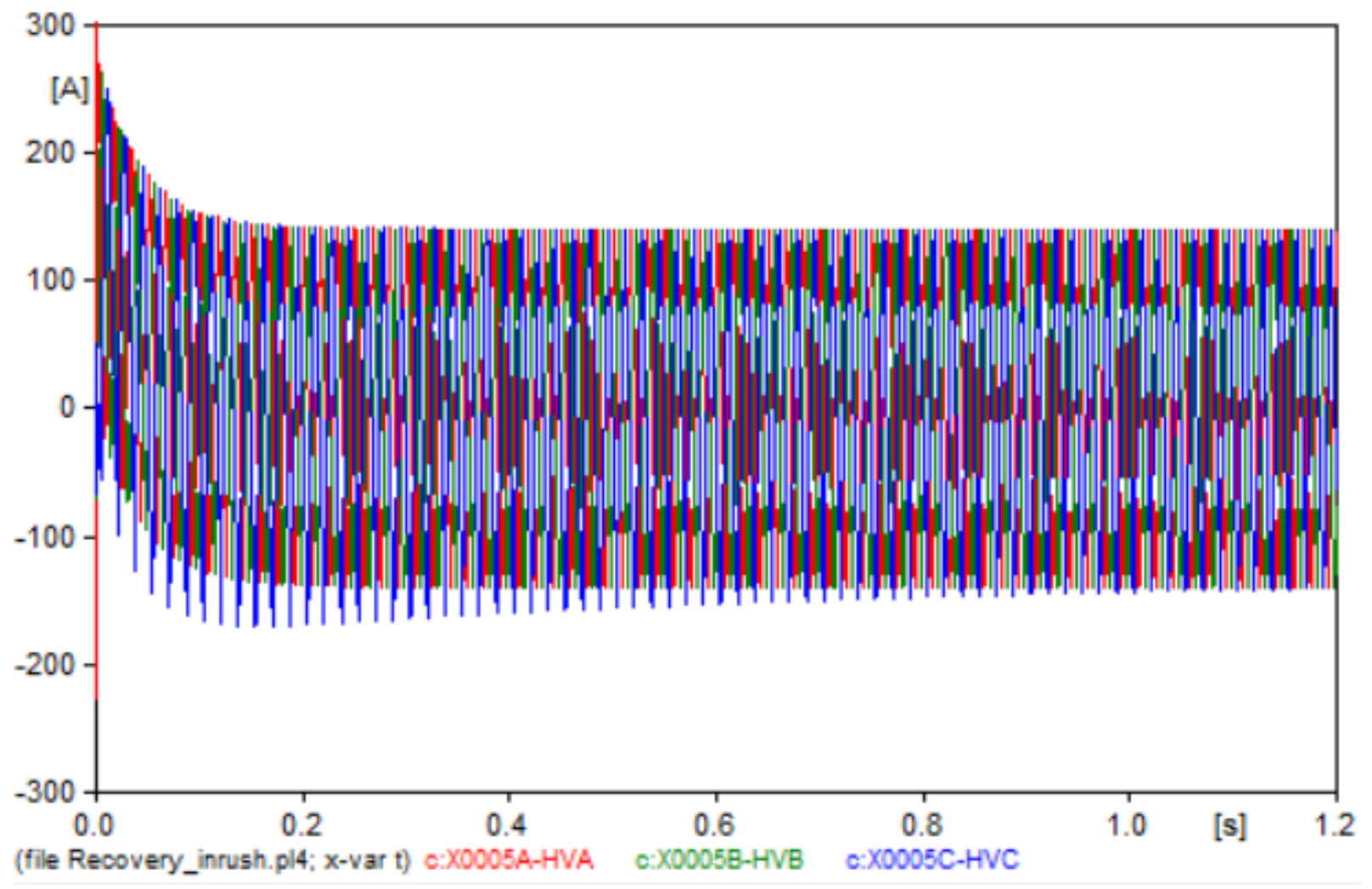

(8) Current during Recovery Inrush

Case 3 - Sympathetic Inrush:

As the results shown below, the current flowing is normal when only one transformer at full load is connected. When another transformer is connected in the circuit the current would flow through parallel path. This current is known as sympathetic inrush current. The sympathetic inrush current amplitude is high and relay did not trip when the same case was carried out in a lab with SEL 787 differential relay. 


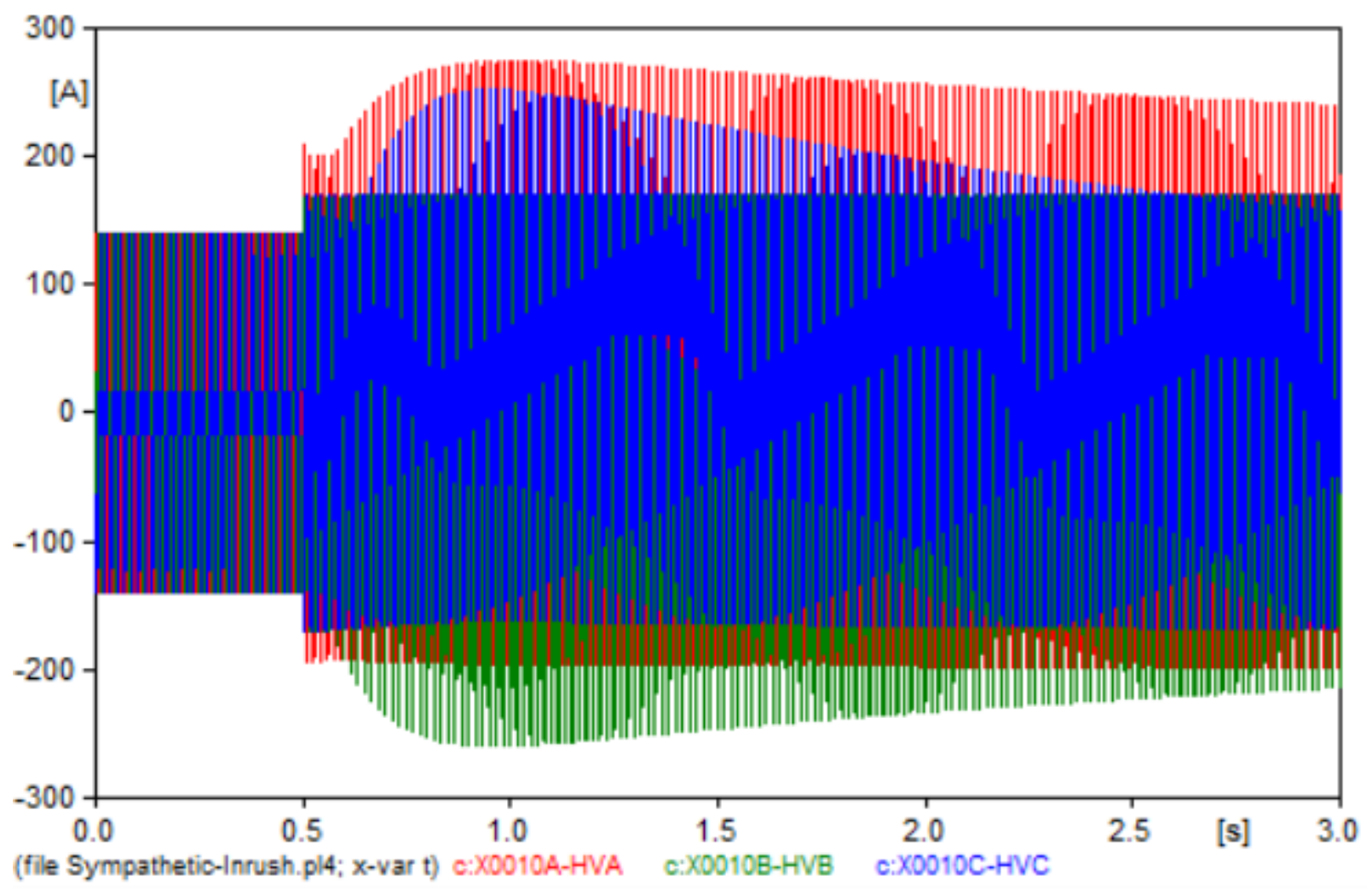

(9) Current during Sympathetic Inrush

\begin{tabular}{|c|c|c|c|c|c|c|}
\hline \multirow[t]{2}{*}{ Cases } & \multirow{2}{*}{$\begin{array}{l}\text { CT Ratio } \\
\text { (HV/LV) }\end{array}$} & \multicolumn{3}{|c|}{ Maximum Current } & \multirow[t]{2}{*}{ 2nd Harmonic } & \multirow[t]{2}{*}{ Trip } \\
\hline & & & $\mathrm{B}$ & & & \\
\hline Energization & $300 / 600$ & 840.1 & 957 & 1463 & $131.40 \%$ & NO \\
\hline Recovery Inrush & $300 / 600$ & 5368 & 262 & 249 & $34.85 \%$ & NO \\
\hline $\begin{array}{l}\text { Sympathetic } \\
\text { Inrush }\end{array}$ & $300 / 600$ & 284 & 279 & 279 & $9.90 \%$ & NO \\
\hline Normal Fault & $300 / 600$ & 1500 & 1500 & 1500 & None & YES \\
\hline
\end{tabular}

Table shown above is the results obtained from hardware in loop performed in lab on SEL 787 relay.

\section{Conclusion}

1. Hybrid model was found to be very useful tool for transformer inrush studies and simulations.

2. The results obtained from ATPDraw simulations were verified and matched with base paper.

3. The hardware in loop testing and doble power simulator settings were obtained from ATPDraw and settings were used to isolate inrush and avoid nuisance tripping.

4. The setting developed, and lab experiment carried out gave expected results during all inrush conditions and fault condition. 


\section{Future Recommendations:}

1. Empirical data from real world transformer from test report would have given out more realistic results.

2. Ratio of over excitation can also be address with similar approach in ATPDraw to ensure the transformer differential relay is able handle different fault phenomenon. 


\section{Appendix}

Hybrid Model Parameters

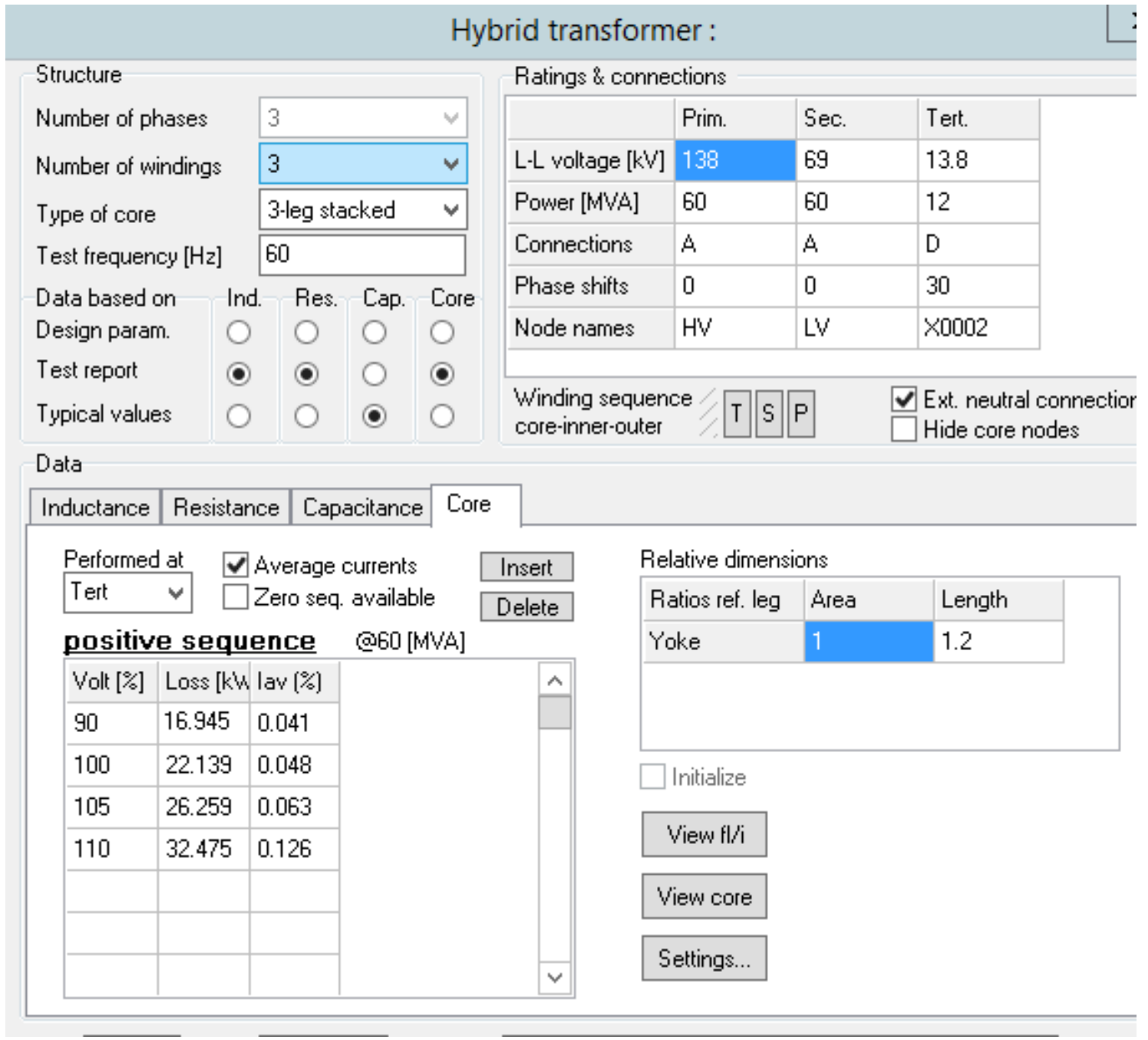

(10) Hybrid Model 
Hybrid Model Parameters

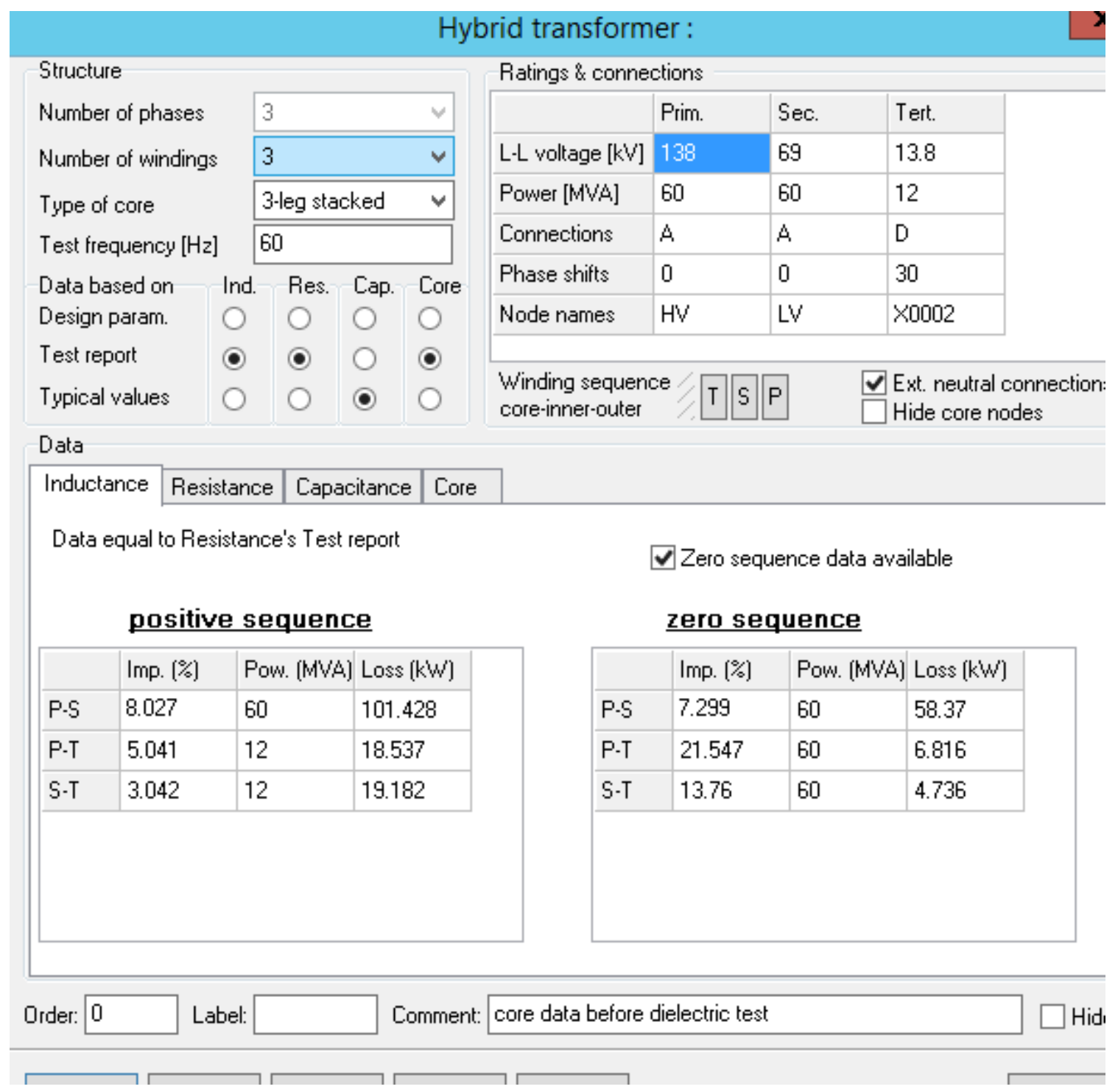

(11) Inductance Data for Hybrid Transformer 
Source impedance

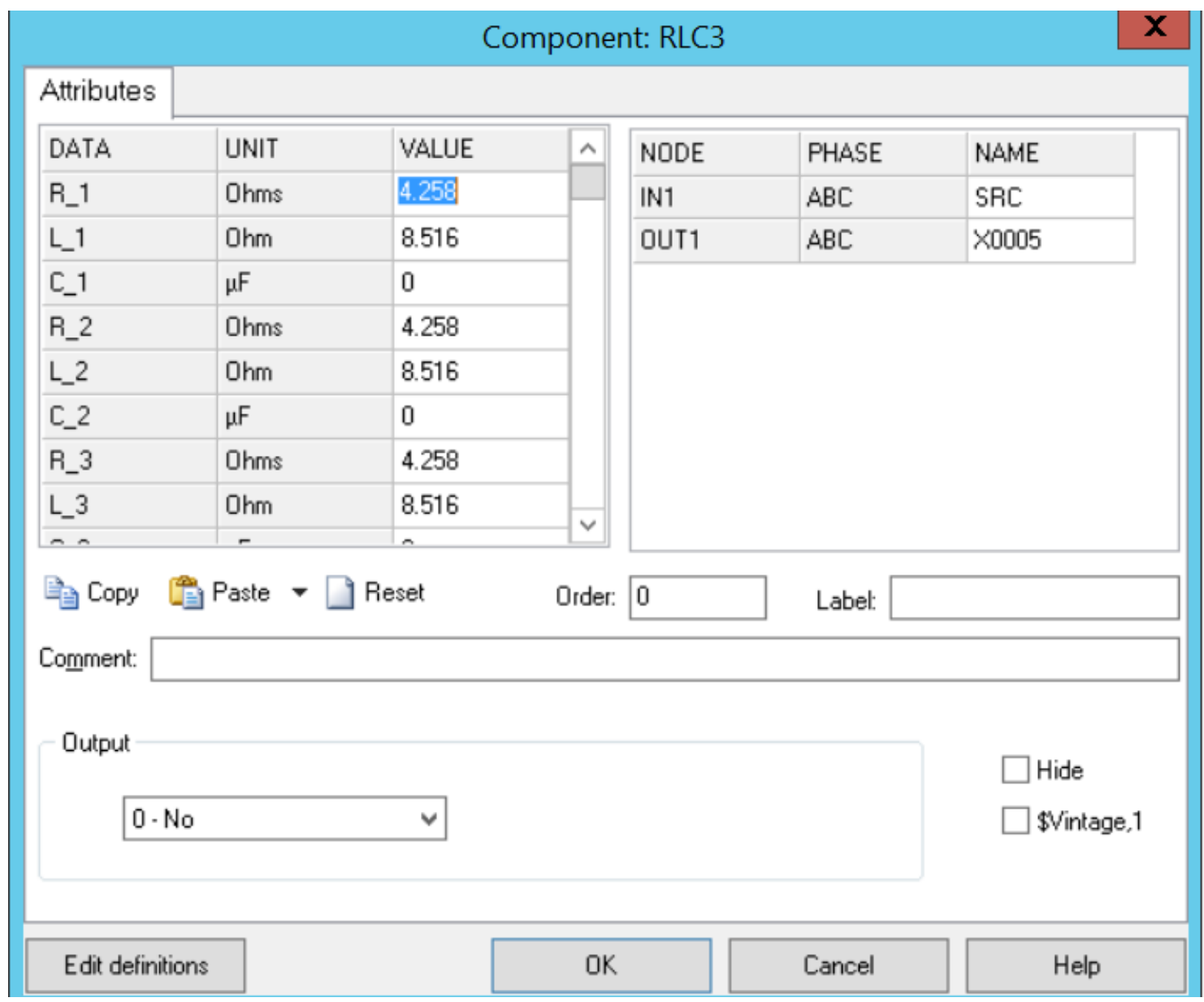

(12) Source impedance data 
Load

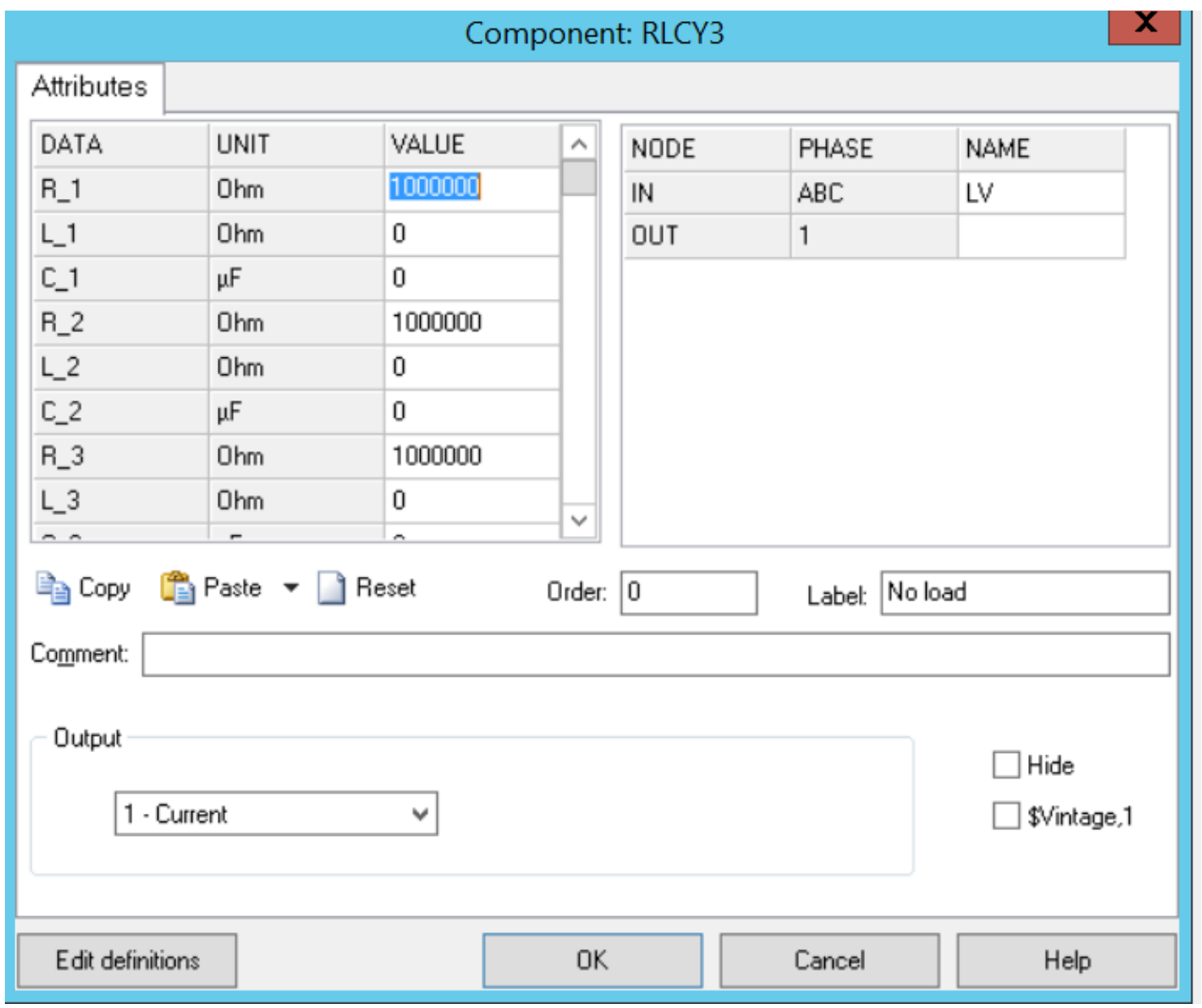

(13) Load 


\section{HIL DOBLE SIMULATOR DATA}

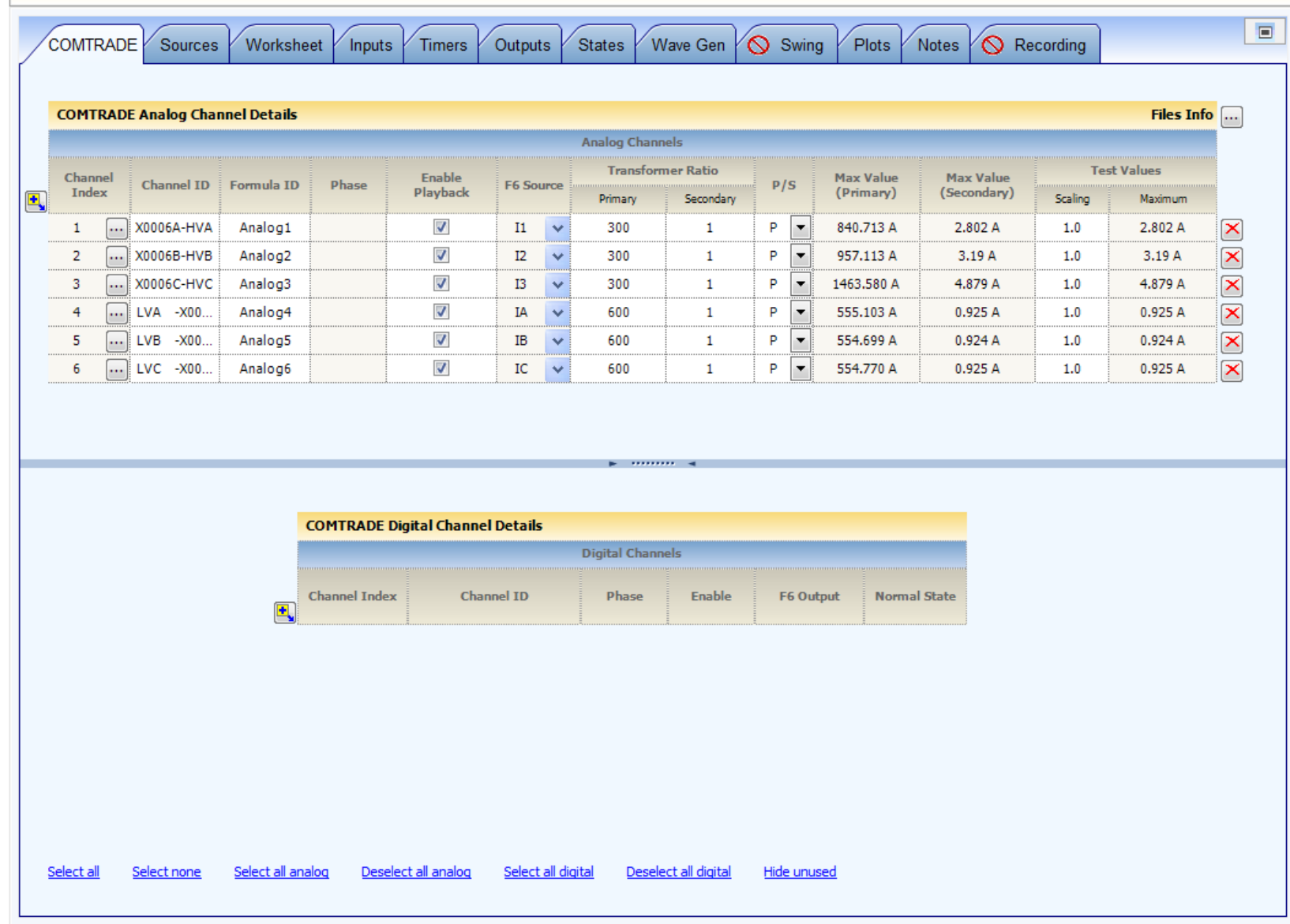

(14) Energization HIL Relay

\begin{tabular}{|c|c|c|c|c|c|c|c|}
\hline \multicolumn{5}{|l|}{ SEL-787-3E } & Date: & \multicolumn{2}{|c|}{ : 04/24/2018 Time: 12:16: } \\
\hline TRNSFRMR R & LAY & & & & Time & Source: & Internal \\
\hline & IAW1 & IBW1 & ICW1 & IAW2 & IBW2 & ICW2 & \\
\hline Fund (sec) & 0.7 & 0.8 & 0.6 & 0.6 & 0.6 & 0.6 & \\
\hline 2nd (z) & 31.0 & 18.1 & 26.7 & 5.4 & 3.5 & 5.0 & \\
\hline 3 rd $\left(\frac{8}{8}\right)$ & 20.2 & 8.6 & 13.3 & 5.0 & 2.8 & 3.3 & \\
\hline 4 th $\left(\frac{8}{8}\right)$ & 7.3 & 7.1 & 9.5 & 2.6 & 2.7 & 3.9 & \\
\hline $5 \operatorname{th}\left(\frac{8}{8}\right)$ & 1.7 & 1.6 & 2.4 & 0.6 & 1.1 & 1.0 & \\
\hline THD ( $\left(\frac{8}{8}\right)$ & 35.3 & 20.8 & 30.0 & 7.8 & 5.4 & 7.2 & \\
\hline & IAW3 & IBW3 & ICW3 & IN & VAB & VBC & $\mathrm{VCA}$ \\
\hline Fund (sec) & 0.0 & 0.0 & 0.0 & 0.0 & 0.0 & 0.0 & 0.0 \\
\hline 2nd (z) & 0.0 & 0.0 & 0.0 & 0.0 & 0.0 & 0.0 & 0.0 \\
\hline 3 rd $\left(\frac{8}{8}\right)$ & 0.0 & 0.0 & 0.0 & 0.0 & 0.0 & 0.0 & 0.0 \\
\hline $4 \operatorname{th}\left(\frac{8}{8}\right)$ & 0.0 & 0.0 & 0.0 & 0.0 & 0.0 & 0.0 & 0.0 \\
\hline 5 th $\left(\frac{8}{8}\right)$ & 0.0 & 0.0 & 0.0 & 0.0 & 0.0 & 0.0 & 0.0 \\
\hline THD (8) & 0.0 & 0.0 & 0.0 & 0.0 & 0.0 & 0.0 & 0.0 \\
\hline
\end{tabular}

(15) Energization Transformer HIL Relay Harmonics 


\section{HIL DOBLE SIMULATOR DATA}

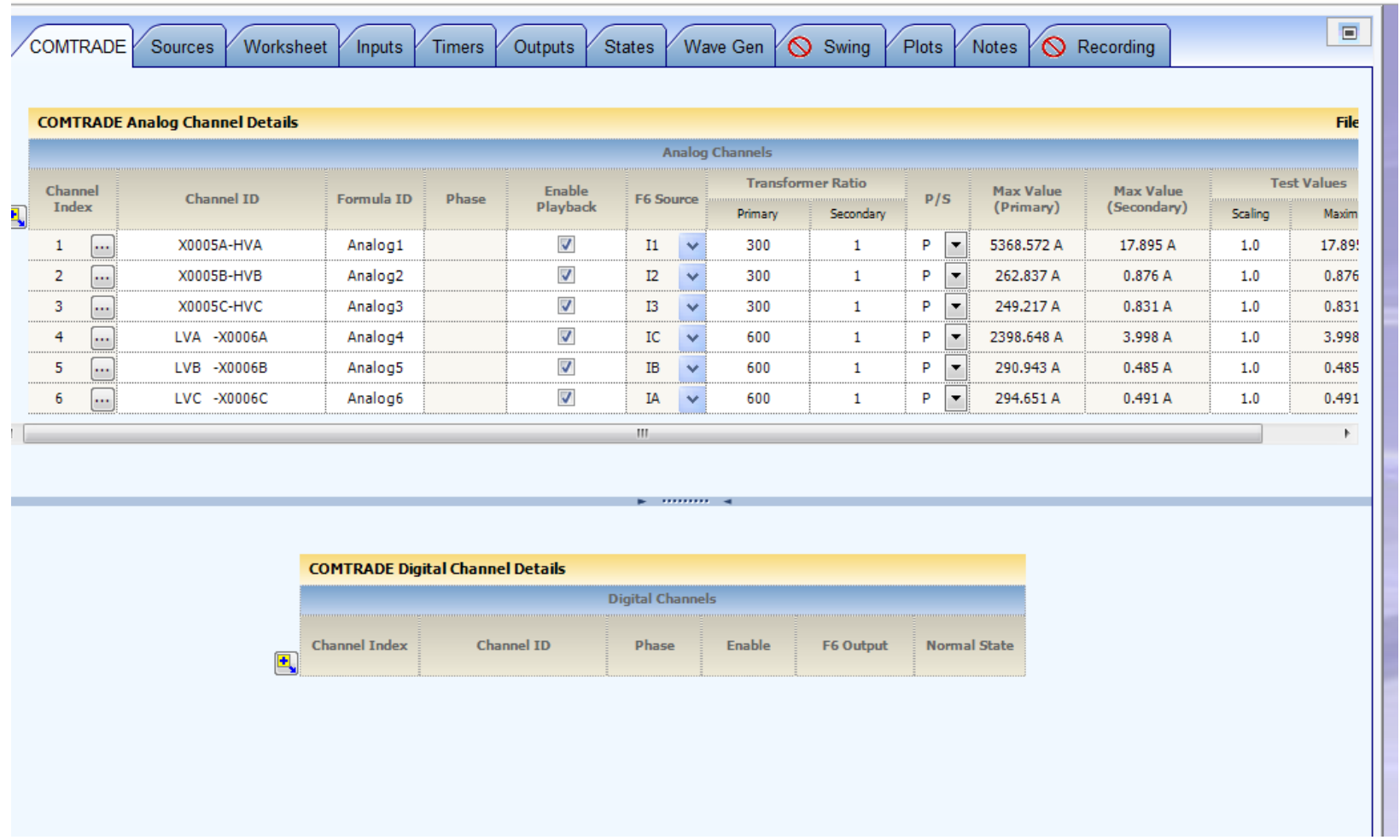

(16) Recovery inrush HIL Relay 


\section{HIL DOBLE SIMULATOR DATA}

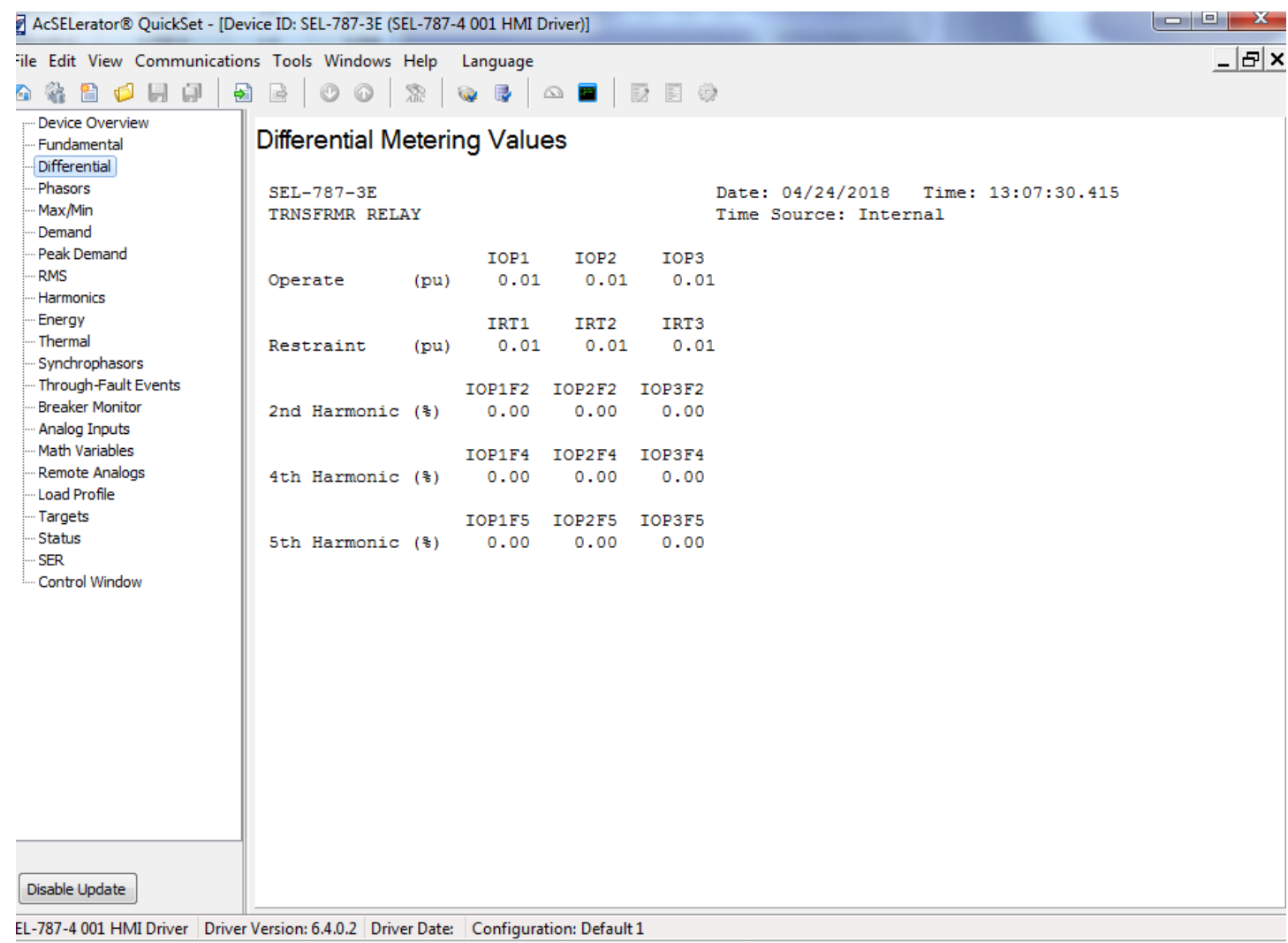

(17) Recovery inrush HIL Relay output 


\section{HIL DOBLE SIMULATOR DATA}

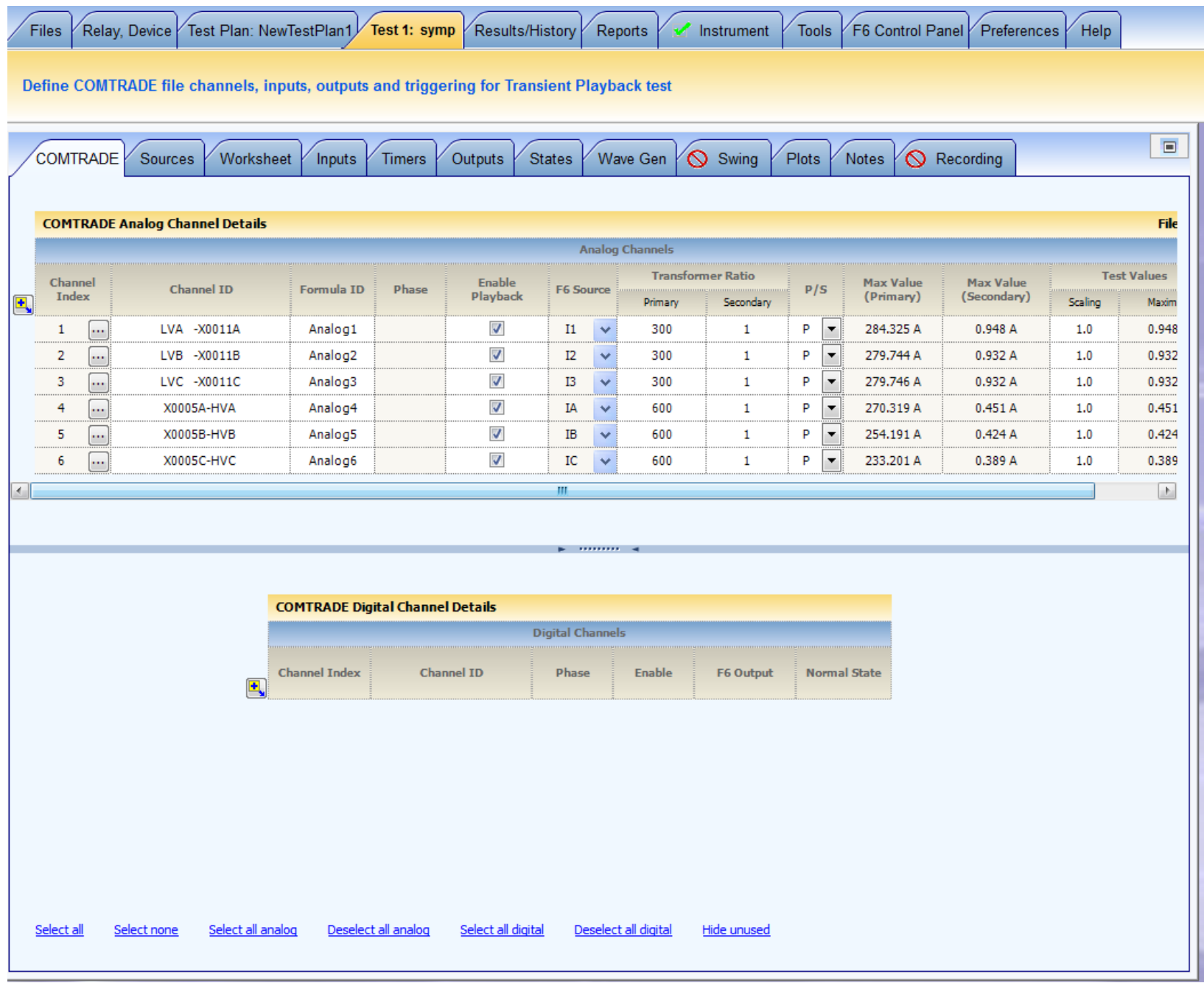

(18) Sympathetic inrush HIL Relay output 


\section{HIL DOBLE SIMULATOR DATA}

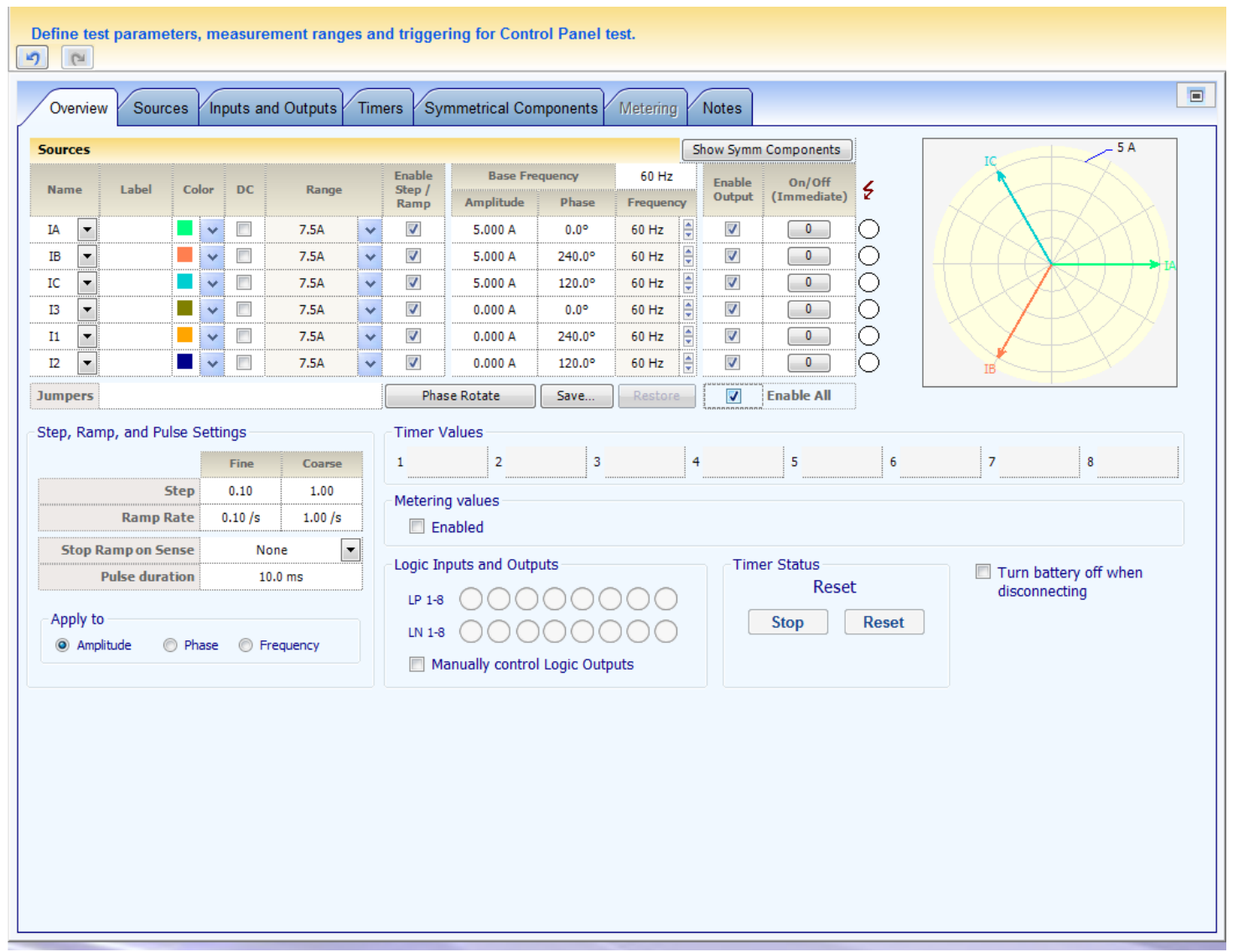

(19) Normal Fault 
Relay Settings

\section{Configuration}

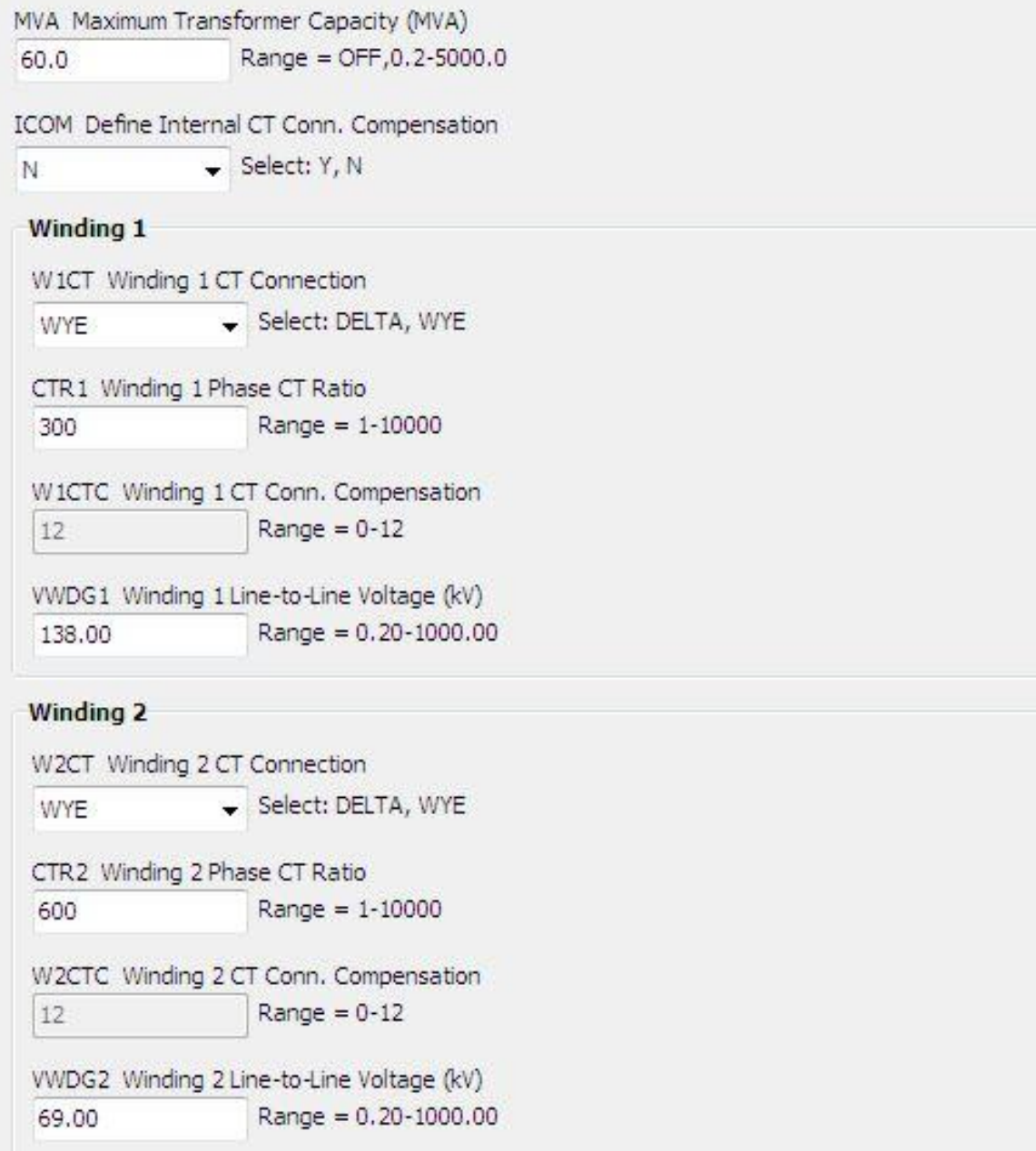

(20) Relay Settings 
Relay Settings

\section{Transformer Differential Elements}

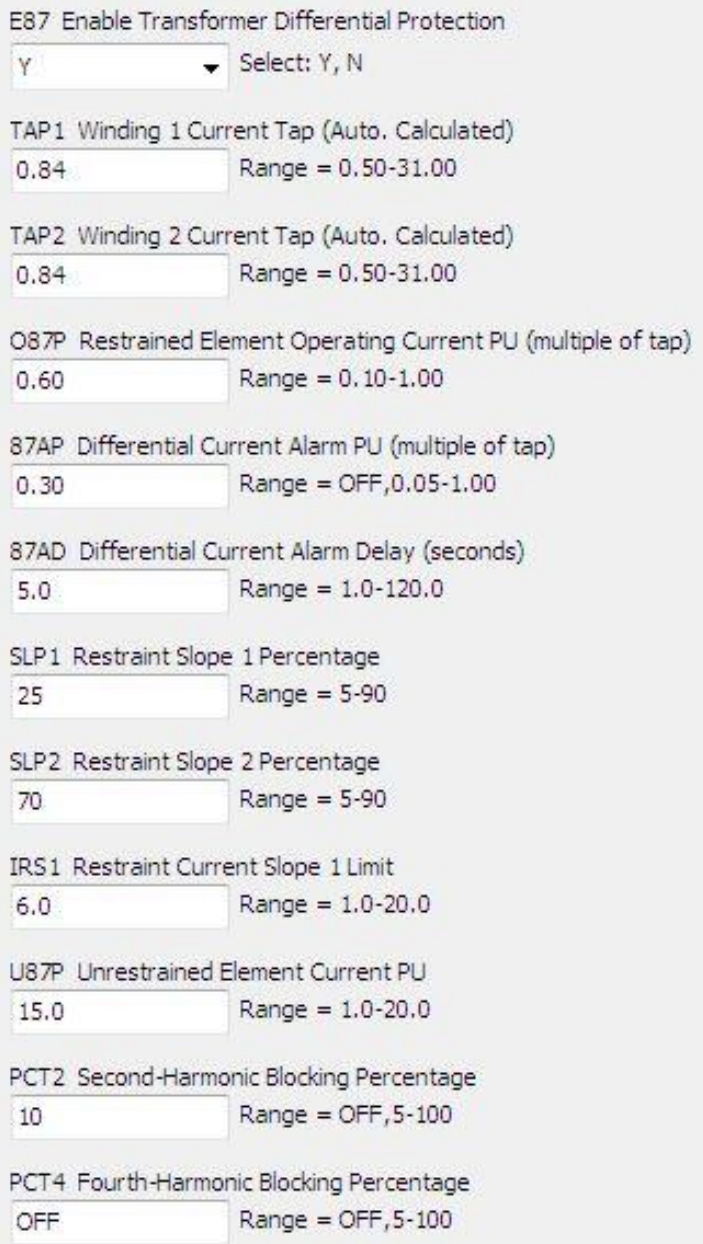

(21) Relay Settings

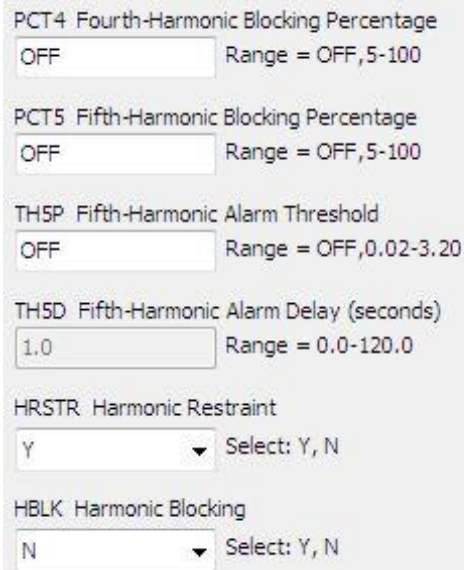

(22) Relay Settings 


\section{References}

[1] N. Chiesa, B.A. Mork, " Transformer Model for Inrush Current Calculations: Simulations, measurements, and Sensitivity Analysis ", IEEE Transactions on Power Delivery, October,2010.

[2] U. Rudez and R. Mihalic, "A Reconstruction of the WAMS-Detected Transformer Sympathetic Inrush Phenomenon," IEEE Transactions on Smart Grid, vol. 9, no. 2, pp. 724-732, May 2016.

[3] B. A. Mork, F. Gonzalez, D. Ishchenko, D. L. Stuehm and J. Mitra, "Hybrid Transformer Model for Transient Simulation-Part I: Development and Parameters," IEEE Transactions on Power Delivery, vol. 22, no. 1, pp. 248-255. Jan 2007.

[4] B. Kasztenny, N. Fischer, and Y. Xia, "A new inrush detection algorithm for transformer differential protection," 12th IET International Conference on Developments in Power System Protection (DPSP 2014), Copenhagen, 2014, pp. 1-6, doi: 10.1049/cp.2014.0033 